Technische Universität München

Fakultät für Medizin

Klinik und Poliklinik für Chirurgie am Klinikum rechts der Isar Direktor: Prof. Dr. Helmut Friess

\title{
Neurons chemoattract cancer cells via MCP-1-CCR4- induced paxillin phosphorylation and activation in the cancer cell cytoskeleton
}

\author{
Xiaobo Wang
}

Vollständiger Abdruck der von der Fakultät für Medizin der Technischen Universität München zur Erlangung des akademischen Grades

Doktors der Medizin (Dr. Med.)

genehmigten Dissertation

Vorsitzender: Prof. Dr. Jürgen Schlegel

Prüfer der Dissertation:

1. apl. Prof. Dr. Güralp O. Ceyhan

2. Prof. Dr. Dieter Saur

Die Dissertation wurden am 16.07.2019 bei der Technischen Universität München eingereicht und durch die Fakultät für Medizin am 10.03.2020 angenommen. 
The results presented in this dissertation have been submitted as an original article with the following title to a peer-reviewed journal:

Xiaobo Wang, Steffen Teller, Melanie Laschinger, Helmut Friess, Güralp O. Ceyhan, Ihsan Ekin Demir. Neurons chemoattract cancer cells via MCP-1-CCR4-induced paxillin phosphorylation and activation in the cancer cell cytoskeleton. 


\section{Table of Contents}

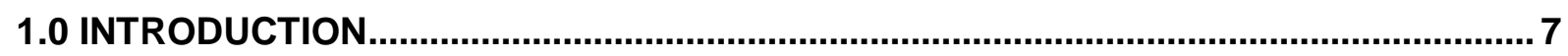

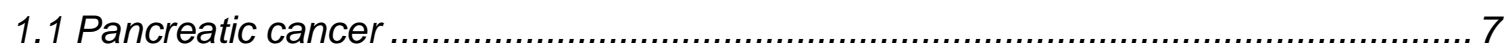

1.2 Neural invasion in pancreatic cancer......................................................... 9

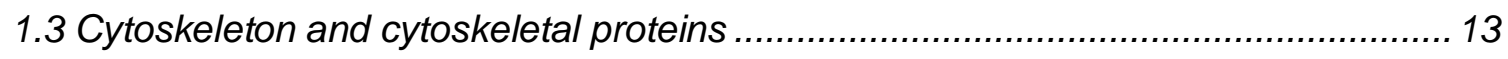

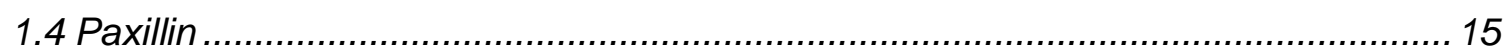

2.0 AIM OF THE PRESENT STUDY ......................................................................... 17

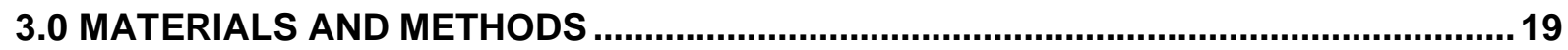

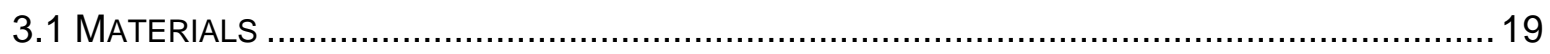

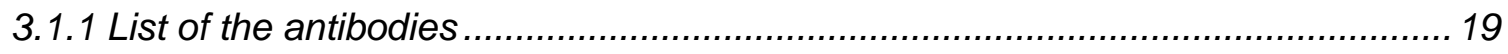

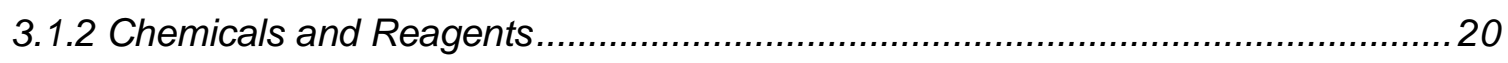

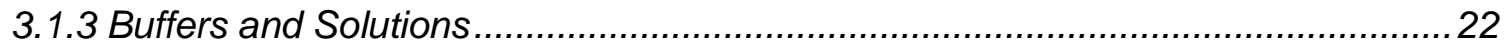

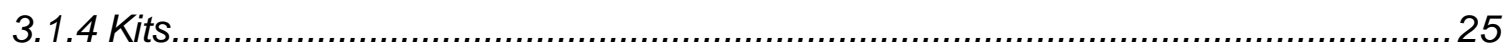

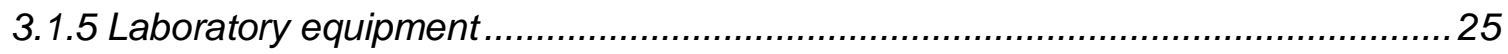

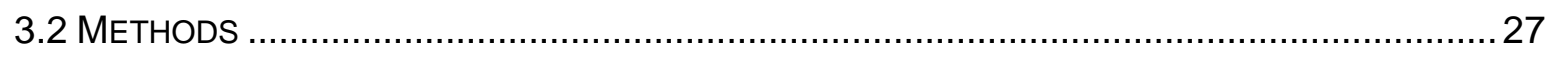

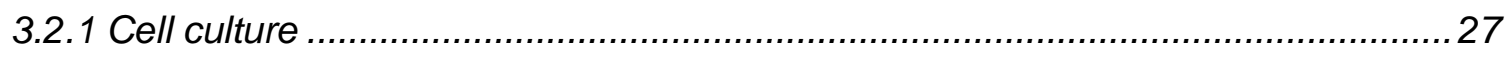

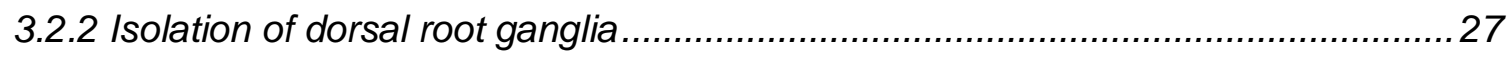

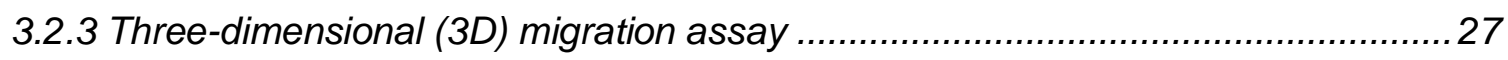

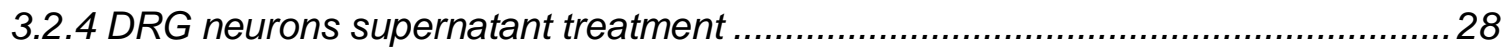


3.2.9 Statistical analysis.

4.2 Pancreatic cancer cells exhibit a more "polygonal shape" during neural invasion...33

4.3 The formation of migratory protrusions is significantly increased during the neural invasion of pancreatic cancer cells.

4.4 Pancreatic cancer cells specifically amplify phospho-paxillin in their lamellipodia during neural invasion.

4.5 The expression of phospho-paxillin is upregulated in PCC after treatment with DRGs supernatants...

4.6 The expression of phospho-paxillin downstream targets in pancreatic cancer cell lines is prominently up-regulated. 38

4.7 Paxillin is increasingly phosphorylated in cancer cells around nerves in the cancer tissue. 39

4.8 MCP-1 is prominently enriched in the co-culture supernatants of cancer cell and DRG neurons. 42 
4.9 The expression of MCP-1 is significantly upregulated in neural invasion in pancreatic cancer patients

4.10 MCP-1/CCL2 induces the phosphorylation of paxillin and enhances the neurondirected migration ability in vitro. 46

4.11 CCR4 antagonist reduced the phosphorylation of paxillin and diminished the neurondirected migration ability of cancer cells in vitro 48

4.12 Phosphorylation of paxillin mediates cancer cells migration to neurons via Src/paxillin/ERK signaling pathway 48

4.13 Dephosphorylation of ERK1/2 decreases the neuron-directed migration ability of pancreatic cancer cells.

\subsection{DISCUSSION}


Figure 1. Chemoattraction of DRG to pancreatic cancer cells.

Figure 2. The alterations of cytoskeleton during the neural invasion.

Figure 3. The formation of filopodia and lamellipodia during the neural invasion.

Figure 4. Phospho-paxillin expression in 3D migration

Figure 5. Phospho-paxillin was overexpressed in pancreatic cancer cells treated with DRG neurons supernatant .38

Figure 6. The expression of phospho-paxillin, phospho-FAK, phospho-Src and phospho-ERK in different cell lines was prominently up-regulated.... 39

Figure 7. Phospho-paxillin is also prominently expressed around nerves in the primary PDAC tissue

Figure 8. MCP-1 is dramatically elevated in the co-culture of cancer cell and DRG neurons supernatant. .44

Figure 9. The expression of MCP-1 was significantly overexpressed at sites of neural invasion in pancreatic cancer. 45

Figure 10. MCP-1/CCL2 induces the phosphorylation of paxillin and enhances the neurondirected migration ability in vitro.

Figure 11. CCR4 antagonist reduced the phosphorylation of paxillin and discourages the neuron-directed migration ability in vitro .50

Figure 12. Paxillin mediates cancer cells migration ability via Src/paxillin/ERK signaling pathway. .51

Figure 13. ERK1/2 phosphorylation inhibitor discourages the neuron-directed migration ability in vitro .53 


\subsection{Introduction}

\subsection{Pancreatic cancer}

Pancreatic cancer is one of the most aggressive and lethal malignancies with a high rate of mortality. It is the 4th cause of cancer-related death in both the United States and Europe (Malvezzi et al. 2013, Von Hoff et al. 2013), and the overall 5-year survival is as low as $8 \%$ (Siegel et al. 2017, Siegel et al. 2018). It is reported that by 2030, pancreatic cancer will become the second leading cause of cancer-related death (Rahib et al. 2014). GLOBOCA estimated that there will be 458,918 new cases ( $2.5 \%$ of all sites) diagnosed with pancreatic cancer worldwide in 2018 , and 432,242 deaths (4.5\% of all sites), almost as many as new cases (Bray et al. 2018). Despite great improvements have been achieved in diagnosis, chemotherapy and perioperative care, the 5 -year survival rate only increased from $3.4 \%$ to $7 \%$ over the past 20 years in the palliative setting. Even after the radical operation, the 5 -year survival is still as low as $25 \%$ because of local recurrence or distant metastasis. Under this situation, new strategies are urgent for understanding this disease.

The initiating event of pancreatic cancer in the majority of patients is the activating mutation of the KRAS oncogene (Roe et al. 2017). The oncogenic KRAS (KrasG12D mutations) leads to sustained proliferation, survival and cancerous development due to continuous signaling (Collins et al. 2012). Subsequently, pancreatic intraepithelial neoplasia (PanINs), which is the pre-malignant/pre-invasive lesion in PDAC, arises in the intralobular ducts (Roe et al. 2017). Loss of tumor suppressor genes, including TP53, p16, DPC4, BRCA2, and MKK4, results in uncontrollable cell proliferation and drives the progression of PanINs to PDAC at the primary site (Hruban et al. 1998, Kim et al. 2006, Makohon-Moore et al. 2016). TP53 is one of the most important tumor suppressor genes and most frequently mutated genes in pancreatic 
cancer. TP53 gene can mediate proliferation, apoptosis (el-Deiry et al. 1994) and cell cycle (el-Deiry et al. 1993). The heterozygous inactivation of TP53 was observed in $90 \%$ of pancreatic carcinomas (Hruban et al. 1998), and the homozygous inactivation combined with the mutation was observed in $50-75 \%$ of pancreatic cancer samples (Redston et al. 1994).

Symptoms of pancreatic ductal adenocarcinoma (PDAC), which account for more than $90 \%$ of all pancreatic malignancies (Tempero et al. 2017), comprise pain, weight loss, jaundice, pruritus, diabetes, ascites, nausea, vomiting. However, it occurs in a stealth mode and no warning signs have been detected in the early stage. Weight loss is the most common symptom in pancreatic cancer. It happens in as high as $92 \%$ of pancreatic head cancer, and almost $100 \%$ of body and tail cancer (Rabow et al. 2017). Abdominal or back pain is another common symptom, which can be classified as both neuropathic and nociceptive, thus "mixed type" pain (Rabow et al. 2017).

Pancreatic cancer is primarily diagnosed by imaging, including ultrasound, multidetectorrow CT (MDCT), MRI, endoscopic ultrasound (EUS), endoscopic retrograde cholangiopancreatography (ERCP). MDCT has almost the same sensitivity and specificity with MRI for pancreatic cancer (Park et al. 2009). The serum tumor biomarkers are also important indicators. The diagnostic biomarkers for pancreatic cancer include carbohydrate antigen 199 (CA 19-9), carbohydrate antigen125, carcinoembryonic antigen (CEA), and laminin $\mathrm{yC}$ (LAMC2).

To date, the therapeutic strategies for pancreatic cancer contain surgical resection, adjuvant chemotherapy, chemoradiation therapy, systemic chemotherapy, and palliative care. Surgical resection remains the only potentially curative option and few other effective therapies exist for prolonging the overall survival. Unfortunately, as the majority patients are asymptomatic until the PDAC progresses to a late stage, up to $80 \%-85 \%$ of patients are not 
eligible for surgical resection (Ryan et al. 2014) because of the local infiltration or distant metastasis. Depending on the location of the resectable tumors, the surgical methods are divided into pancreaticoduodenectomy (Whipple procedure), distal pancreatectomy, and total pancreatectomy (Kamisawa et al. 2016). The purpose of curative surgery is to achieve R0 resection, as $\mathrm{R} 1$ resection is positively correlated with impaired survival (Demir et al. 2018). To increase the resectability rates, neoadjuvant therapy has been increasingly investigated in recent years. Our previous study demonstrated that response to neoadjuvant therapy is positively correlated with a decreased tumor stage, increased rates of R0 resection, and less neural invasion (Schorn et al. 2017).

\subsection{Neural invasion in pancreatic cancer}

As for the neuropathic pain, an important mechanism seems to be the infiltration of the intrapancreatic and extrapancreatic nerves by pancreatic cancer cells (Dobosz et al. 2016), which occurs in up to $100 \%$ of the patients with true pancreatic ductal adenocarcinoma (Bapat et al. 2011, Demir et al. 2015). Besides, neural invasion is also associated with local recurrence and metastasis (Bapat et al. 2011), and has been identified as an important prognostic factor for pancreatic cancer (Schorn et al. 2017). Therefore, understanding the mechanisms of the neural invasion is indispensable in pancreatic cancer.

Current insights indicate that several signaling molecules from nerves or/and from pancreatic cancer cells and the interactions between nerves and tumor cells are essential for neural invasion (Bapat et al. 2011). The molecules contain a variety of neurotrophic factors (such as the neurotrophin family, glial cell line-derived neurotrophic factor family) (Zhu et al. 1999, Schneider et al. 2001), cytokines (such as Transforming growth factor alpha) (Bockman 
et al. 1994), as well as chemokines (such as CX3CL1) (Marchesi et al. 2008, Marchesi et al. 2010).

Neurotrophic factors are important in controlling the survival, growth, and differentiation of cancer and nerve cells (Liebig et al. 2009, Imoto et al. 2013). Neurotrophin family is composed of 4 members: Nerve growth factor (NGF), brain-derived neurotrophic factor (BDGF), neurotrophin-3 and neurotrophin-4 (Bapat et al. 2011). NGF family can interact with two types of receptors, tropomyosin-receptor kinase (Trks, the high-affinity receptor) and p75 neurotrophin receptor (p75LNTR, the low-affinity receptor) (Lee et al. 2001, Nykjaer et al. 2004). Each neurotrophin has a specific Trk receptor: 1) NGF binds with high affinity to TrkA and at low affinity to p75NTR (Kaplan et al. 1991); 2) Brain-derived neurotrophic factor and neurotrophin-4 bind with TrkB (Klein et al. 1991, Soppet et al. 1991, Squinto et al. 1991); 3) Neurotrophin-3 binds with TrkC (Lamballe et al. 1991). Interestingly, the binding of nerve growth factor and TrkA is increased in the presence of p75LnTR (Esposito et al. 2001). The expressions of nerve growth factor, Trks and p75LNTR are strikingly up-regulated in pancreatic cancer cells (Miknyoczki et al. 1999, Zhu et al. 1999, Schneider et al. 2001) and positively associated with the poor prognosis and the severity of neural invasion (Wang et al. 2009). Interaction of nerve growth factor with TrkA can activate the ERM1/2 signaling pathway and increase the expression of matrix metalloproteinase-2 (MMP-2) (Okada et al. 2004). Specifically, the binding of nerve growth factor with TrkA contributes toward the proliferation and neural invasion in pancreatic cancer cells (Ketterer et al. 2003). Brain-derived neurotrophic factor is also over-expressed in pancreatic cancer, which can stimulate the proliferation and invasive capacity of cancer cells (Kowalski et al. 2002, Zhu et al. 2002).

The glial cell line-derived neurotrophic factor family, which contains 4 members [glial cell line-derived neurotrophic factor family (GDNF), artemin (ARTN), neurturin (NRTN) and 
persephin (PSPN)], also plays an important role in the neural invasion (Ceyhan et al. 2008). The GDNF receptor family consists of 4 members: GFR $\alpha 1$ (binding to GDNF), GFR $\alpha 2$ (binding to NRTN), GFRa3 (binding to ARTN), and GFRa4 (binding to PSPN). GDNF promotes tumor cells invasiveness by modulating matrix metalloproteinase-9 (MMP-9) through several different signaling pathways in pancreatic cancer (Okada et al. 2003). The expression of artemin is upregulated in human pancreatic specimens and closely correlated with pancreatic cancer cells neural invasion capacity (Ceyhan et al. 2006, Ceyhan et al. 2010, Demir et al. 2010). The expression of neurturin and its receptor GFRa2 in pancreatic cancer is overall up-regulated (Wang et al. 2014). The neurturin/GFRa2 axis promotes sustained proliferation and neurondirected migration in pancreatic cancer (Wang et al. 2014).

The chemokine CX3CL1 and its receptor CX3CR1 are also involved in neural invasion. Human pancreatic cancer cell lines strongly express CX3CR1 and also in pancreatic cancer patients, the high expression of CX3CR 1 is positively correlated with neural invasion and early recurrence (Marchesi et al. 2008). CX3CL1 can influence cell adhesive properties which subsequently affect the neural invasion (Imai et al. 1997, Fong et al. 1998). Moreover, CX3CL1/CX3XR1 signaling also contributes to apoptosis resistance and mediates proliferation through AKT/NF-kB/p65 signaling pathway in pancreatic cancer cells (Wang et al. 2017).

C-X-C motif chemokine 12 (CXCL12) has been demonstrated to be ubiquitously expressed in many cancers (Schrader et al. 2002). It is important in mediating proliferation and metastasis in pancreatic cancer cells (Sun et al. 2010, Roy et al. 2014). CXCR4 and CXCR7 are two proved receptors of CXCL12. The CXCL12/CXCR4 axis mediates cancer cells migration and angiogenesis, thereby influencing progression (Koshiba et al. 2000, Marechal et al. 2010). In our previous study, we also demonstrated that CXCL12/CXCR4/CXCR7 axis can regulate the chemoattraction of human Schwann cells to pancreatic cancer cells, and subsequently influence neural invasion (Demir et al. 2017). 
Pancreatic cancer cells have a strong tendency to invade to nerves. Neural invasion is strongly associated with the generation of pain in pancreatic cancer (Ceyhan et al. 2010, Demir et al. 2010). Abdominal or back pain sensation is a representative feature of pancreatic adenocarcinoma. During the neural invasion $(\mathrm{NI})$, the features of intrapancreatic nerves are increased in size (neural hypertrophy) and density (Friess et al. 2002, Ceyhan et al. 2009, Demir et al. 2011, Demir et al. 2012), which may result from the interactions of pancreatic cancer cells and nerves. In the interaction, the sheaths of nerves are damaged by tumor cells, remaining the nerves assailable to be stimulated by infiltrated inflammatory cells, extracellular matrix, as well as cancer cells (Ceyhan et al. 2008, di Mola et al. 2008). Another mechanism of pain generation is vascularization in pancreatic cancer. A possible explanation is that the molecular factors, including vascular endothelial growth factor, artemin, can stimulate the formation of the vessel which also promote the growth of nerve fibers (Lindsay et al. 2005, di Mola et al. 2008).

The severity of the neural invasion is an independent prognostic factor regarding the overall survival for many solid tumors (Ceyhan et al. 2009, Schorn et al. 2017), including pancreatic cancer (Friess et al. 2002, Ceyhan et al. 2009, Demir et al. 2011, Demir et al. 2012), prostate cancer (Feng et al. 2011), head and neck cancer (Johnston et al. 2012). Neural invasion is correlated with local recurrence and neuropathic pain sensation (Demir et al. 2015). The presence of abdominal or back pain reduces the quality of life of pancreatic cancer patients. Neural invasion-targeting therapeutic strategies are a potential and convincing approach for pancreatic cancer patients since it would not only prevent the invasion and progression of cancer, but also relieve the pain from the neural invasion and improve the quality of life. Nevertheless, an effective targeted treatment for neural invasion is still not available (Scanlon et al. 2015). The NGF/TrkA pathway is a potential strategy, which 
intervenes in the interaction between NGF and TrkA by using NGF-neutralizing antibody (Hefti et al. 2006, Abdiche et al. 2008, Watson et al. 2008, Wood 2010).

\subsection{Cytoskeleton and cytoskeletal proteins}

The cytoskeleton is composed of 3 elements: actin, microtubules and intermediate filaments (Dogterom et al. 2019). In normal cells, a fairly large number of core biological cellular activities lean on the cytoskeleton and its components (Dogterom et al. 2019). The crosstalk of actin and microtubules is essential for regulating cell migration (Huda et al. 2012). Microtubules play vital roles in the mediation of cell proliferation, migration, invasion, vesicular transport, and mitosis (Jordan et al. 2004). The coordination and remodeling of actin are essential for cell motility, cell differentiation, and cell division (Gunning et al. 2008). The activities of cytoskeleton can be sorted by intermediate filaments through conveying information between the cell surface and cytoplasmic interior (Chang et al. 2004).

On the other hand, the reorganization of the cytoskeleton and the formation of membrane protrusions and the abnormal expression of related proteins are vital for the acquirement of migratory and chemoresistance properties of the cancer cells (Yilmaz et al. 2009, Fife et al. 2014). The metastasis of cancer cells occurs over several multifaceted steps. First, cancer cells detach and escape from the primary tumor. Then, cancer cells invade into and spread along either the lymphatics or vessels. After extravasation, the secondary tumor is developed at the new site or organ (Steeg 2006). An important alteration within migrating cells is the dynamic reorganization of the cytoskeleton, which also plays an important role in the epithelialmesenchymal transition (EMT) process (Thiery et al. 2009). In the context of the metastatic and EMT processes, the orchestrated cytoskeleton and its components are critical for maintaining the cell structure (Fife et al. 2014). 
The Rho GTPases act as cytoskeletal regulators during cancer cell migration. The Rho GTPase family is comprised of several subfamilies, including Rac subfamily, Cdc42 subfamily, RhoA subfamily, and other Rho GTPases (Ridley 2006). The Rho GTPase family affects cell migration through regulating the cytoskeleton by interacting with various effectors (Jaffe et al. 2005). For example, the components Rho, Rac, and Cdc42 emerge as regulators in the assembly and the organization of the actin cytoskeleton in different kinds of cells, including fibroblasts, epithelial cells and mast cells (Hall 1998). Rac stimulates the formation of lamellipodia by reorganizing the actin cytoskeleton. Cdc42 also can promote the formation of filopodia, thereby initiating and controlling the migration directed by chemokines (Hall 2012). Moreover, high expression of Rho GTPase in several tumors is positively associated with increased metastasis and poor prognosis (Karlsson et al. 2009).

Focal adhesion kinase (FAK), a tyrosine kinase, affects the migration of tumor cells by sensing the mechanical forces and consequently regulates the reorganization of cytoskeleton during tumor cell migration (Huang et al. 1999). During the processes of tumor cell migration or adhesion, the activity of FAK is associated with changes in the stabilization of actin filaments (Lim et al. 2008). Moreover, the high expression of FAK is also correlated with increased metastasis and poor prognosis (de Vicente et al. 2013).

The typical migratory phenotypes of cancer cell are characterized by the formation of migratory protrusions, including filopodia, lamellipodia, and invadopodia (Alblazi et al. 2015). Filopodia are narrow, dynamic and actin-rich structures that direct the migration of cancer cells. The formation of filopodia is mediated by Cdc42, a component of the Rho family small G protein, via a series of proteins, including fascin, diaphanous, and Mena/VASP (Machesky 2008). Fascin, an actin-bundling protein, has the ability to encourage the growth of filopodia (Svitkina et al. 2003). Diaphanous is involved in the interactions with microtubules (Faix et al. 2006). Mena/VASP, composed of the membrane-targeting module and the actin-interacting module, 
is able to enforce the extension of the long parallel actin bundles and plays an important role in the formation of filopodia (Applewhite et al. 2007). Filopodia are vital for cell motility (Stevenson et al. 2012) and cell adhesion (Vasioukhin et al. 2000). During the process of cancer cell invasion and migration, the transport of signal molecules between cells and filopodia contributes to the formation of the intercellular junctions (Vasioukhin et al. 2000).

Lamellipodia are also observed in migrating cells in the edge of the migrating side and sustain the migratory "drive". Lamellipodia are among the most prominent cytoskeletal alterations that play clear and established roles in driving cell locomotion (Johnson et al. 2015). Similar with filopodia, the formation of lamellipodia is signalled by another component of small G protein of the Rho family, the Rac protein (Machesky 2008).

Moreover, the formation of lamellipodia and filopodia is also controlled by cytokines, including epidermal growth factor (EGF) (Yasui et al. 2017), transforming growth factor- $\beta$ (TGF- $\beta$ ) (Feng et al. 2013), tumor necrosis factor (TNF) (Marivin et al. 2014), hepatocyte growth factor (HGF) (Yasui et al. 2017). However, the significance of filopodia and lamellipodia during neural invasion in pancreatic cancer remains unclear.

\subsection{Paxillin}

Actin-bundling-proteins, like paxillin (Lopez-Colome et al. 2017), play essential roles in the formation of migratory protrusions (Salvi et al. 2017). Paxillin is a major component of focal adhesions (FAs) with a multifunctional focal adhesion adapter protein, which is vital in the conversion of signals from extracellular into endocellular.

Paxillin protein, which is $64.5 \mathrm{kDa}$ in molecular weight and contains 591 amino acids, is encoded by the paxillin gene. The activation of paxillin is stimulated by phosphorylation. 
Various stimuli can stimulate the phosphorylation of paxillin, including growth factors, as well as integrin-dependent adhesion to the extracellular matrix (ECM). In addition to the major phosphorylation sites tyrosines 31 and tyrosines 118, paxillin also has other sites, such as Tyr40, Tyr88, Ser85, Ser126, Ser130 (Webb et al. 2005). After phosphorylation of paxillin by integrin ligation via Src kinase at Tyr118, the cellular proliferation state and the reorganization of the cytoskeleton are provoked via mitogen-activated protein kinase (MAPK) (Brown et al. 2004) signaling pathway.

Paxillin is critical for cancer development and metastasis (Lopez-Colome et al. 2017). Changes in the expression of paxillin are linked with cancer cell progression and invasion, including osteosarcoma (Azuma et al. 2005), lung carcinomas (Mackinnon et al. 2011), colorectal cancer (Cui et al. 2006), breast tumors (Farmer et al. 2005, Finak et al. 2008), prostate tissue (Mestayer et al. 2003, Miyoshi et al. 2003).

Reorganization of focal adhesions via phosphorylation of paxillin by FAK and Src is essential for the promotion of cancer cell migration, which is considered as an indicator of metastasis (Pribic et al. 2012, Devreotes et al. 2015). Phosphorylation of paxillin and FAK are requested in the insulin-like growth factor (IGF)-induced cell motility (Leventhal et al. 1997). Interactions between FAK and paxillin result in the initiation of migration signaling (Wu et al. 2013). Vinculin emerges as a modulator in FAK-paxillin interactions, and thereby controls cell survival and motility by regulating ERK pathway (Subauste et al. 2004). In pancreatic cancer cells, loss of paxillin is strongly correlated with inhibition of migratory ability (Burdyga et al. 2013). Overexpression of paxillin is positively associated with poor survival and increased migration and invasion ability (Sun et al. 2017). 


\subsection{Aim of the present study}

Neural invasion ( $\mathrm{NI})$ is the leading cause of local recurrence and neuropathic pain sensation in many solid cancers including pancreatic ductal adenocarcinoma and colorectal cancer. The alterations that occur in the cytoskeleton and the abnormal expression of cytoskeletal proteins play an important role during cancer cell migration and neural invasion. Therefore, dissecting what happens specifically to the cytoskeleton and cytoskeletal-related proteins, such as paxillin, during neural invasion is vital for facilitating the development of novel therapeutics targeting pancreatic cancer and neural invasion, which may improve patient survival and, especially, quality-of-life. However, the alterations of the cytoskeleton and the "cytoskeletal" mechanisms underlying the impacts of cytoskeletal-related proteins on the neural invasion of pancreatic cancer cells have, however, never been analyzed.

Therefore, the first aim of the presented study was to illuminate what happens specifically to the cytoskeleton and to elucidate the alterations of the migratory protrusions, including filopodia and lamellipodia. For this purpose, a three-dimensional (3D) migration assay was used and the morphology of pancreatic cancer cells in the migration front was compared with that of cells in the back front. Furthermore, pancreatic cancer cells were stained for phalloidin, and the formation of the migratory protrusions was quantified with the FiloQuant@ software and compared between the pancreatic cancer cells in the migration front and the back front.

The second aim of the study was to elucidate the effect of cytoskeletal related protein on the neural invasion of pancreatic cancer cells. Since paxillin phosphorylation plays an important role in the alteration of cytoskeleton. Hereby, the expression of phospho-paxillin of pancreatic cancer cells in the neural invasion front was characterized and compared to that in the back front in the 3D migration assay. 
The third aim of the study was to investigate the cytokines which possibly be involved in the stimulation of paxillin phosphorylation during the neural invasion of pancreatic cancer cells. For this purpose, pancreatic cancer cells and DRG neurons were either cultured alone or cultured together. After cultivation, the supernatant was collected, and the concentration of related cytokines was measured by sandwich ELISA assay.

The fourth aim of the study was to ascertain the mechanism of how the cytokines affect the neural invasion of pancreatic cancer cells. For this purpose, pancreatic cancer cells were exposed to cytokines or receptor antagonists. Afterwards, the alteration of the neuron-directed migration ability was determined by 3D migration assay. 
3.0 Materials and Methods

\subsection{Materials}

\subsubsection{List of the antibodies}

\section{Primary antibodies}

\begin{tabular}{|c|c|c|c|}
\hline Antibody & Catalogue number & Application & Source \\
\hline $\begin{array}{l}\text { Rabbit anti-phospho- } \\
\text { paxillin (Y118) Ab }\end{array}$ & 2541 & WB, IHC & $\begin{array}{l}\text { Cell Signaling } \\
\text { Technology }\end{array}$ \\
\hline $\begin{array}{l}\text { Rabbit anti-paxillin } \\
\text { Ab }\end{array}$ & $12065 S$ & WB & $\begin{array}{l}\text { Cell Signaling } \\
\text { Technology }\end{array}$ \\
\hline $\begin{array}{l}\text { Rabbit anti-phospho- } \\
\text { Src (Y416) Ab }\end{array}$ & $2101 S$ & WB & $\begin{array}{l}\text { Cell Signaling } \\
\text { Technology }\end{array}$ \\
\hline Rabbit anti-Src Ab & $2102 S$ & WB & $\begin{array}{l}\text { Cell Signaling } \\
\text { Technology }\end{array}$ \\
\hline $\begin{array}{l}\text { Rabbit anti-phospho- } \\
\text { FAK (Y397) Ab }\end{array}$ & $8556 S$ & WB & $\begin{array}{l}\text { Cell Signaling } \\
\text { Technology }\end{array}$ \\
\hline $\begin{array}{c}\text { Rabbit anti-FAK } \\
\text { (D507U) } \mathrm{Ab}\end{array}$ & $71433 S$ & WB & $\begin{array}{l}\text { Cell Signaling } \\
\text { Technology }\end{array}$ \\
\hline $\begin{array}{c}\text { Rabbit anti-phospho- } \\
\text { ERK1/2 (T202/Y204) } \\
\text { Ab }\end{array}$ & $4370 S$ & WB & $\begin{array}{l}\text { Cell Signaling } \\
\text { Technology }\end{array}$ \\
\hline $\begin{array}{c}\text { Rabbit anti-ERK1/2 } \\
\text { (137F5) Ab }\end{array}$ & $4695 s$ & WB & $\begin{array}{l}\text { Cell Signaling } \\
\text { Technology }\end{array}$ \\
\hline $\begin{array}{l}\text { Rabbit anti-PGP9.5 } \\
\mathrm{Ab}\end{array}$ & Z5116 & IF & $\begin{array}{c}\text { Dako Deutschland } \\
\text { GmbH }\end{array}$ \\
\hline Mouse anti-S100 Ab & MAB079-1 & $\mathrm{IHC}$ & EMD Millipore \\
\hline $\begin{array}{c}\text { Mouse anti- } \\
\text { Cytokeratin Pan Ab }\end{array}$ & Ab17154 & IF & Abcam \\
\hline Rat anti-CK19 Ab & - & IF & $\begin{array}{c}\text { Developmental } \\
\text { Studies Hybridoma } \\
\text { Bank } \\
\end{array}$ \\
\hline $\begin{array}{l}\text { Mouse anti-GAPDH } \\
\mathrm{Ab}\end{array}$ & SC-32233 & WB & $\begin{array}{c}\text { Santa Cruz } \\
\text { Biotechenology }\end{array}$ \\
\hline Phalloidin-TRITC & P1951 & IF & $\begin{array}{l}\text { Sigma-Aldrich } \\
\text { Chemie GmbH }\end{array}$ \\
\hline
\end{tabular}


Secondary antibodies

\begin{tabular}{|c|c|c|c|}
\hline Antibody & Catalogue number & Application & Source \\
\hline $\begin{array}{c}\text { Alexa Fluor goat } \\
\text { anti-mouse IgG } \\
488 / 594\end{array}$ & $1834337 / 1830459$ & IF & $\begin{array}{c}\text { Thermo Fisher } \\
\text { Scientific }\end{array}$ \\
\hline $\begin{array}{c}\text { Alexa Fluor goat } \\
\text { anti-rabbit IgG } \\
488 / 594\end{array}$ & $1885240 / 1851471$ & IF & $\begin{array}{c}\text { Thermo Fisher } \\
\text { Scientific }\end{array}$ \\
\hline $\begin{array}{c}\text { Goat HRP-Labelled } \\
\text { Polymer Anti-Mouse } \\
\text { Ab }\end{array}$ & K4000 & IHC & $\begin{array}{c}\text { Dako Deutschland } \\
\text { GmbH }\end{array}$ \\
\hline $\begin{array}{c}\text { Goat HRP-Labelled } \\
\text { Polymer Anti-Rabbit } \\
\text { Ab }\end{array}$ & K4003 & IHC & $\begin{array}{c}\text { Dako Deutschland } \\
\text { GmbH }\end{array}$ \\
\hline $\begin{array}{c}\text { ECL anti-mouse IgG } \\
\text { Horseradish } \\
\text { peroxidase lined } \\
\text { antibody }\end{array}$ & NA931V & WB & $\begin{array}{c}\text { GE Healthcare Life } \\
\text { Sciences }\end{array}$ \\
\hline $\begin{array}{c}\text { ECL anti-rabbit IgG } \\
\text { Horseradish } \\
\text { peroxidase lined } \\
\text { antibody }\end{array}$ & NA9340V & WB & $\begin{array}{c}\text { GE Healthcare Life } \\
\text { Sciences }\end{array}$ \\
\hline
\end{tabular}

\subsubsection{Chemicals and Reagents}

\begin{tabular}{|c|c|c|}
\hline Chemical/Reagent & Product number & Source \\
\hline Albumin Fraction V (BSA) & T844.3 & Carl Roth GmbH \\
\hline Ammonium persulfate (APS) & 9592.1 & Carl Roth GmbH \\
\hline B-27 Supplement (50x) & 1116531 & Thermo Fisher Scientific \\
\hline BCA protein assay & 23225 & Carl Roth GmbH \\
\hline $\begin{array}{c}\text { Citric acid (Monohydrate) } \\
\text { Collegenase type 2 }\end{array}$ & 3958.4 & Worthington Biochemicals \\
\hline $\begin{array}{c}\text { Dulbecco's Phosphate } \\
\text { Buffered Saline }\end{array}$ & LS004176 & Sigma \\
\hline $\begin{array}{c}\text { ECL Plus Western Blotting } \\
\text { substrate }\end{array}$ & 32132 & Thermo Fisher Scientific \\
\hline \begin{tabular}{c} 
EGF \\
\hline
\end{tabular} & 17005042 & Invitrogen \\
\hline
\end{tabular}




\begin{tabular}{|c|c|c|}
\hline Ethanol $70 \%$ & 7078027 & Otto Fischer GmbH \\
\hline Ethanol $96 \%$ & 7138032 & Otto Fischer GmbH \\
\hline Ethanol absolute & 7127114 & Otto Fischer GmbH \\
\hline Ethanol absolute & $64-17-5$ & Merck KGaA \\
\hline $\begin{array}{c}\text { Extracellular matrix (ECM) } \\
\text { gel }\end{array}$ & E1270 & $\begin{array}{l}\text { Sigma-Aldrich Chemie } \\
\text { GmbH }\end{array}$ \\
\hline Fetal Bovine Serum & F7524 & $\begin{array}{c}\text { Sigma-Aldrich Chemie } \\
\text { GmbH }\end{array}$ \\
\hline $\begin{array}{c}\text { Fluorescence Mounting } \\
\text { Medium }\end{array}$ & S3023 & Dako Deutschland $\mathrm{GmbH}$ \\
\hline formaldehyde & & Carl Roth $\mathrm{GmbH}$ \\
\hline Glycin & 3908.3 & Carl Roth $\mathrm{GmbH}$ \\
\hline Hank's BSS & $\mathrm{H} 15-010$ & PAA \\
\hline HEPES solution & H0887 & $\begin{array}{l}\text { Sigma-Aldrich Chemie } \\
\text { GmbH }\end{array}$ \\
\hline hydrogen peroxide $30 \%$ & 9681.1 & Carl Roth $\mathrm{GmbH}$ \\
\hline Keratinocyte SFM & 17005042 & Invitrogen \\
\hline L-Glutamine solution & G7513 & $\begin{array}{l}\text { Sigma-Aldrich Chemie } \\
\text { GmbH }\end{array}$ \\
\hline Methanol & 4627.5 & Carl Roth $\mathrm{GmbH}$ \\
\hline Milk & T145.3 & Carl Roth $\mathrm{GmbH}$ \\
\hline $\begin{array}{l}\text { Minimum Essential medium } \\
\text { Eagle (MEM) media }\end{array}$ & M2279 & $\begin{array}{l}\text { Sigma-Aldrich Chemie } \\
\text { GmbH }\end{array}$ \\
\hline Natriumchlorid (NaCl) & 3957.2 & Carl Roth GmbH \\
\hline Neuralbasal medium & 21103 & Gibco \\
\hline Normal goat serum & $50062 Z$ & Life technologies \\
\hline PBS Dulbecco & L182-50 & Biochrom GmbH \\
\hline Penicillin-Streptomycin & P0781 & $\begin{array}{c}\text { Sigma-Aldrich Chemie } \\
\text { GmbH }\end{array}$ \\
\hline phosphatase inhibitor & 4906837001 & $\begin{array}{l}\text { Sigma-Aldrich Chemie } \\
\text { GmbH }\end{array}$ \\
\hline protease inhibitor & 4693159001 & $\begin{array}{c}\text { Sigma-Aldrich Chemie } \\
\text { GmbH }\end{array}$ \\
\hline
\end{tabular}




\begin{tabular}{|c|c|c|}
\hline RIPA buffer & R0278 & $\begin{array}{l}\text { Sigma-Aldrich Chemie } \\
\text { GmbH }\end{array}$ \\
\hline Roticlear & A538.1 & Carl Roth $\mathrm{GmbH}$ \\
\hline Rotiphorese Gel 30 & 3029.1 & Carl Roth $\mathrm{GmbH}$ \\
\hline RPMI-1640 Medium & R8758 & $\begin{array}{c}\text { Sigma-Aldrich Chemie } \\
\text { GmbH }\end{array}$ \\
\hline SDS, ultra-pure & 2326.2 & Carl Roth $\mathrm{GmbH}$ \\
\hline $\begin{array}{c}\text { SuperSignal West Pico } \\
\text { PLUS Chemiluminescent } \\
\text { Substrate }\end{array}$ & 34577 & Thermo Fisher Scientific \\
\hline TEMED & 2367.3 & Carl Roth $\mathrm{GmbH}$ \\
\hline Transfer Membrane 0.2 um & ISEQ00010 & Merck Millipore \\
\hline Tris base & T1503 & $\begin{array}{l}\text { Sigma-Aldrich Chemie } \\
\text { GmbH }\end{array}$ \\
\hline Tris- $\mathrm{HCl}$ & T3253 & $\begin{array}{c}\text { Sigma-Aldrich Chemie } \\
\text { GmbH }\end{array}$ \\
\hline Triton X 100 & 3051.2 & Carl Roth $\mathrm{GmbH}$ \\
\hline Tween 20 & 9127.2 & Carl Roth $\mathrm{GmbH}$ \\
\hline Typsin-EDTA solution & T3924 & $\begin{array}{c}\text { Sigma-Aldrich Chemie } \\
\text { GmbH }\end{array}$ \\
\hline $\begin{array}{c}\text { VectaMount permanent } \\
\text { mounting medium }\end{array}$ & $H-5000$ & Vector \\
\hline$\varepsilon$-aminocaproic acid & 7260 & $\begin{array}{l}\text { Sigma-Aldrich Chemie } \\
\text { GmbH }\end{array}$ \\
\hline
\end{tabular}

\subsubsection{Buffers and Solutions}

\section{Immunohistochemistry}

10x Tris Buffered Saline (TBS)

\begin{tabular}{|c|c|}
\hline Tris base & $24.2 \mathrm{~g}$ \\
\hline $\mathrm{NaCl}$ & $85 \mathrm{~g}$ \\
\hline Distilled Water & $800 \mathrm{~mL}$ \\
\hline Adjust pH to 7.4 with & $5 \mathrm{M} \mathrm{HCl}$ \\
\hline
\end{tabular}


20x Citrate buffer

\begin{tabular}{|c|c|}
\hline Citric acid (Monohydrate) & $21 \mathrm{~g}$ \\
\hline Distilled Water & $300 \mathrm{~mL}$ \\
\hline Adjust pH to 7.4 with & $5 \mathrm{M} \mathrm{NaOH}$ \\
\hline Constant volume with distilled water to & $500 \mathrm{~mL}$ \\
\hline
\end{tabular}

Washing Buffer (1x TBST)

\begin{tabular}{|c|c|}
\hline $10 x$ TBS & $100 \mathrm{~mL}$ \\
\hline Tween 20 & $1 \mathrm{~mL}$ \\
\hline Constant volume with distilled water to & $1000 \mathrm{~mL}$ \\
\hline
\end{tabular}

Washing Buffer (1x PBST)

\begin{tabular}{|c|c|}
\hline PBS & $9.55 \mathrm{~g}$ \\
\hline Tween 20 & $1 \mathrm{~mL}$ \\
\hline Constant volume with distilled water to & $1000 \mathrm{~mL}$ \\
\hline
\end{tabular}

\section{Western Blotting}

Electrophoresis buffer (10x)

\begin{tabular}{|c|c|}
\hline Tris base & $30.3 \mathrm{~g}$ \\
\hline Glycin & $144 \mathrm{~g}$ \\
\hline SDS & $10 \mathrm{~g}$ \\
\hline Constant volume with distilled water to & $1000 \mathrm{~mL}$ \\
\hline
\end{tabular}

Lower Tris buffer (4x)

\begin{tabular}{|c|c|}
\hline Tris- $\mathrm{HCl}$ & $181.5 \mathrm{~g}$ \\
\hline SDS & $4 \mathrm{~g}$ \\
\hline
\end{tabular}




\begin{tabular}{|c|c|}
\hline Check pH 8.8 & \\
\hline Constant volume with distilled water to & $1000 \mathrm{~mL}$ \\
\hline
\end{tabular}

Upper Tris buffer (4x)

\begin{tabular}{|c|c|}
\hline Tris-HCl & $60.5 \mathrm{~g}$ \\
\hline SDS & $4 \mathrm{~g}$ \\
\hline Check pH 6.8 & \\
\hline Constant volume with distilled water to & $1000 \mathrm{~mL}$ \\
\hline
\end{tabular}

$10 \%$ APS

\begin{tabular}{|c|c|}
\hline APS & $10 \mathrm{~g}$ \\
\hline Constant volume with distilled water to & $100 \mathrm{~mL}$ \\
\hline
\end{tabular}

Anode buffer I

\begin{tabular}{|c|c|}
\hline Tris base & $36.3 \mathrm{~g}$ \\
\hline Methanol & $200 \mathrm{~mL}$ \\
\hline Constant volume with distilled water to & $1000 \mathrm{~mL}$ \\
\hline
\end{tabular}

Anode buffer II

\begin{tabular}{|c|c|}
\hline Tris base & $3.03 \mathrm{~g}$ \\
\hline Methanol & $200 \mathrm{~mL}$ \\
\hline Constant volume with distilled water to & $1000 \mathrm{~mL}$ \\
\hline
\end{tabular}

Cathode buffer

\begin{tabular}{|c|c|}
\hline Tris base & $3.03 \mathrm{~g}$ \\
\hline Methanol & $200 \mathrm{~mL}$ \\
\hline$\varepsilon$-aminocaproic acid & $5.24 \mathrm{~g}$ \\
\hline Constant volume with distilled water to & $1000 \mathrm{~mL}$ \\
\hline
\end{tabular}


Washing Buffer (1x TBST)

\begin{tabular}{|c|c|}
\hline 10x TBS & $100 \mathrm{~mL}$ \\
\hline Tween 20 & $1 \mathrm{~mL}$ \\
\hline Constant volume with distilled water to & $1000 \mathrm{~mL}$ \\
\hline
\end{tabular}

Blocking Buffer (1x TBST)

\begin{tabular}{|c|c|}
\hline Dry milk or BSA & $0.5 \mathrm{~g}$ \\
\hline Washing buffer & $10 \mathrm{~mL}$ \\
\hline
\end{tabular}

\subsubsection{Kits}

\begin{tabular}{|c|l|}
\hline SCF ELISA Kit & Sigma-Aldrich Chemie GmbH \\
\hline IGF ELISA Kit & Sigma-Aldrich Chemie GmbH \\
\hline PDGF ELISA Kit & Sigma-Aldrich Chemie GmbH \\
\hline EGF ELISA Kit & Sigma-Aldrich Chemie GmbH \\
\hline MCP-1/CCL2 ELISA Kit & Sigma-Aldrich Chemie GmbH \\
\hline HGF ELISA Kit & Sigma-Aldrich Chemie GmbH \\
\hline VEGF ELISA Kit & Sigma-Aldrich Chemie GmbH \\
\hline NGF ELISA Kit & Sigma-Aldrich Chemie GmbH \\
\hline
\end{tabular}

\subsubsection{Laboratory equipment}

\begin{tabular}{|c|c|}
\hline Accumax & Sigma-Aldrich Chemie GmbH \\
\hline Balance & SCAL TEC SBC 52 \\
\hline centrifuge & Eppendorf \\
\hline Freezer $-20^{\circ} \mathrm{C}$ & \\
\hline
\end{tabular}




\begin{tabular}{|c|c|}
\hline Freezer $-80^{\circ} \mathrm{C}$ & Heraeus \\
\hline Microscopes & $\begin{array}{c}\text { Olympus IX50 inverse microscope and } \\
\text { Zeiss Axioplan } 2\end{array}$ \\
\hline $\mathrm{PH}$-meter & BECKMAN (Washington, DC, USA) \\
\hline Power supple & Bio RAD MODLL 200/2.0 \\
\hline \multicolumn{2}{|l|}{ Refrigerator $4^{\circ} \mathrm{C}$} \\
\hline \multicolumn{2}{|l|}{ Vortex Mixer } \\
\hline Water bath & Lauda ecoline RE 104, MEDAX \\
\hline Tissue embedding machine & Leica \\
\hline Tissue processor & Leica \\
\hline Shaker & IKA-Shaker MTS 4 \\
\hline Glass coverslips & Plano \\
\hline Magnetic mixer & IKA-COMBIMAG RET \\
\hline Photometer & Thermo-Labsystem Opsys MR \\
\hline Stereomicroscope & Zeiss Stemi 2000 \\
\hline Imaging software & $\begin{array}{l}\text { Olympus analysis software and Zeiss } \\
\text { KS300 program }\end{array}$ \\
\hline microtome & Leica JUNG RM2055 \\
\hline X-ray films & Hyperfilm, Amersham Bioscience \\
\hline
\end{tabular}




\subsection{Methods}

\subsubsection{Cell culture}

Pancreatic cancer cell lines AsPC-1, BxPC-3, Capan-1, Colo-357, MIA PaCa-2, Panc-1, SU.86.86 were purchased from American Type culture collection (ATCC) and the pancreatic cancer cell line T3M4 was a kind gift from Dr. Metzgar (Durham. North Carolina). All cancer cell lines were cultured according to the supplier's recommendations at $37^{\circ} \mathrm{C}, 5 \% \mathrm{CO}_{2}$. The human immortalized pancreatic epithelial cell line HPDE was a kind gift from Professor M.S. Tsao of the Ontario Cancer Institute (Toronto, Canada) (Furukawa et al. 1996, Ouyang et al. 2000) and was cultured with Keratinocyte SFM, +EGF + bovine pituitary extract supplemented with $1 \%$ Penicillin/Streptomycin.

\subsubsection{Isolation of dorsal root ganglia}

The primary dorsal root ganglia (DRG) neurons were isolated from the lumbar spinal region of newborn C57BL/6 mouse (2-day to 2-week old) after anterior laminectomy, as described previously (Ceyhan et al. 2008). The neurons were kept in MEM on ice, and the roots were removed under microscopy. After collection, the DRG neurons were incubated in $900 \mu \mathrm{L}$ Hanks' BSS and $100 \mu \mathrm{L}$ collagenase type II for 40 minutes in incubator for digesting the DRG capsules, easing the subsequent dissociation of neurons.

\subsubsection{Three-dimensional (3D) migration assay}

The 3D migration assay and digital time-lapse microscopy were used to determine the affinity and the neuron-directed migration of cancer cells to DRG neurons. ${ }_{105}$ SU.86.86 
pancreatic cancer cells and DRG neurons were respectively suspended in an extracellular matrix (ECM) gel droplet, placed at a distance of 1 millimeter. To generate a chemoattractive gradient, an ECM or fibronectin "bridge" was applied between the suspensions. An additional cell-free ECM gel droplet was placed at the other side and connected to the cancer cell suspension so that unspecific cellular migration could be excluded. After polymerization of the suspensions and bridges in the incubator, neurobasal medium supplemented with $100 \mathrm{U} / \mathrm{mL}$ penicillin and $100 \mu \mathrm{g} / \mathrm{mL}$ streptomycin, 2\% B-27, 0.5mM L-Glutamine and 10\% FCS were applied to the assay. After 48 hours incubation, the migratory behavior of cancer cells was recorded by digital time-lapse microscopy. To analyze the migratory behavior of the cancer cells, several morphometric parameters were applied, including velocity (cancer cells migrate to neuronal structures), the Euclidean distance, and forward migration index (FMI).

\subsubsection{DRG neurons supernatant treatment}

After collection, the DRG neurons were seeded in 24-well plates precoated with $4 \mu \mathrm{g} / \mathrm{mm} 2$ poly-D-lysine hydrobromide, supplied with $500 \mu \mathrm{L}$ neurobasal medium supplemented with $100 \mathrm{U} / \mathrm{mL}$ penicillin and $100 \mu \mathrm{g} / \mathrm{mL}$ streptomycin, $2 \%$ B-27, 0.5mM L-Glutamine and $10 \%$ FCS. The medium was changed to serum-free medium 24 hours later, and the supernatant was collected after an additional 48 hours and kept at $-80^{\circ} \mathrm{C}$. SU.86.86 and T3M4 pancreatic cancer cells were seeded in 6-well-plate and serum-starved overnight and then treated with control medium or DRG neurons supernatant for 15 or 25 minutes. 


\subsubsection{Western blotting}

Cells were washed with PBS for 3 times and total protein were extracted with lysis buffer which contain protease inhibitor and phosphatase inhibitor. Protein concentration was measured by BCA protein assay kit. After measurement, $20 \mu \mathrm{g}$ of protein was diluted into same volume and boiled for 5 minutes, and cooled on ice. Proteins were electrophoretically fractionated in 10\% SDS-polyacrylamide gels and then transferred to nitrocellulose membranes. After blocked with 5\% BSA, the membrane was incubated with primary antibody at $4^{\circ} \mathrm{C}$ overnight. After incubation, the membrane was washed with washing buffer for 3 times and incubated with ECL IgG horsereddish peroxidase.coupled secondary antibody for 1 hour at room temperature. Afterwards, antibody detection was performed with ECL Plus Western Blotting substrate. After scanning of the films, the density of the target bands was measured by ImageJ.

\subsubsection{Immunohistochemistry, Immunofluorescence}

$3 \mu \mathrm{m}$ sections were prepared from paraffin-embedded tissues. After deparaffinization in Roticlear® and rehydrated in ethanol, the sections were boiled with citrate buffer for the retrieval of the antigen for 15 minutes and blocked with normal goat serum to exclude the nonspecific binding for 1 hour at room temperature. Then, the sections were incubated with the primary antibody at $4{ }^{\circ} \mathrm{C}$ overnight. After incubation, the sections were washed with washing buffer for 3 times and incubated with Dako Envision+ system-HRP secondary antibody for 1 hour at room temperature. Then, Dako Liquid DAB+ Substrate Chromogen System was used for the color reaction. Afterwards, the sections were then dehydrated with ethanol and Roticlear® successively. 
For immunofluorescence, after incubation with the primary antibody and wash with washing buffer, the sections were incubated with Alexa Fluor goat IgG secondary antibody.

\subsubsection{Immunocytochemistry}

For immunocytochemistry, the cultured cells were fixed with $4 \%$ formaldehyde for 15 minutes and blocked with normal goat serum for 1 hour at room temperature. After incubation with primary antibody overnight, the cells were washed and incubated with Alexa Fluor goat IgG secondary antibody and Phalloidin-TRITC for 1 hour at room temperature. After washing again with washing buffer, the slides were mounted with Fluorescence Mounting Medium.

\subsubsection{ELISA}

$10_{5}$ SU.86.86/T3M4 pancreatic cancer cells or/and DRG neurons were seeded in $2 \mathrm{~cm}$ dish and cultured with the completed medium in $37^{\circ} \mathrm{C}, 5 \% \mathrm{CO}_{2}$. After 24 hours incubation, 4 $\mathrm{mL}$ serum-free medium was added to control group, cancer cell mono-culture group, DRG neuron mono-culture, co-culture group, and $2 \mathrm{~mL}$ serum-free medium was added to the mixed groups (cancer cells supernatant mixed with DRG neurons supernatant after cultivation). After 48 hours cultivation, the supernatant was collected and kept at $-80^{\circ} \mathrm{C}$. The concentrations of each cytokine, including MCP-1/CCL2, IGF-1, VEGF, EGF, PDGF, HGF, SCF and NGF, in each group were measured by sandwich ELISA assay.

$100 \mu \mathrm{l}$ of standard and samples from each group were added into appropriate wells and incubated with gentle shaking at $4^{\circ} \mathrm{C}$ overnight. After incubation, the solution in appropriate wells was discarded carefully. After washing with wash solution, $100 \mu$ of prepared detection antibody was added into each well and incubated for 1 hour at room temperature with gentle shaking. After washing, $100 \mu \mathrm{l}$ of Streptavidin solution was added into each well and incubated 
for 45 minutes at room temperature with gentle shaking. After washing again, $100 \mu \mathrm{l}$ of TMB One-Step Substrate Reagent was added into each well and incubated for 30 minutes at room temperature with gentle shaking. After incubation, $50 \mu \mathrm{l}$ of Stop Solution was added into each well. The absorbance was measured at $450 \mathrm{~nm}$ immediately.

\subsubsection{Statistical analysis}

Statistical analysis was performed by the GraphPad Prism 8 Software. The data was presented with mean \pm SEM from three independent experiments. $T$-test was used for determining statistically significant and an effect was considered statistically significant at a $p$ value $\leq 0.05$ 


\subsection{Results}

\subsection{Pancreatic cancer cells show affinity to DRG neurons}

To evaluate the affinity of pancreatic cancer cells to neurons, we used our recently demonstrated three-dimensional (3D) migration assay, in which the pancreatic cancer cell line SU.86.86 and DRG neurons were suspended in an ECM gel to simulate the in vivo circumstance (Demir et al. 2014). Here, cancer cells were confronted with mouse DRG neurons on one side and empty ECM gel on the other side to excluded the unspecific interaction (Fig. 1a).

The affinity of pancreatic cancer cells to DRG neurons is best demonstrated by the differences between the migration front FMI and the back front FMI. Comparative quantification of the neuron-directed cancer cell migration showed that the cancer cells revealed a highly targeted migration toward mouse DRG neurons at the migration front, which obviously surpassed the FMI values in the back front (0.32 versus 0.16$)$ (Fig. 1b).

When the cancer cells in the migration front were compared with that in the back front, it is apparent that pancreatic cancer cells migrated much faster toward DRG neurons, as evidenced by their higher velocity values to DRGs $(0.09 \mu \mathrm{m} / \mathrm{min}$ versus $0.05 \mu \mathrm{m} / \mathrm{min})($ Fig. 1 C) .

Comparing the euclidean distance between two groups, neuron facing cancer cells in the migration-front covered prominently longer distance than those in back front $(42.21 \mu \mathrm{m}$ versus $24.57 \mu \mathrm{m})$ (Fig. 1d). These results indicated that pancreatic cancer cells have strong affinity to neurons. 
a

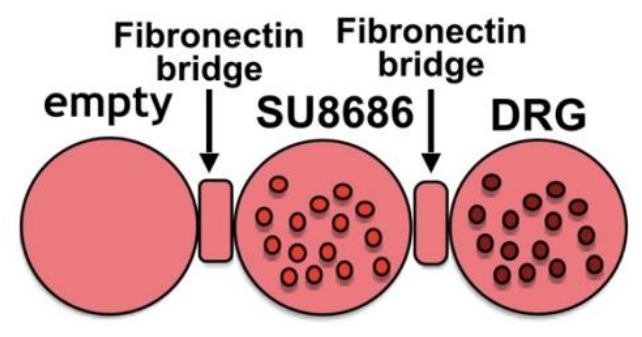

C

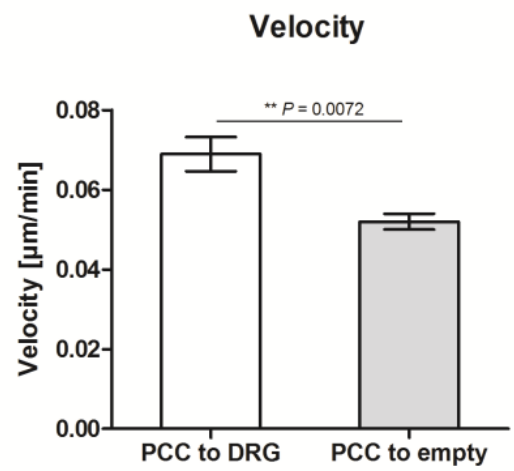

b

Forward Migration Index/FMI

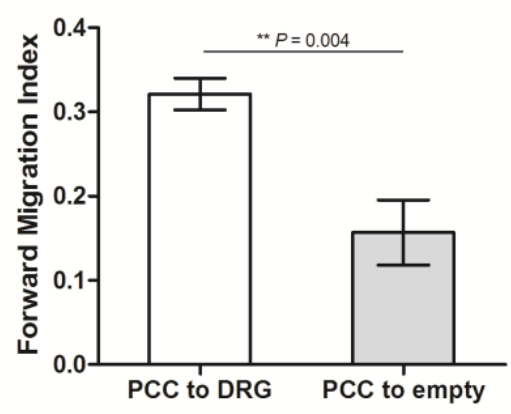

d Euclidian Distance

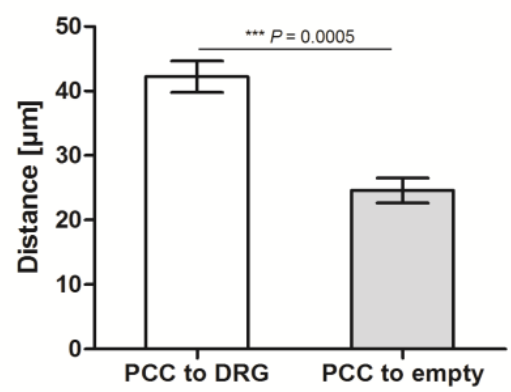

Figure 1. Chemoattraction of DRG to pancreatic cancer cells. (a) Schematic illustration of 3D-migrationassay. (b, c, d) Quantification of pancreatic cancer cell FMI, velocity and Euclidian distance toward DRG in comparison to the control extracellular matrix gel suspension. The results showed that the cancer cells' FMI, velocity and Euclidian distance in the migration front were significantly increased. All data are expressed as mean \pm SEM from triplicate independent experiments. $P$ value was determined by unpaired $t$-test.

\subsection{Pancreatic cancer cells exhibit a more "polygonal shape" during neural invasion.}

The reorganization of the cytoskeleton is essential for the acquirement of migratory and invasive properties of pancreatic cancer cell. To better understand the alteration of the cytoskeleton in cancer cells during the neural invasion, cancer cells were immunostained with Phalloidin-TRITC and DAPI. Here, we demonstrated, that in the migration front, the number of the migrating cells was dramatically increased (Fig. 2a). 
Interestingly, the neuron-facing cancer cells in the migration front acquired a typical morphological change in their cytoskeleton. In particular, phalloidin staining showed that pancreatic cancer cells without the stimulation of neurons revealed a relatively round shape, whereas cells migrating towards DRG exhibited a more "polygonal shape" and a rather spindlelike morphology with a consequent increase of cell volume (Fig. 2b). In addition, the actin filaments in the neuron-facing pancreatic cancer cell seemed to align along the macroaxis of the cancer cells.

a

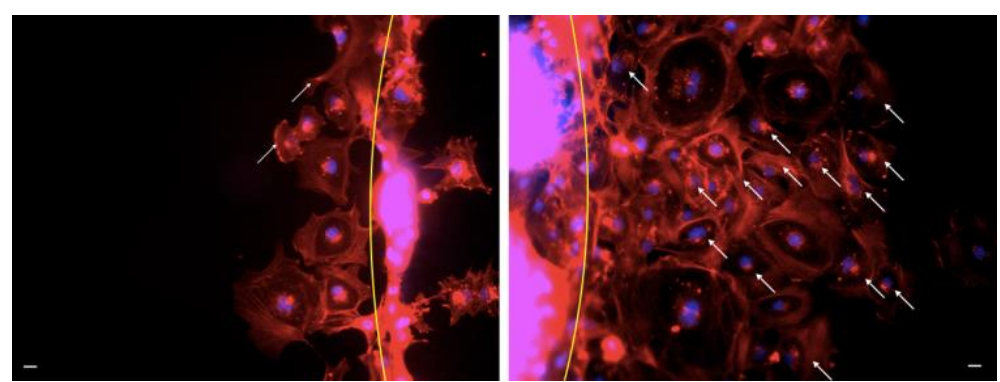

b
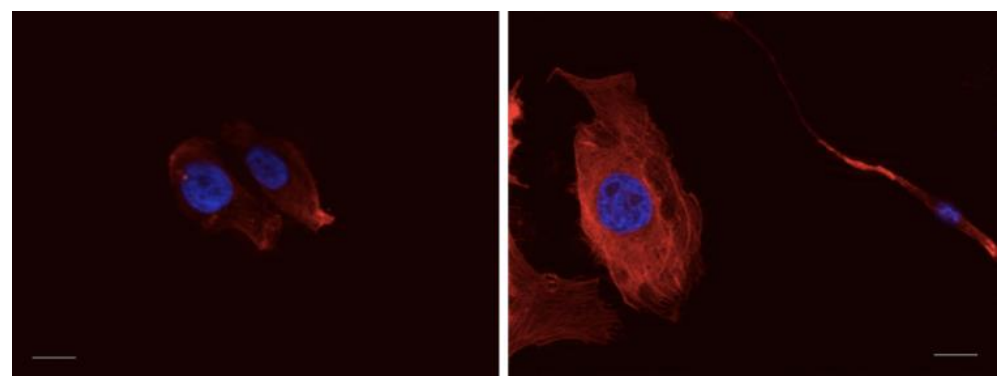

Figure 2. The alterations of cytoskeleton during the neural invasion. (a) Pancreatic cancer cells were simultaneously confronted with DRG neurons on one side and ECM gel on the other side in a 3D-migration assay. More migrating cells (white arrows) were observed in migration-front in (right) comparison to backfront (left). (b) Cell cytoskeleton changes of cancer cells. The neuron-facing tumor cells acquired a typical morphological change of their cytoskeleton. Cancer cells (images to the right) migrating towards DRG exhibited a more "polygonal shape" with a consequent increase of their cell volume. (Scale bar: $20 \mu \mathrm{m}$ ). 


\subsection{The formation of migratory protrusions is significantly increased during the}

neural invasion of pancreatic cancer cells.

Next, to further investigate the impact of cytoskeletal reorganization on the neural invasion, we determined the formation of migratory protrusions in nerve-infiltrating pancreatic cancer cells. For this purpose, we applied Apotome-supported digital tome-lapse microscopy after immunostaining in the 3D migration assay. Further on, the density and the length of cancer cell filopodia were quantified with the FiloQuant® software (Jacquemet et al. 2017). Intriguingly, cancer cells in the migration front exhibited a prominently increase in the density and length of filopodia (Fig. 3a). Additionally, the number and the area of the lamellipodia was also increased in the neuron-facing cancer cells (Fig. 3b). These findings confirmed the reorganization of the cytoskeleton and formation of microfilaments specifically in neurontargeting cancer cells.

a
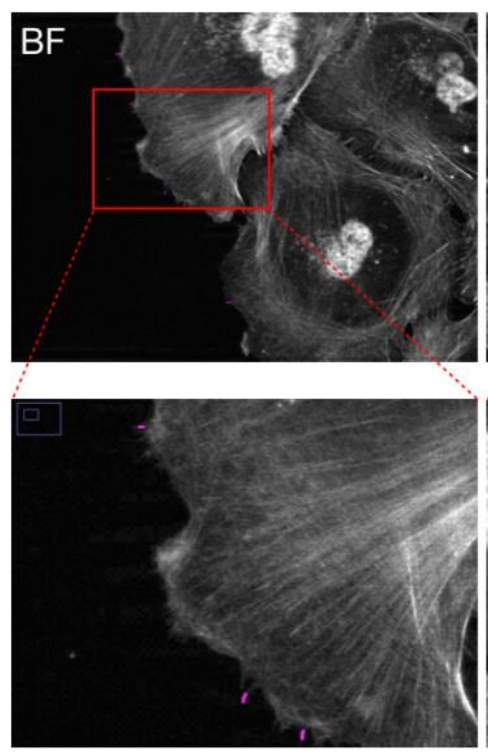

b

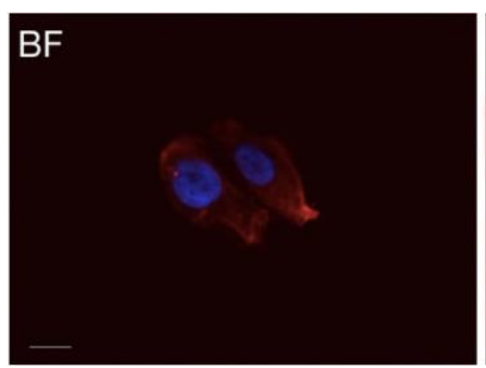

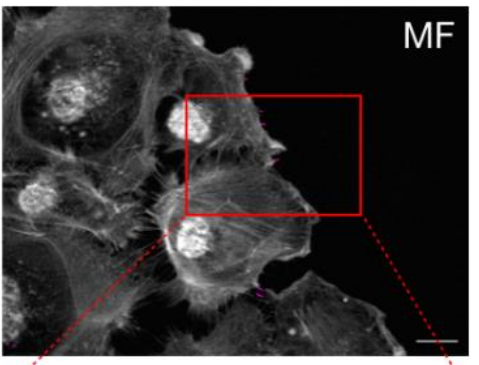
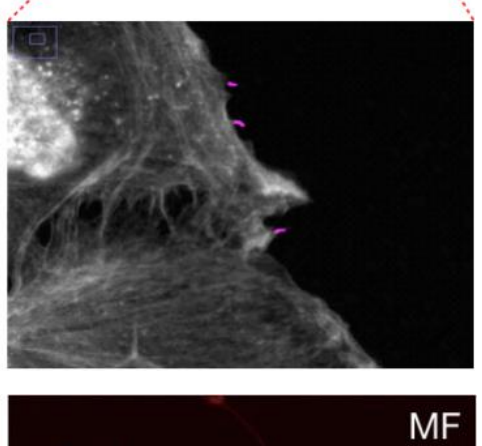

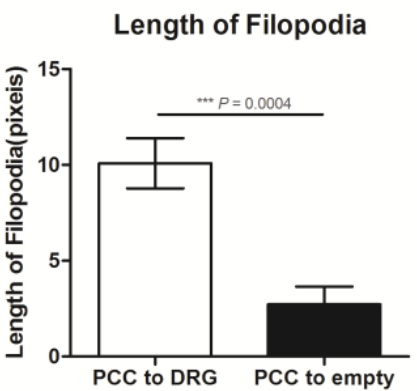

Number of Filopadia

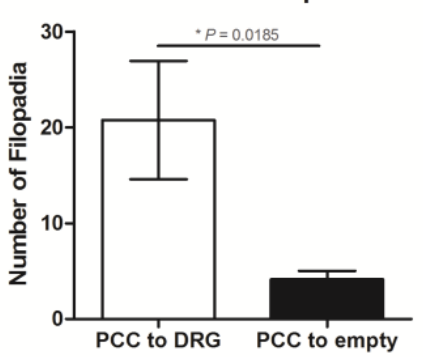

Area\% or Lamelıpoda

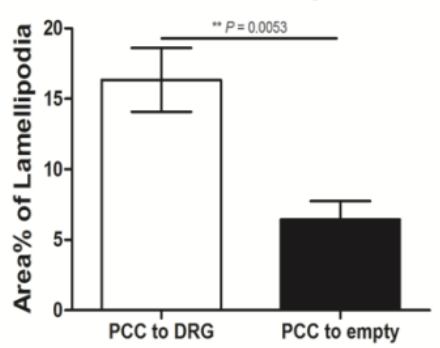




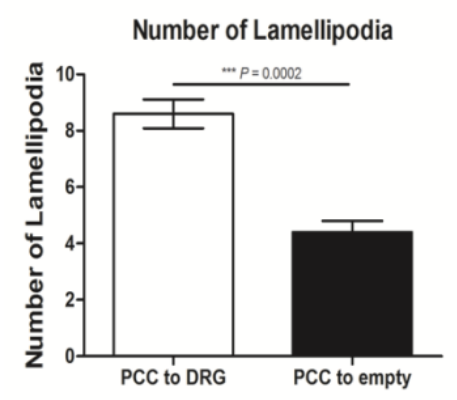

Figure 3. The formation of filopodia and lamellipodia during the neural invasion. (A) After 3D-migration assay, the density and length of cancer cell filopodia were quantified with the FiloQuant ${ }^{\circledR}$ software. Filopodia density was quantified and compared between cells. The density and length of filopodia were increased in the migration front (MF). (B) The number and the area of lamellipodia was also increased in the migration front (white arrows). Data are expressed as mean \pm SEM from triplicate independent experiments. $P$ value was determined by unpaired $t$-test. (Scale bar: $20 \mu \mathrm{m}$ ).

\subsection{Pancreatic cancer cells specifically amplify phospho-paxillin in their lamellipodia during neural invasion.}

One of the major aims of this study was to investigate the impact of cytoskeleton-related proteins on neural invasion in pancreatic cancer. Paxillin activation is strongly associated with the cytoskeletal reorganization. For this purpose, the expression of phospho-paxillin was determined by double immunolabeling with Phalloidin-TRITC and phospho-paxillin after 3D migration assay. The phospho-paxillin positive dots were counted and compared between the migration front and back front.

Here, phospho-paxillin-positive dots were seen to be abundant in the neuron-facing pancreatic cancer cells, as opposed to the cells in the back front. By comparison with cancer cells in the back front, there was an evident increase in the amount of phospho-paxillin-positive dots in the neuron-facing cells, demonstrating that DRG neurons could stimulate the phosphorylation of paxillin (Fig. 4). 

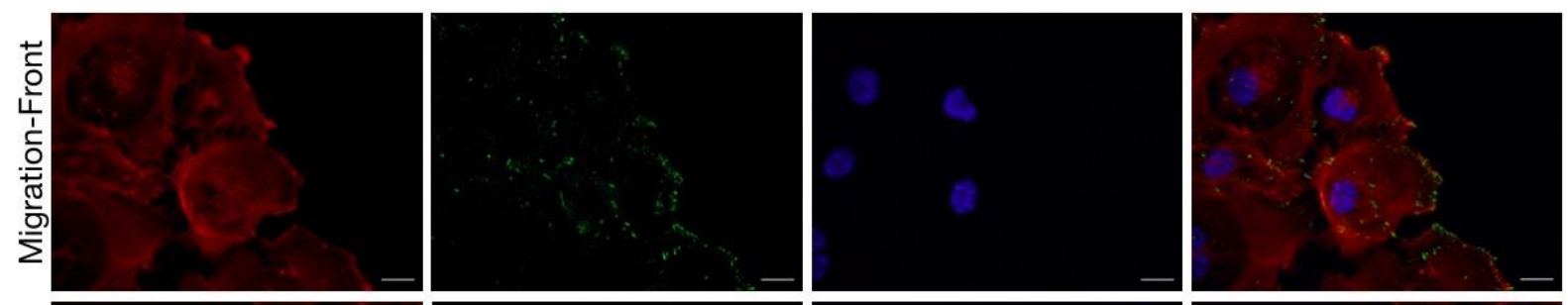

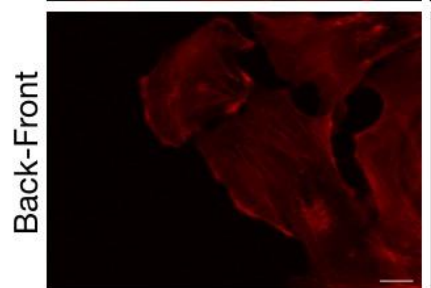

Phalloidin

P-paxillin-positive dots

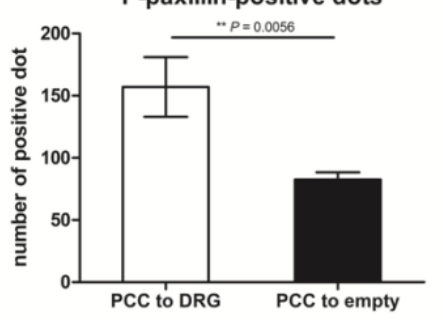

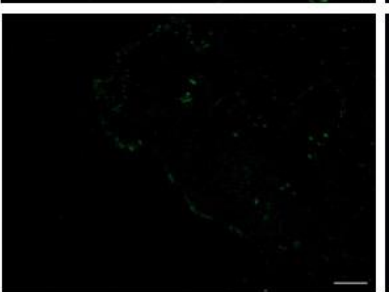

Phospho-paxillin Y118

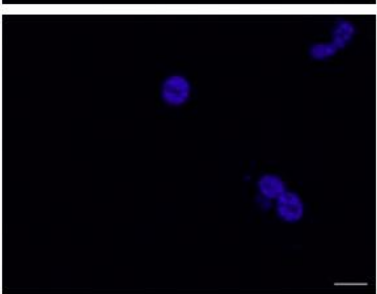

DAPI

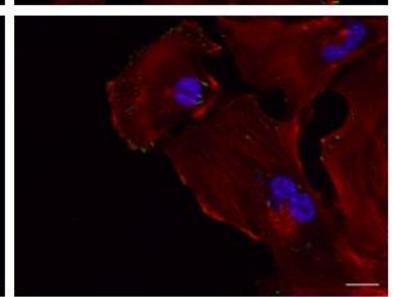

Overlay

Figure 4. Phospho-paxillin expression in 3D migration. Pancreatic cancer cells in migration-front (upper panel) and back-front (lower panel) were immunofluorescently stained with phalloidin and phospho-paxillin after 3D-migration assay. The filopodia exhibited a specific enrichment of phospho-paxillin in the migration front, when compared to the back front. Data are expressed as mean \pm SEM from triplicate independent experiments. $P$ value was determined by unpaired $t$-test. (Scale bar: $20 \mu \mathrm{m})$.

\subsection{The expression of phospho-paxillin is upregulated in PCC after treatment}

\section{with DRGs supernatants}

The up-regulation of phospho-paxillin in the neuron-facing cells in 3D migration assay prompted us to further assess the role of DRG neurons in neural invasion. For this purpose, SU.86.86 and T3M4 human pancreatic cancer cells were treated with DRG neurons supernatants for different time intervals. The amount of phospho-paxillin was measured by western blotting. DRG neurons were supplied with serum-free medium and the supernatant was collected after 48 hours. Then, cancer cells were treated with DRG neurons supernatant or control medium for 15 or 25 minutes. Western blotting results revealed that the phosphorylation of paxillin was amplified after treatment with DRG neuron supernatants (Fig. 
5). Hence, it was conceivable that DRG neurons can secrete cytokines which can induce the phosphorylation of paxillin.
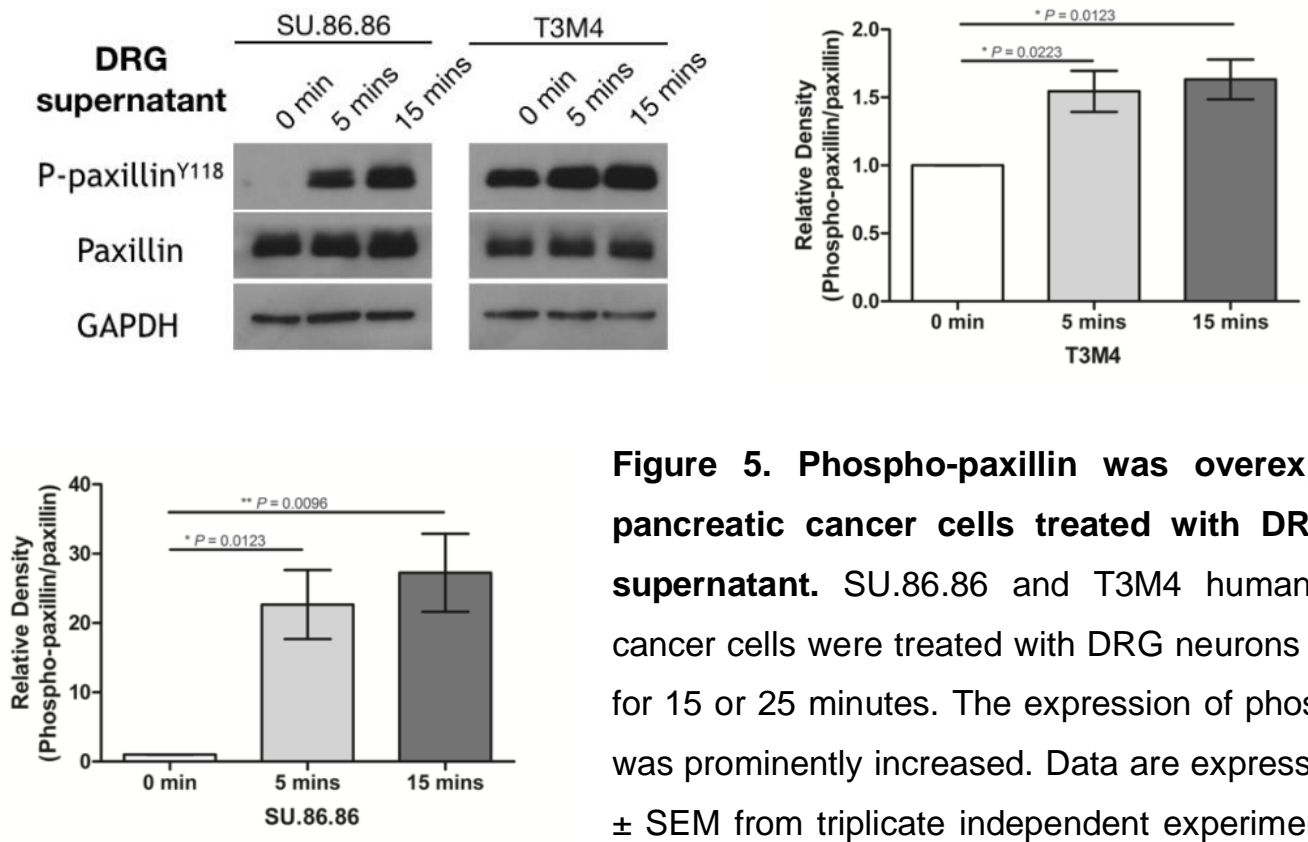

Figure 5. Phospho-paxillin was overexpressed in pancreatic cancer cells treated with DRG neurons supernatant. SU.86.86 and T3M4 human pancreatic cancer cells were treated with DRG neurons supernatant for 15 or 25 minutes. The expression of phospho-paxillin was prominently increased. Data are expressed as mean \pm SEM from triplicate independent experiments. $P$ value was determined by unpaired $t$-test.

\subsection{The expression of phospho-paxillin downstream targets in pancreatic cancer cell lines is prominently up-regulated}

In the next step, to further investigate the potential role of paxillin phosphorylation in pancreatic cancer cells, we determined the expression of phospho-paxillin, phospho-FAK, phospho-Src and phospho-ERK1/2 content of human PDAC cell lines.

We detected that phospho-paxillin, phospho-FAK, phospho-Src and phospho-ERK1/2 and phospho-FAK proteins were elevated in all different PDAC cell lines, including AsPC-1 (AsP), BxPC-3 (BxP), Capan-1 (Cap), Colo-357 (Col), MIA PaCa-2 (MIA), Panc-1 (Pan), SU.86.86 (SU) and T3M4 (T3), which exhibited much higher levels that the immortalized pancreatic epithelial cell line HPDE (HP) (Fig. 6). These findings imply that the expression of phospopaxillin, phospho-Src and phospho-FAK is abnormally up-regulated in cancer cells. 


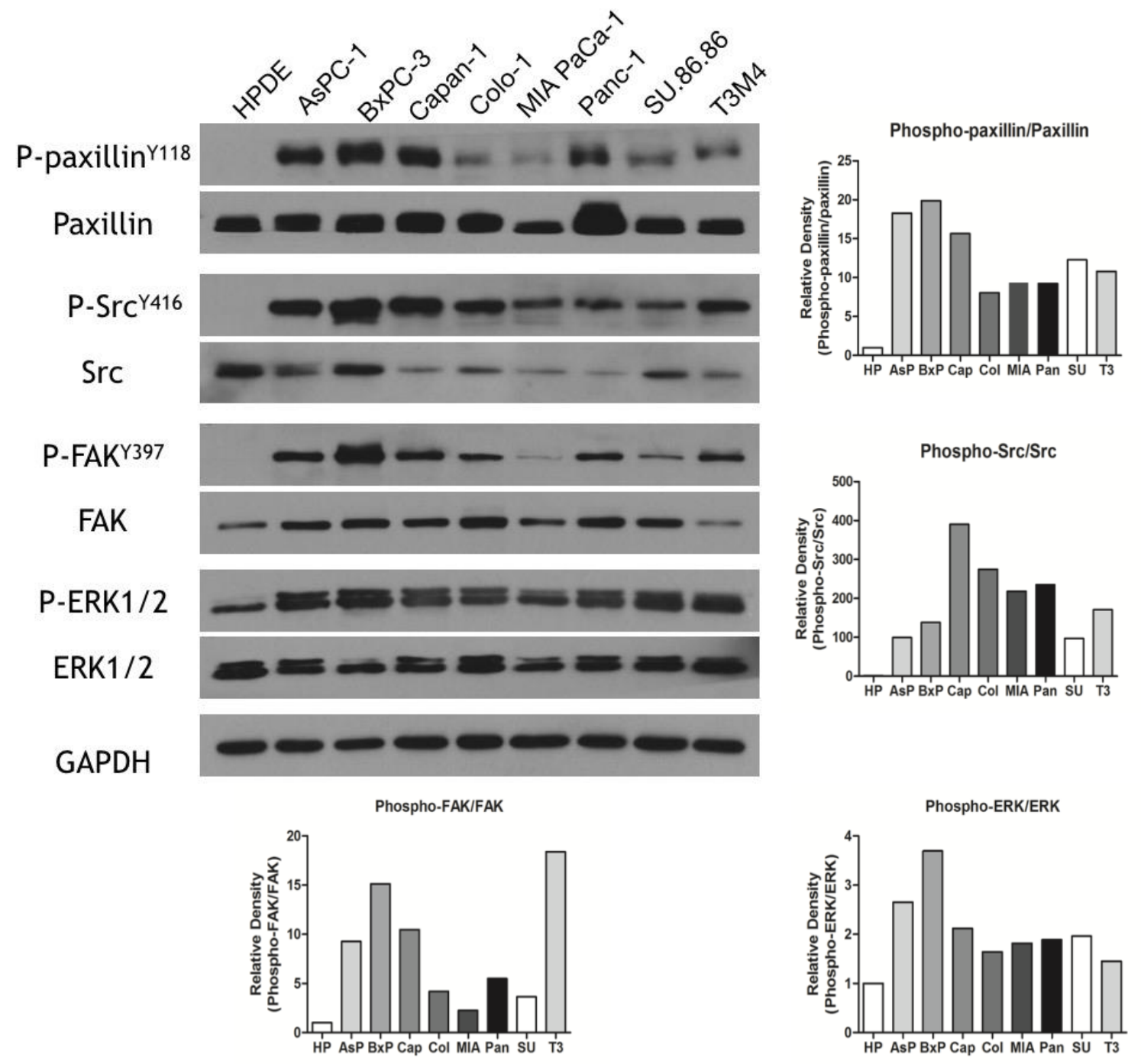

Figure 6. The expression of phospho-paxillin, phospho-FAK, phospho-Src and phospho-ERK in different cell lines was prominently up-regulated. The expressions of phospho-paxillin, phospho-FAK, phospho-Src and phospho-ERK in different pancreatic cancer cell lines were increased in comparison to HPDE.

\subsection{Paxillin is increasingly phosphorylated in cancer cells around nerves in the cancer tissue.}

Because of the strong affinity of cancer cells to DRG neurons, we next investigated the expression of phospho-paxillin around neurons in pancreatic cancer tissues using two consecutive 3-um-thick section obtained from PDAC patients. The first slide was 
immunostained against anti-PGP 9.5/anti-Cytokeratin Pan for locating the neural invasion regions. The second slide was immunostained against anti-Phospho-paxillin/anti-Cytokeratin Pan for detecting the expression of phospho-paxillin. The phospho-paxillin content of cancer cells around nerves was compared to cancer cells that were in no contact with nerves. In accordance with the in vitro results, we frequently detected a relatively stronger presence of phospho-paxillin in cancer cells invading nerves (Fig. 7a).

The genetically engineered mouse models (GEMMs) provided a unique opportunity to investigate the characteristic features of the tumor and improved our understanding of neural invasion. Pdx1 cre/+;LSL-KrasG12D/+;Tp53fl/+ (KPC) mouse tumor model was reported to harbor neural invasion (Na'ara et al. 2018). Consistent with our findings in human PDAC tissue, the phospho-paxillin content was significantly increased in cancer cells that were in the vicinity of nerves, when compared to cancer cells away from nerves (Fig. 7b) 
a
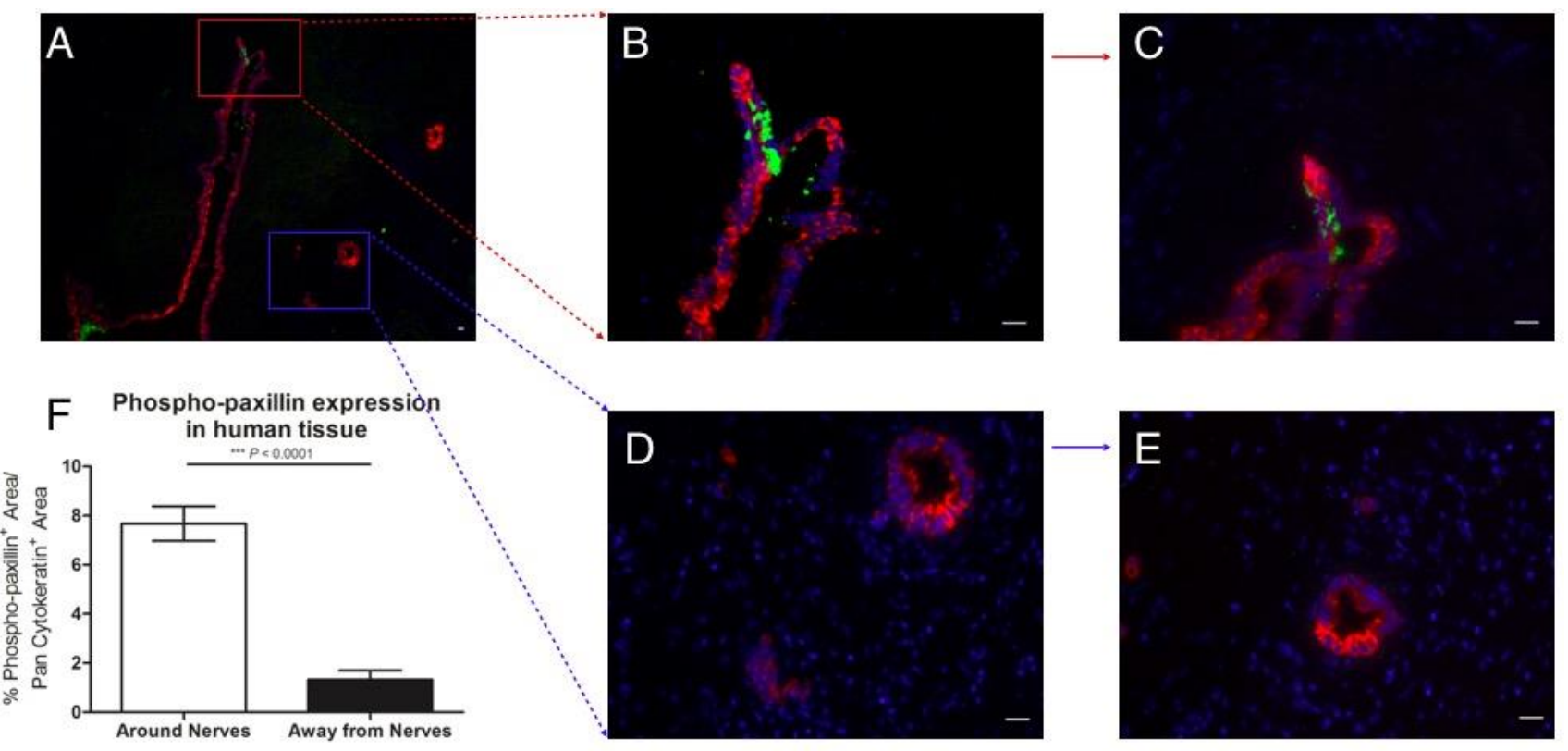

Pan-CK/PGP 9.5/DAPI

Pan-CK/Phospho-paxillin Y118/DAPI

b
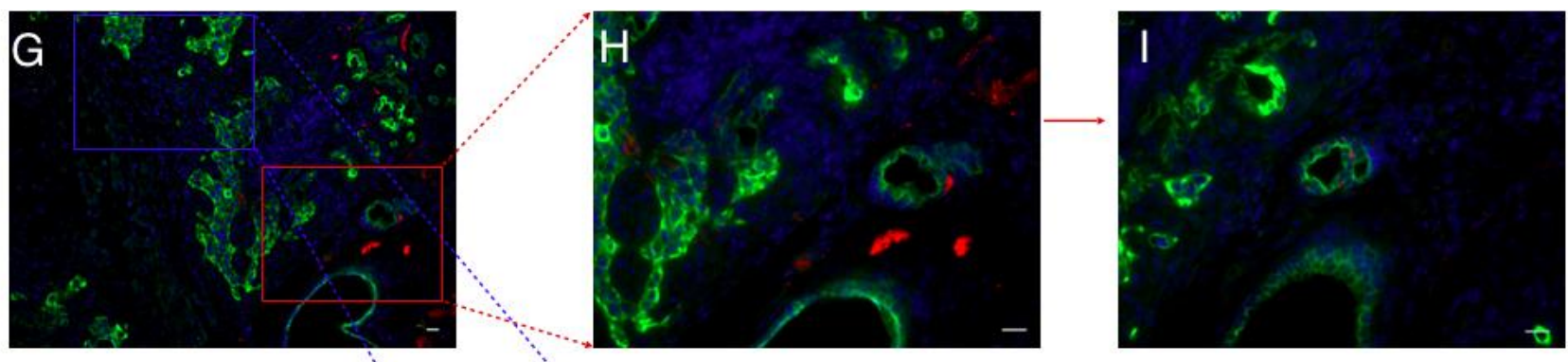

$\mathrm{L} \quad \begin{gathered}\text { Phospho-paxillin expressiơn } \\ \text { in KPC mouse tissue }\end{gathered}$
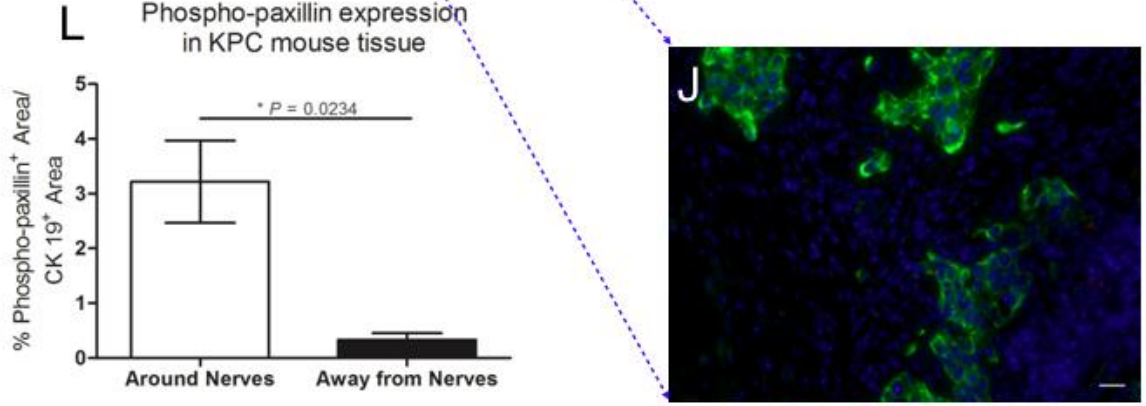

PGP 9.5/CK 19/DAPI

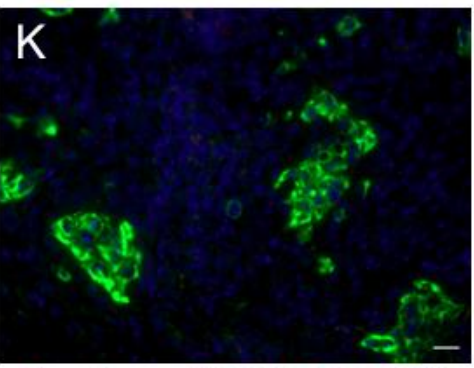

Phospho-paxillin ${ }^{\text {118 }}$ /CK 19/DAPI

Figure 7. Phospho-paxillin is also prominently expressed around nerves in the primary PDAC tissue. Two consecutive 3-um-thick sections obtained from PDAC patients (A) or KPC mice (B) were immunostained against cancer cell marker pan-cytokeratin ( $A$, red), or against phospho-paxillin ( $A$, green), or against the pan-neural marker PGP9.5 (B, red). The phospho-paxillin content of cancer cells around nerves was compared to cancer cells that were in no contact with nerves. The expression phospho-paxillin of was increased in tumor cells around nerves when compared to tumor cells away from nerves. Data are expressed as mean \pm SEM from triplicate independent experiments. $P$ value was determined by $t$-test. (Scale bar: $20 \mu \mathrm{m})$. 


\subsection{MCP-1 is prominently enriched in the co-culture supernatants of cancer cell and DRG neurons}

The up-regulated expression of phospho-paxillin in the pancreatic cancer cells treated with DRGs supernatant motivated us to further investigate the stimuli for paxillin phosphorylation during neural invasion. The phosphorylation of paxillin can be triggered by a series of cytokines, including Monocyte chemoattractant protein 1 (MCP-1, also known as CCL2) (Yamasaki et al. 2001), insulin-like growth factor I (IGF-I) (Butler et al. 1997), vascular endothelial growth factor (VEGF) (Abedi et al. 1997), epidermal growth factor (EGF) (Tapia et al. 1999), platelet-derived growth factor (PDGF) (Rankin et al. 1996), hepatocyte growth factor (HGF) (Herrera 1998), stem cell factor (SCF) (Scott et al. 1996), and nerve growth factor (NGF) (Melamed et al. 1995). To investigate the roles of these cytokines in neural invasion, DRG neurons or cancer cells were seeded either alone or co-culture with each other and the levels of these cytokines in the supernatants were assayed by sandwich ELISA. 5 groups were measured, including control group, cancer cell monoculture group, DRG neuron monoculture group, co-culture group and mixed group. In the mixed group, cancer cell supernatant was mixed with DRG neuron supernatant after cultivation to compare the alteration in a more intuitively way. Intriguingly, when SU.86.86 cancer cells were monocultured, we did not observe any significant variation in the MCP-1/CCL2 secretion compared to control group (Fig. 8a). Meanwhile, when T3M4 cancer cells were monocultured, the MCP-1/CCL2 levels in the supernatant was slightly increased (Fig. 8a). Specifically, when DRG neurons were monocultured, the secretion was mildly increased (Fig. 8a, 8b). However, the secretion level of MCP-1/CCL2 was dramatically increased when DRG neurons were co-cultured together with either SU.86.86 or T3M4 PDAC cancer cells (Fig. 8a, 8b), which implied that MCP-1/CCL2 plays a critical role in neural invasion. 
Furthermore, the expression of VEGF (Fig. 8b) and PDGF (Fig. 8c) was apparently enhanced when DRG neurons or cancer cells monocultured, whereas the expression level was not observed to significantly change in the co-culture situation. On the other hand, as for IGF (Fig. 8e), EGF (Fig. 8f), and NGF (Fig. 8g), there was no obvious alteration between the control group and monoculture group. Besides, compared to monoculture, co-culture of DRG neurons and cancer cells did also not influence the expression of IGF, EGF, and NGF. Concerning SCF (Fig. 8d). In fact, although the expression was increased in the cancer cell supernatant, the expression was attenuated when co-cultured with DRG neurons. As for HGF (Fig. 8h), neither DRG neurons nor cancer cells altered the expression of HGF. Moreover, the expression was even hampered in the co-culture condition. 

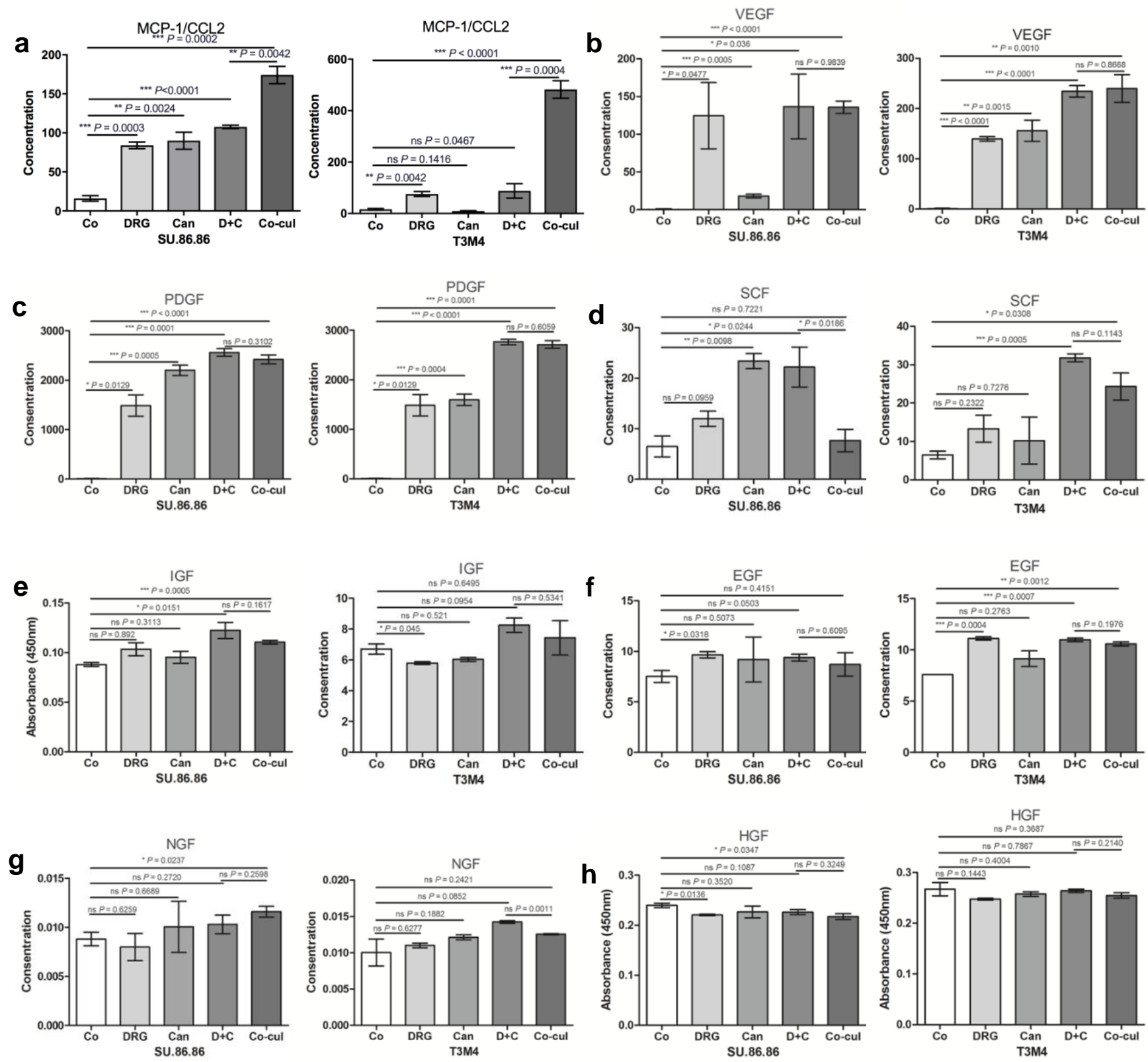

Figure 8. MCP-1 is dramatically elevated in the co-culture of cancer cell and DRG neurons supernatant.

(a) The expression level of MCP-1 was dramatically increased when DRG neurons were mixed together with cancer cells. (b, c) The expression of VEGF and PDGF was enhanced when DRG neurons or cancer cells monocultured, whereas the expression level was not significantly changed in the co-culture situation. (d) The expression of SCF was slightly attenuated in the co-culture group. $(e, f, g)$ The secretion of IGF, EGF and NGF showed no obvious alteration between control group and monoculture group. Besides, compared to monoculture, co-culture of DRG neurons and cancer cells did not influence their expression. (h) Neither DRG neurons nor cancer cells altered the expression of HGF. Data are expressed as mean \pm SEM from triplicate independent experiments. $P$ value was determined by $t$-test. (Co: control supernatant. DRG: DRG supernatant. Can: Cancer supernatant. D+C: DRG supernatant + cancer supernatant. Co-cul: Co-culture supernatant.) 


\subsection{The expression of MCP-1 is significantly upregulated in neural invasion in pancreatic cancer patients}

To find out the potential role of MCP-1/CCL2 during neural invasion, we investigated the expression of MCP-1/CCL2 in human pancreatic cancer tissue by immunohistochemistry. Two consecutive 3-um-thick section were used. The first slide was immunostained with anti-S100 for labeling the nerves and the second slide was immunostained with anti-MCP-1. Nerves were separated into $\mathrm{NI}$ group and non-NI group depending on the presence of the NI. The immunoreactivity of MCP-1 differed considerably between NI group and non-NI group. Figure 9 shows that the expression of MCP-1 in non-NI group was quite low in nerves and cancer cells, whereas in the $\mathrm{NI}$ group, the expression was prominently up-regulated. Interestingly, in the NI-group, the expression of MCP-1 in pancreatic cancer cells was also increased compared with non-NI group.

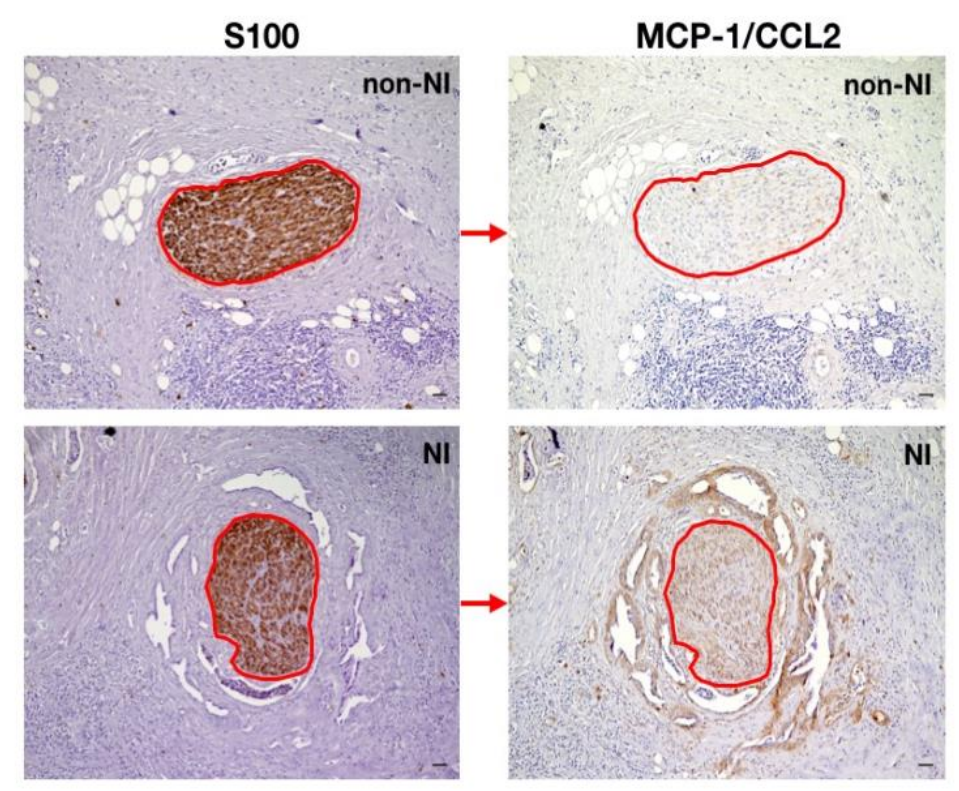

Figure 9. The expression of MCP-1 was significantly overexpressed at sites of neural invasion in pancreatic cancer. The expression of MCP-1 in non-NI group was quite low, whereas in the NI group, the expression was prominently up-regulated. (Scale bar: $50 \mu \mathrm{m}$ ) 


\subsection{MCP-1/CCL2 induces the phosphorylation of paxillin and enhances the neuron-directed migration ability in vitro}

Due to the important role of MCP-1/CCL2 in promoting neural invasion in pancreatic cancer cells, we sought to evaluate if MCP-1/CCL2 can stimulate paxillin phosphorylation. Strikingly, figure 10a shows that $100 \mathrm{ng}$ MCP-1/CCL2 in the SU.86.86 cancer cell supernatant significantly enhanced phosphorylation of paxillin at 5, 15 and 25 minutes by $172 \%, 186 \%$, and $150 \%$, respectively. Similarly, $100 \mathrm{ng}$ MCP-1/CCL2 addition to T3M4 cancer cells also increased the phosphorylation of paxillin by $130 \%, 181 \%$, and $133 \%$, respectively. Subsequently, cancer cells were lysed15 minutes after the treatment of MCP-1/CCL2. Figure $10 \mathrm{~b}$ shows that 15 minutes after addition of $0 \mathrm{ng}, 10 \mathrm{ng}, 50 \mathrm{ng}$ and 100ng MCP-1/CCL2 to SU.86.86 and T3M4 pancreatic cancer cell, phosphorylation of paxillin was significantly increased in a dose-dependent manner.

In additional 3D migration assays, DRG neurons were simultaneously confronted with cancer cells treated with vehicle and with cancer cells treated with MCP-1/CCL2 protein or the CCR4 antagonist C 021 dihydrochloride (Fig 10c). After 48 hours incubation, the neurontargeted migration of cancer cells was recorded via digital time-lapse microscopy. Here, we observed significantly amplified neuron-directed migration ability of pancreatic cancer cells upon treatment with MCP-1CCL/2, as demonstrated by the increase in their FMI ( 0.33 versus 0.25) (Fig 10d). Moreover, the migration of stimulated pancreatic cancer cells was characterized by a rather longer Euclidian distance $(46.71 \mu \mathrm{m}$ versus $41.61 \mu \mathrm{m})$ and faster velocity $(0.10 \mu \mathrm{m} / \mathrm{min}$ versus $0.08 \mu \mathrm{m} / \mathrm{min})$ than those of vehicle-treated cancer cells (Fig 10d). 
a

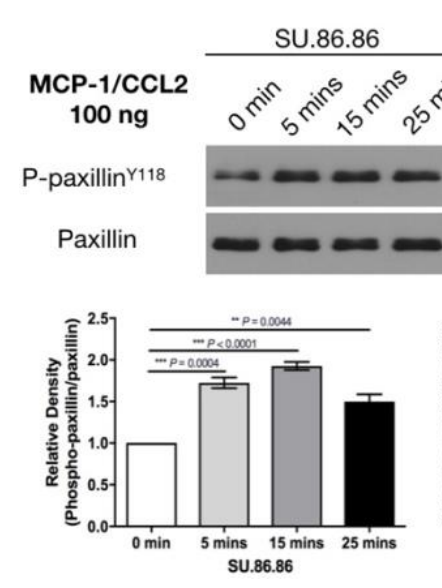

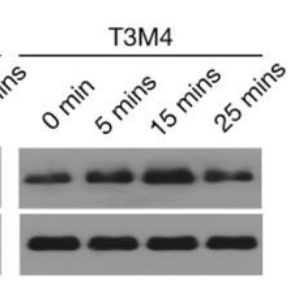

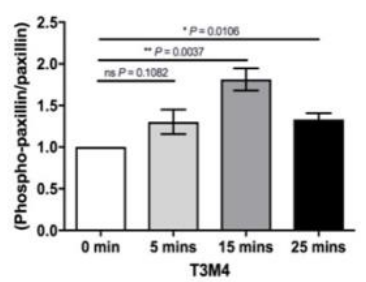

b
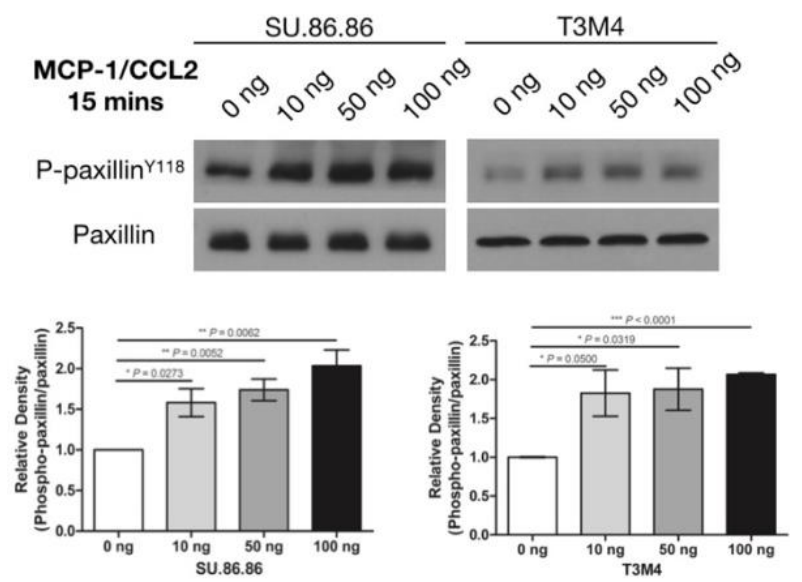

C

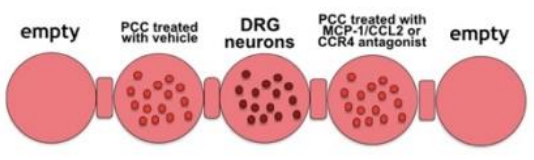

d

Forward Migration Index/FMI

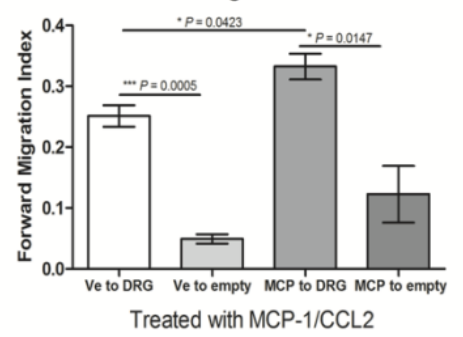

Velocity

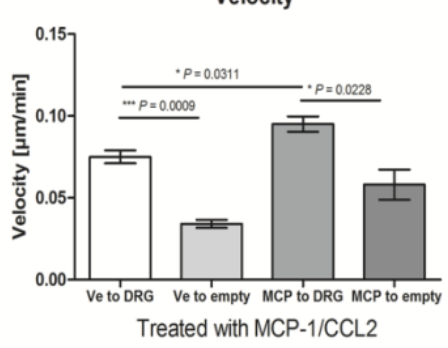

Euclidian Distance

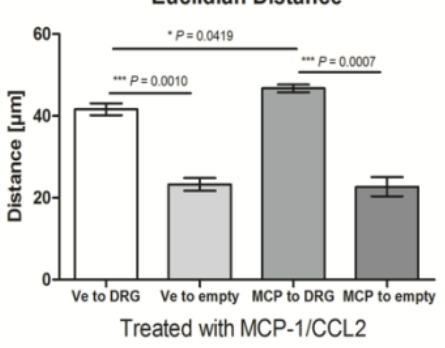

Figure 10. MCP-1/CCL2 induces the phosphorylation of paxillin and enhances the neuron-directed migration ability in vitro. (a) When SU.86.86 and T3M4 pancreatic cancer cells were treated with 100 ng MCP-1/CCL2 for different times, the expressions of paxillin were significantly enhanced. (b) 15 minutes after addition of $0 \mathrm{ng}, 10 \mathrm{ng}, 50 \mathrm{ng}$ and 100ng MCP-1/CCL2 to SU.86.86 and T3M4 pancreatic cancer cell culture medium, phosphorylation of paxillin was significantly increased in a dose-dependent manner. (c) Schematic illustration of 3D migration assay. (d) The FMI, velocity and Euclidian distance of pancreatic cancer cells treated with MCP-1 were prominently greater than that of pancreatic cancer cells treated with vehicle. Data are expressed as mean \pm SEM from triplicate independent experiments. $P$ value was determined by $t$-test. 


\subsection{CCR4 antagonist reduced the phosphorylation of paxillin and diminished the neuron-directed migration ability of cancer cells in vitro}

To further ascertain the potential role of phospho-paxillin in cancer cell migration to neurons in more detail, SU.86.86 and T3M4 pancreatic cancer cells were treated with the antagonist of MCP-1/CCL2 receptor CCR4 (C 021 dihydrochloride) and receptor CCR2 (RS 504393). The amount of phospho-paxillin was identified by western blotting. After treatment with the RS 504393, we did not observed alteration in the expression of phospho-paxilin (Fig. 11a). However, figure $11 \mathrm{~b}$ shows that treatment with $\mathrm{C} 021$ led to a dose-dependent attenuation of paxillin phosphorylation. Quantification of the band density suggested that 0.14 $\mu \mathrm{M} \mathrm{C} 021$ dihydrochloride significantly lowered the phosphorylation of paxillin at 5,15 , and 25 minutes in both SU.86.86 and T3M4 cells.

Meanwhile, when CCR4 was blocked by the specific antagonist, decreased migration ability towards DRG neurons was observed. As shown in figure 11c, the FMI value of C 021 treated cancer cells was diminished in comparison to the vehicle-treated cancer cells $(0.17$ versus 0.24$)$. In line with this, after treatment of C 021 dihydrochloride, the velocity of pancreatic cancer cells toward DRG neurons was prominently decelerated $(0.05 \mu \mathrm{m} / \mathrm{min}$ versus $0.07 \mu \mathrm{m} / \mathrm{min})$ and the Euclidian distance was also reduced $(31.03 \mu \mathrm{m}$ versus 40.12 $\mu \mathrm{m})$, implying an essential role for the MCP-1/CCL2-CCR4 cytokine-cytokine receptor in the neural invasion in pancreatic cancer.

\subsection{Phosphorylation of paxillin mediates cancer cells migration to neurons via Src/paxillin/ERK signaling pathway}

ERK1/2 plays an essential role in promoting migration ability in cancer cells, including breast cancer (Wang et al. 2018), neuroblastoma (Yeh et al. 2016), gastric cancer (Hou et al. 2016), thyroid cancer (Ren et al. 2017), as well as pancreatic cancer (Ono et al. 2014). For 
this purpose, we sought to investigate whether paxillin mediates ERK1/2 phosphorylation during neural invasion. SU.86.86 and T3M4 pancreatic cancer cells were treated with MCP1/CCL2 or the CCR4 antagonist, and the expressions of phospho-Src and phospho-ERK1/2 were checked via western blotting. Here, we detected that the protein levels of phospho-Src and phospho-ERK1/2 were both up-regulated when treated with MCP-1/CCL2 (Fig. 12a), whereas the amounts were down-regulated after the treatment of CCR4 antagonist (Fig. 12b). Meanwhile, consistent with MCP-1/CCL2, after treatment with DRG supernatant, we observed up-regulation of phospho-Src and phospho-ERK1/2 in both SU.86.86 and T3M4 pancreatic cancer cells (Fig. 12c). Our findings illuminated that Src and ERK1/2 phosphorylation is closely linked to migration in pancreatic cancer cells. However, the expression of phospho-FAK did not change after treatment of MCP-1/CCL2 or with CCR4 antagonist (Fig. 12d).

a
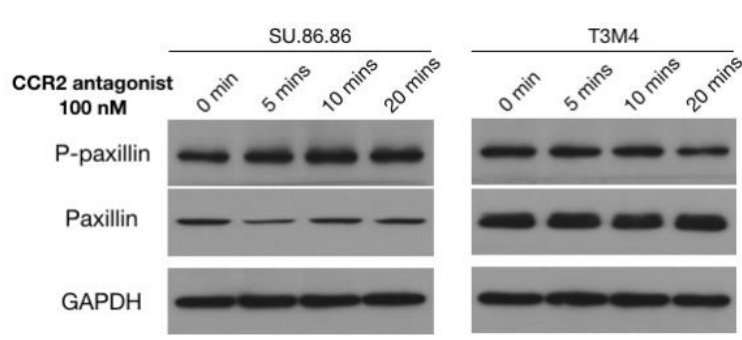

b
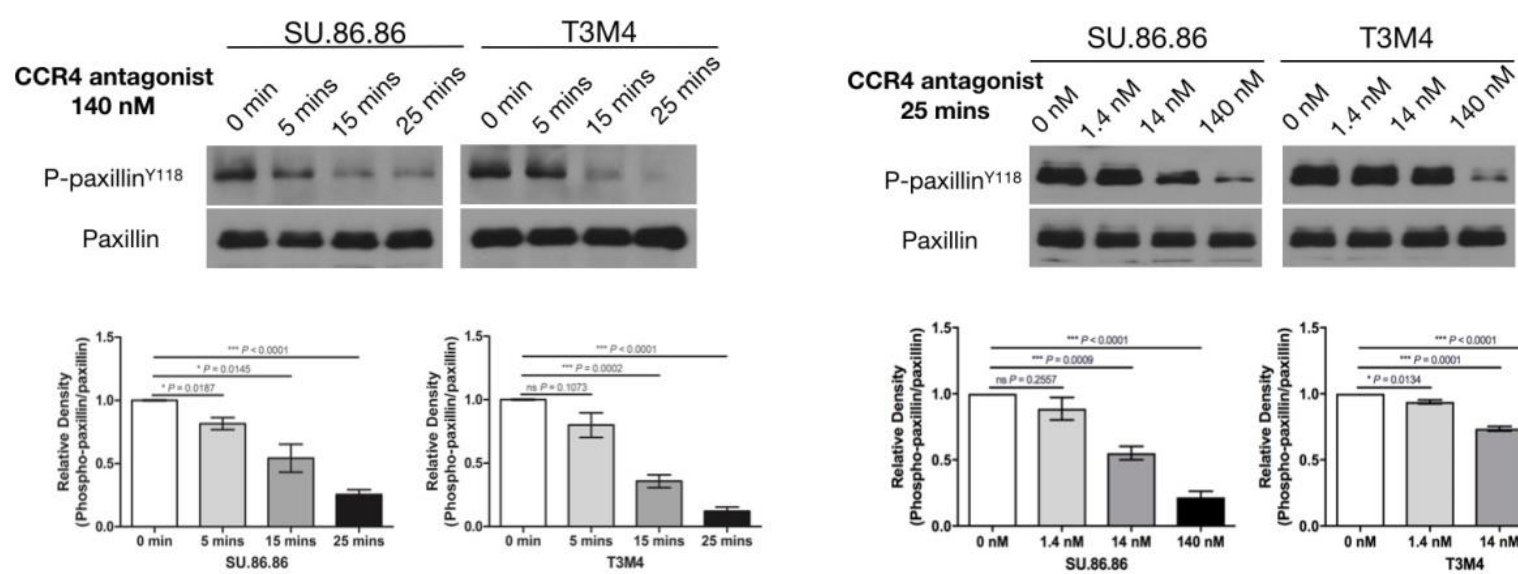

C
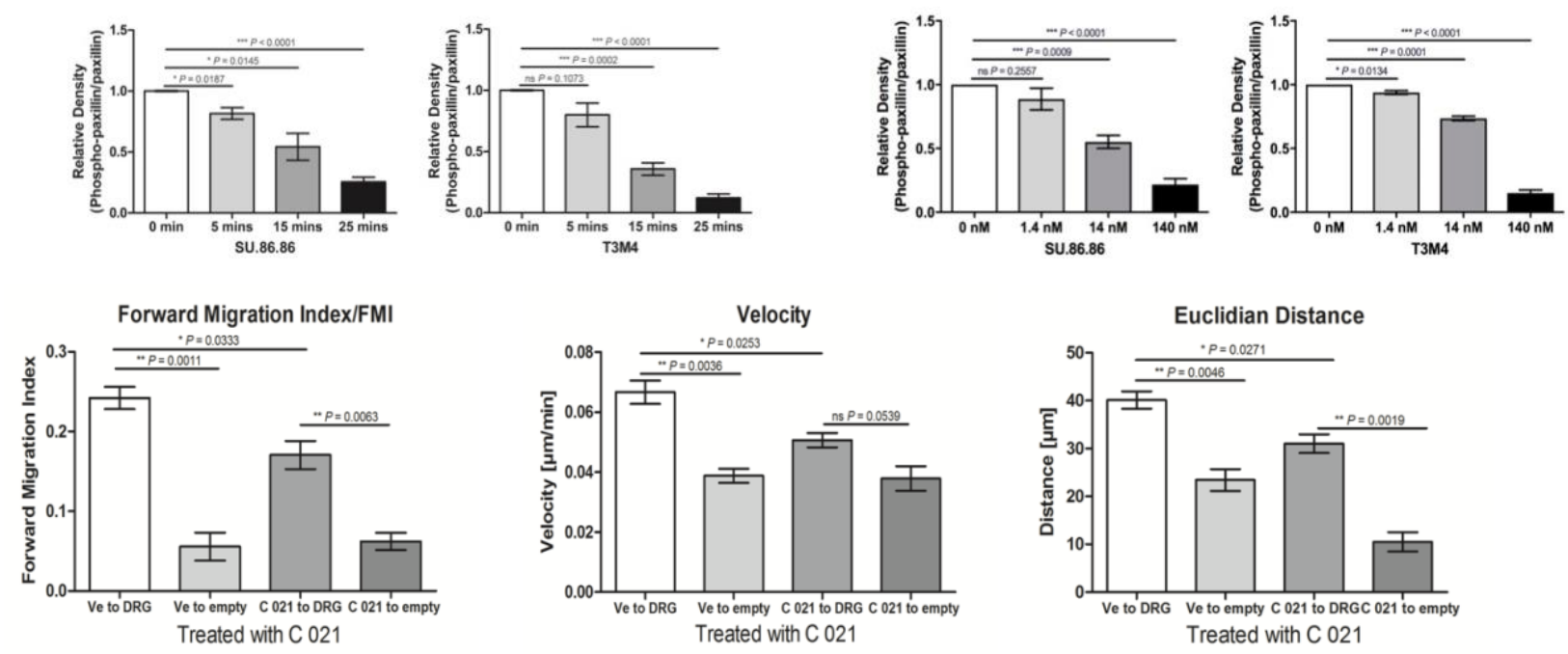
Figure 11. CCR4 antagonist reduced the phosphorylation of paxillin and discourages the neurondirected migration ability in vitro. (a) after the treatment of the CCR4 antagonist C 021 dihydrochloride (C 021), the expression of phospho-paxillin in SU.86.86 and T3M4 pancreatic cancer cells were decreased in a dose-dependent manner. (b) The FMI, velocity and Euclidian distance of pancreatic cancer cells treated with $C 021$ were less than that of pancreatic cancer cells treated with vehicle. Data are expressed as mean \pm SEM from triplicate independent experiments. $P$ value was determined by $t$-test.

a
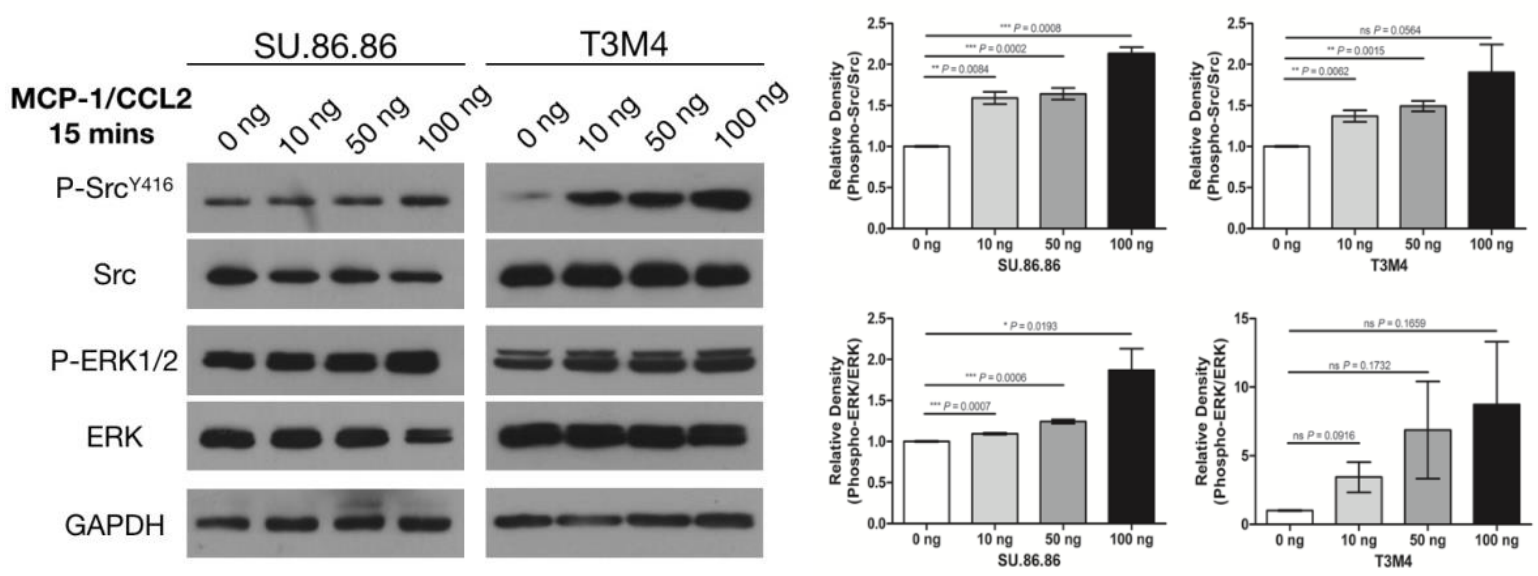

b
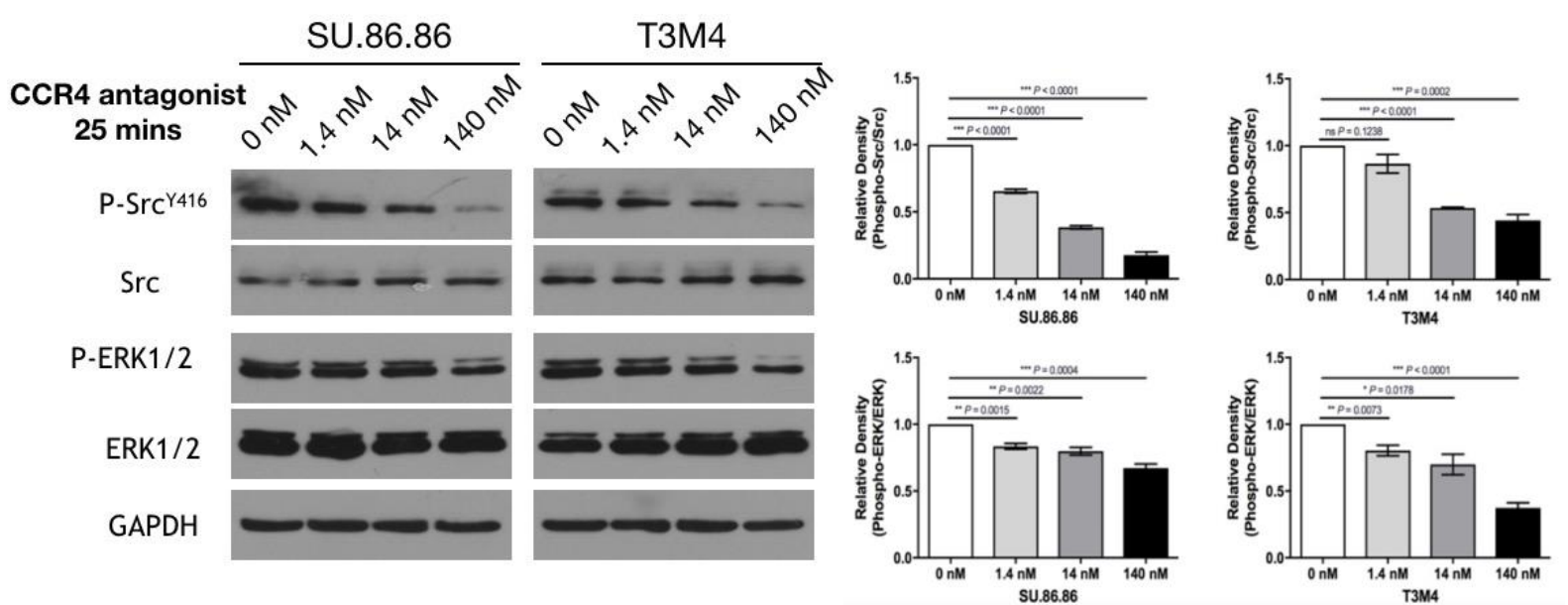

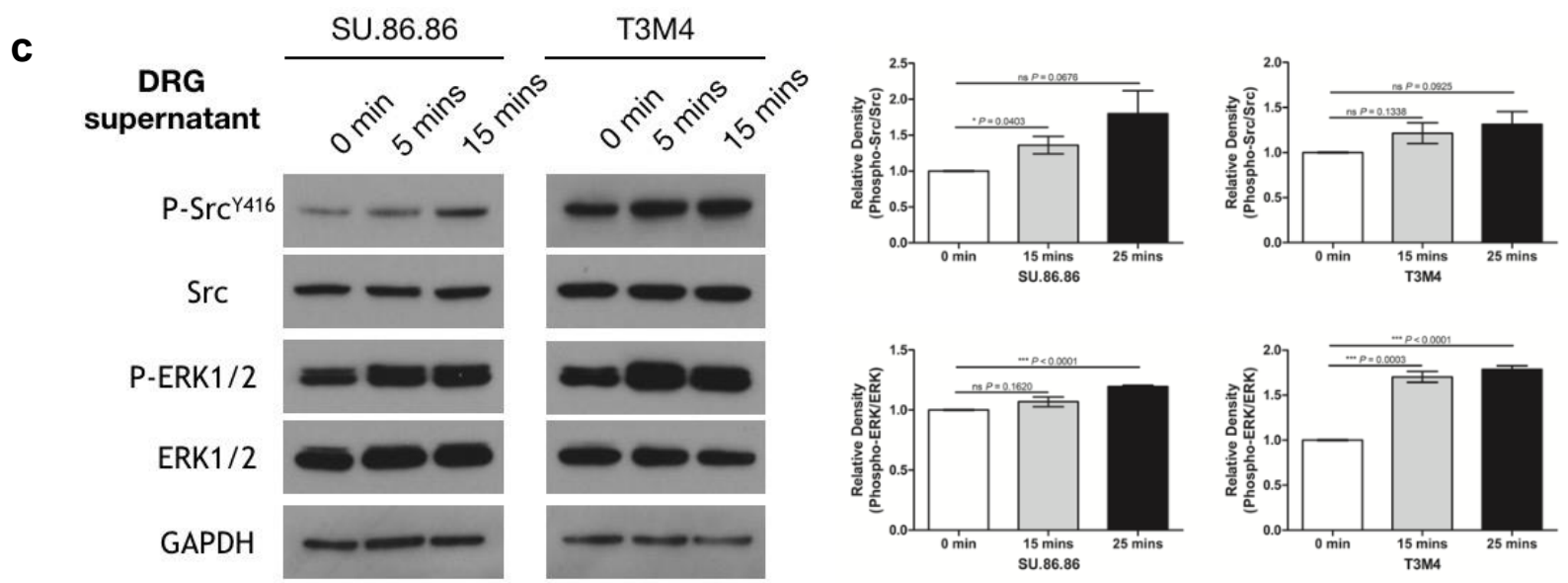

d

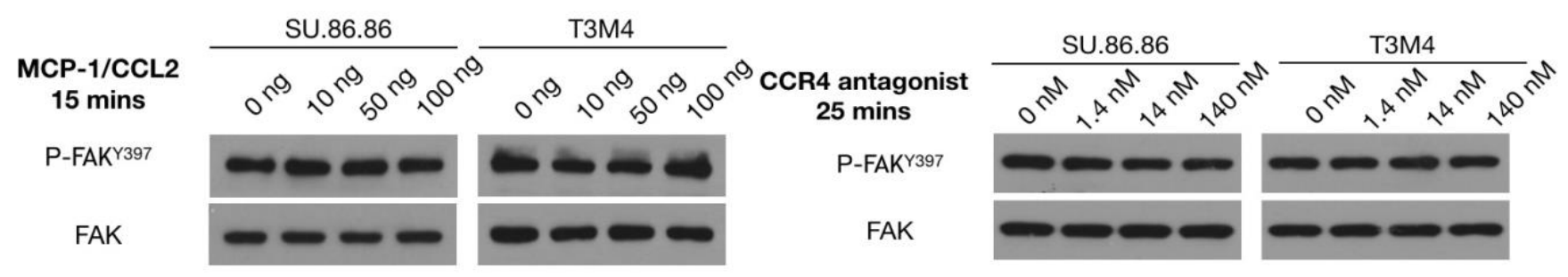

Figure 12. Paxillin mediates cancer cells migration ability via Src/paxillin/ERK signaling pathway. (a) 15 minutes after addition of $0 \mathrm{ng}, 10 \mathrm{ng}, 50 \mathrm{ng}$ and 100ng MCP-1/CCL2 to SU.86.86 and T3M4 pancreatic cancer cells, phospho-Src and phospho-ERK1/2 were significantly increased. (b) After the treatment with the CCR4 antagonist (C 021 dihydrochloride), the amounts of phospho-Src and phospho-ERK1/2 in SU.86.86 and T3M4 pancreatic cancer cells were decreased. (c) After treatment with DRG supernatants, the phospho-Src and phospho-ERK1/2 expression was prominently enhanced in PDAC cells. (d) The expression of phospho-FAK did not change after treatment with MCP-1/CCL2 or with CCR4 antagonist. Data are expressed as mean \pm SEM from triplicate independent experiments. $P$ value was determined by $t$ test. 


\subsection{Dephosphorylation of ERK1/2 decreases the neuron-directed migration ability of pancreatic cancer cells}

As we found a close correlation between the phospho-paxillin and phospho-ERK1/2 in mediating the neuron-directed migration of cancer cells, in the next step, we suppressed the phospho-ERK1/2 by the ERK1/2 phosphorylation inhibitor AZD8330. SU.86.86 and T3M4 pancreatic cancer cells were treated with different concentrations of the inhibitor for 1 hour and the expression of phospho-ERK1/2 was subsequently determined by western blotting. The results showed that ERK1/2 phosphorylation inhibitor AZD8330 markedly induced the dephosphorylation of ERK1/2 in both SU.86.86 and T3M4 pancreatic cancer cells. Quantification of the band density revealed that the treatment with AZD8330 for 1 hour decreased the amounts of phospho-ERK1/2 at $0.004 \mathrm{nM}$ and $0.04 \mathrm{nM}$ by $5.3 \%, 2.5 \%$ in SU.86.86 and $2.0 \%, 1.9 \%$ in T3M4 cells, respectively (Fig. 13).

In the next step, to further assess the role of phospho-ERK1/2 in the neural invasion of pancreatic cancer cells, the 3D migration assay was utilized. DRG neurons were simultaneously confronted with cancer cells treated with vehicle and with cancer cells treated with $0.04 \mathrm{nM}$ ERK1/2 phosphorylation inhibitor AZD8330. Here, we observed significantly decreased migration ability. As shown in figure 13b, the FMI value of inhibitor-treated pancreatic cancer cells was attenuated in comparison with vehicle-treated cancer cells. In accordance with FMI, the cancer cells also decelerated after the treatment of ERK1/2 inhibitor. 
Moreover, we also observed that the inhibitor-treated pancreatic cancer cells covered a shorter Euclidian distance.
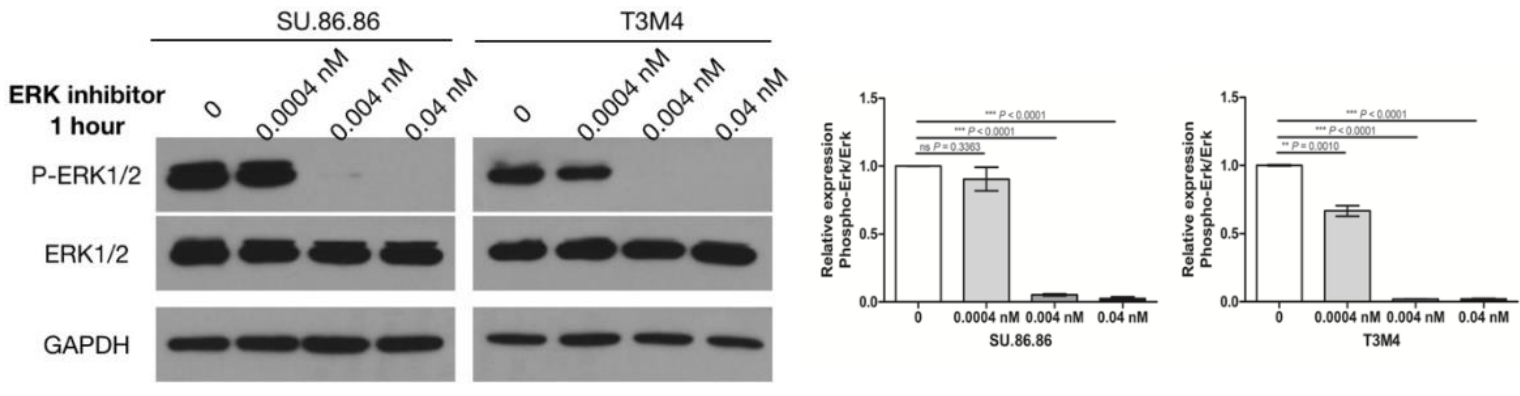

Forward Migration Index/FMI
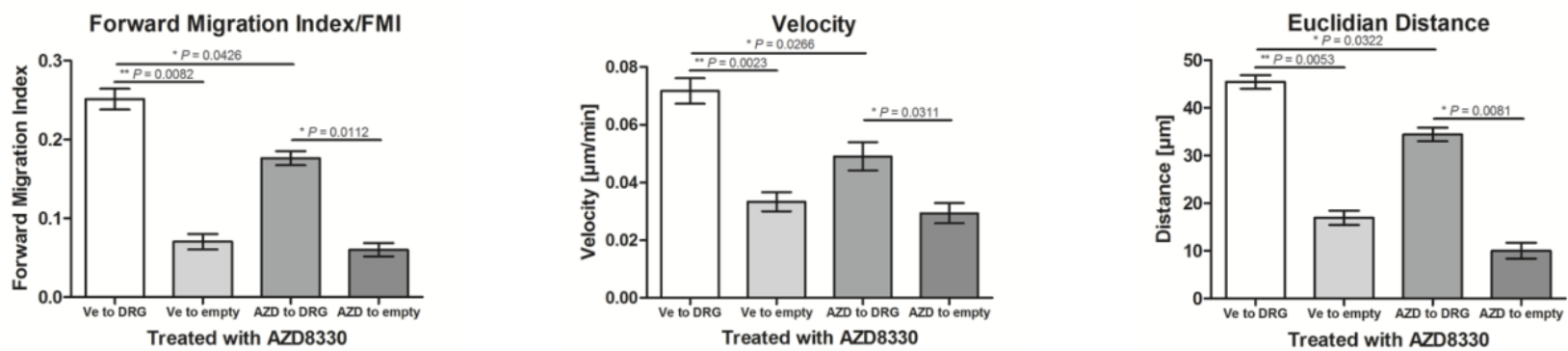

Figure 13. ERK1/2 phosphorylation inhibitor discourages the neuron-directed migration ability in vitro. (a) After treatment with the ERK1/2 phosphorylation inhibitor AZD8330, the expression of phosphoERK1/2 in SU.86.86 and T3M4 pancreatic cancer cells were decreased in a dose-dependent manner. (b) The FMI, velocity and Euclidian distance of pancreatic cancer cells treated with AZD8330 were less than that of pancreatic cancer cells treated with vehicle. Data are expressed as mean \pm SEM from triplicate independent experiments. $P$ value was determined by $t$-test. 


\subsection{Discussion}

The present study aimed to illustrate the cytoskeletal changes, and the role of paxillin phosphorylation in neural invasion in pancreatic cancer. In this study, we demonstrate that, during neural invasion, the cellular conformation of pancreatic cancer cells is altered, and the microfilament formation is increased in the cytoskeleton. Moreover, the formation of migratory protrusions, including filopodia and lamellipodia, is markedly increased. More importantly, we also detected that neurons can secrete cytokine MCP-1/CCL2, which amplifies the paxillin phosphorylation in the filopodia via MCP-1/CCR4/Src/ERK pathway. Activation or inhibition of MCP-1/CCL2 by MCP-1/CCL2 protein or CCR4 receptor antagonist could mediate the phosphorylation of paxillin and influence the neuron-directed migration of pancreatic cancer cells. We furthermore demonstrate that the inhibition of ERK1/2 phosphorylation suppresses the neural invasion. Collectively, our findings clarify that paxillin phosphorylation is involved in tumor progression and neural invasion, which makes paxillin a potentially novel important therapeutic target.

Previous studies showed that alterations of the cytoskeleton are continually detected particularly in cancer cells, from which cancer cells acquire specific characteristic features, including invasion, migration, uncontrolled proliferation, adhesion, and death evasion (Sherr 1996, Hanahan et al. 2011). It is also reported that the cytoskeleton is an important target of chemotherapy due to its established role in proliferation and survival (Zhou et al. 2005). Rearrangement of the cytoskeleton contributes to migration and invasion of several solid tumors, including pancreatic cancer (Pandey et al. 2015, Taniuchi et al. 2018, Taniuchi et al. 2018), lung cancer (Zhao et al. 2015), breast cancer (Wicki et al. 2006, Meng et al. 2014), epithelial ovarian cancer (Tang et al. 2015), glioblastoma (Memmel et al. 2017). Alteration of actin structures has been proven to contribute to pancreatic cancer metastasis (Pandey et al. 
2015). High expression of WAVE2, a member of the actin cytoskeletal regulatory protein, augmented motility and invasiveness of pancreatic cancer cells by inducing the establishment of cell protrusions. More importantly, over-expression of WAVE2 is positively correlated with impaired prognosis and survival in pancreatic cancer patient (Taniuchi et al. 2018). Similar results were observed in BCL7B, a member of the B-cell CLL/lymphoma 7 families, which can influence the formation of membrane protrusions in pancreatic cancer cells via dephosphorylation of CREB. Overexpression of BCL7B in pancreatic cancer cells resulted in amplified migratory and invasive capacity, and strongly associated with diminished overall survival (Taniuchi et al. 2018). Consistent with pancreatic cancer, in the study by Wicki et al. (Wicki et al. 2006), the investigators also found that rearrangement of the actin cytoskeleton in lung cancer was positively correlated with the formation of filopodia, cancer cells' migratory and invasive ability. In epithelial ovarian cancer cells, the microtubule-associated protein 1 light chain 3B (LC3B) mediated tumor cell migration and invasion by cytoskeletal rearrangement. Down-regulation of light chain 3B by siRNA or specific inhibitor suppressed tumor cell migratory and invasive ability, whereas elevated expression of light chain 3B promoted cell migration and invasion (Tang et al. 2015). These studies revealed the importance of cytoskeletal properties on a variety of cancer cells, as well as on prognosis. Yet the roles of the cytoskeleton in neural invasion still remain unclear.

Consistent with these studies, in our study, we found that during neural invasion of pancreatic cancer cells, the cells altered their cytoskeleton. Pancreatic cancer cells exhibited a more "polygonal shape" with a consequent increase in their cell volume. More importantly, we observed that the formation of migratory protrusions, including filopodia and lamellipodia, was significantly increased, which contributed to the motility of pancreatic cancer cells in neural invasion. Previous studies have also proven that the formation of filopodia in the pancreatic cancer cell line PANC-1 increased the cell motility (Bao et al. 2015). These observations 
provided important insights into the effects of the cytoskeletal rearrangement in pancreatic cancer cells migrating toward neurons.

Paxillin is one of the main components of focal adhesions, and it is involved in the transduction of signals, regulation of cell morphology, and control of cell spread and migration by interaction with a multitude of structural proteins (Huang et al. 2004). Recent studies have shown that phosphorylation of paxillin by FAK or Src at Tyr118 and Ser178 is necessary for the stimulation of the cancer cell migration. It is reported that paxillin phosphorylation was related with cell adhesion, epithelial-mesenchymal transition, and cell cycle via WNT5A/JNK pathway in pancreatic cancer cells (Wei et al. 2013). Phosphorylation of paxillin by gastrin promoted cancer cell migration and invasion. Furthermore, phosphorylation of paxillin regulated the formation of focal adhesions and cell polarization in pancreatic cancer cells $\mathrm{Mu}$ et al. 2018). More importantly, paxillin was reported to be a potential target in pancreatic cancer (Kanteti et al. 2016).

Changes in paxillin protein expression were shown to be involved in the acceleration of several other cancers, including breast carcinoma (Madan et al. 2006), lung cancer (Jagadeeswaran et al. 2008), hepatocellular carcinoma (Li et al. 2005), melanoma (VelascoVelazquez et al. 2008). Moreover, overexpression of paxillin augmented migration and invasiveness and induced metastasis in colorectal cancer (Jun et al. 2011). A previous study demonstrated that the down-regulation of paxillin protein levels was associated with suppression of cell migration proliferation, migration and invasion in colorectal cancer (Qin et al. 2015). Chen et al. also demonstrated phosphorylation events of paxillin were vital for cancer cell migration in breast cancer (Chen et al. 2012). In lung carcinoma, the expression of paxillin was positively correlated with higher stage and metastasis. Furthermore, suppression of paxillin expression by siRNA decreased the cell viability in lung cancer cell lines, whereas promotion of paxillin expression increased tumor growth and invasiveness in vivo 
(Jagadeeswaran et al. 2008). In melanoma cells, the reduction of paxillin expression weakened tumor cell adhesion and motility (Velasco-Velazquez et al. 2008).

In this study, we demonstrated that during the neural invasion, the expression of phosphopaxillin was amplified particularly in the lamellipodia and filopodia of pancreatic cancer cells. In line with this, by suppression or stimulation of phospho-paxillin, we further demonstrated that the neuron-directed migration ability of cancer cells was significantly altered. In accordance with this, paxillin phosphorylation is linked with cancer cells' migration and plays a critical role in mediating neural invasion of pancreatic cancer cells.

Based on our findings, the phospho-paxillin expression was markedly enhanced in neural invasion. Along with this line, we identified cytokines involved in stimulation of phospho-paxillin by performing ELISA assays in the supernatants of cancer cells, DRG neurons, or cancer cellneuron co-culture. Initially, we did not observe the obvious variations of MCP-1/CCL2 levels in the monoculture supernatant of the pancreatic cancer cell line SU.86.86, but the level was slightly increased in the supernatant when DRG neurons or the pancreatic cancer cell line T3M4 were cultured alone, indicating that the differential expression of MCP-1/CCL2 might be attributed to DRG neurons in our experiments. Surprisingly, we detected highly enhanced secretion of MCP-1/CCL2 in co-culture supernatants, which suggested that the interaction between neurons and pancreatic cancer cells is critical during neural invasion and MCP$1 / C C L 2$ is vital in this interaction. MCP-1/CCL2 has been demonstrated to be one of the potent chemokines mediating the migration of monocytes/macrophages, natural killer cells, and $\mathrm{T}$ cells (Bose et al. 2013). In breast cancer, the high levels of MCP-1/CCL2 were significantly associated with early recurrence and played a vital role in the meditation of angiogenesis (Ueno et al. 2000). Moreover, the MCP-1/CCL2 expression level was significantly different between the various breast cancer genotypes, and breast cancer patients with low expression of MCP-1/CCL2 trended to have better outcomes (Wang et al. 2015). In bladder cancer, MCP- 
1/CCL2 mediated the migration and invasiveness of bladder cancer cells. Inhibition of MCP1/CCL2 decreased the motility in bladder cancer cells (Chiu et al. 2012). Similarly, MCP1/CCL2 secreted by hepatic myofibroblasts could also increase the migratory and invasive ability of human hepatoma cells (Dagouassat et al. 2010).

In this line, it is conceivable that cancer-infiltrated nerves are injured or stimulated and consequently secrete MCP-1/CCL2, which causes a vicious circle by aggravating neural invasion. Similar results were also found in prostate cancer (He et al. 2015). In the studies by He et al., they also demonstrated that DRG neurons could express MCP-1/CCL2, and it was a leading candidate in mediating nerve-derived migration capacity of prostate cancer cells. Moreover, neural invasion was significantly hampered in the migration assay by using DRG neurons isolated from MCP-1/CCL2-- mouse (He et al. 2015). It is noted that the MCP-1/CCL2 was deregulated after nerve injury (Kim et al. 2011). Overall, MCP-1/CCL2 may, therefore, be a crucial factor for neural invasion of pancreatic cancer.

It was noted that paxillin phosphorylation stimulates cancer cells' migration and invasiveness. Nevertheless, little is known about the exact pathogenesis. Some reports have linked paxillin phosphorylation with activation of the MAPK pathway (Monami et al. 2006, Zhu et al. 2007, Lee et al. 2012, Montone et al. 2018). It has been reported that in bladder cancer cells, the migration and invasiveness were enhanced by the growth factor proepithelin through the phosphorylation of ERK1/2 via paxillin/ERK signaling pathway, whereas reduction of endogenous paxillin withdrew the proepithelin-mediated migration ability (Monami et al. 2006). In hepatocellular carcinoma, Sorafenib combined with vitamin K1 significantly inhibited the hepatocellular carcinoma cell migration through decreased ERK1/2 phosphorylation (D'Alessandro et al. 2018). Furthermore, inhibition of the platelet-derived growth factor receptor resulted in an obvious suppression of migration and proliferation in glioma cells via regulation of the FAK/paxillinERK signaling pathway (Singh et al. 2018). 
Meantime, several studies have also reported that MCP-1/CCL2 is tightly correlated with MAPK pathway (Fang et al. 2012, Li et al. 2012, Wang et al. 2015). In human breast cancer, CC-chemokine receptor-like protein 2 (CCRL2) was hampered in highly invasive cancer cells, while blocking MCP-1/CCL2-induced phosphorylation of p38 MAPK by CCRL2 suppressed invasion and growth of cancer cells in vivo and in vitro. It was also reported that MCP-1/CCL2 mediated EMT and migration via ERK pathway (Li et al. 2017). Similarly, MCP-1/CCL2 can augment the proliferation and invasiveness in a dose- and time-dependent manner in endometrial stromal cells, whereas the anti-MCP-1/CCL2 neutralizing antibody can block proliferation and invasiveness (Li et al. 2012). In the present study, we demonstrated that after treatment with MCP-1/CCL2, the expression of phospho-Src and phospho-ERK1/2 was increased in both SU86.86 and T3M4 pancreatic cancer cells. Meanwhile, after treatment with the receptor CCR4 antagonist, the expression of phospho-Src and phospho-ERK1/2 was decreased. Consistent with this, the expression of phospho-ERK1/2 was decreased after treatment with the CCR4 receptor antagonist in Merkel cell carcinoma (Rasheed et al. 2018). Altogether, paxillin-mediated neuron-directed migration in pancreatic cancer is herewith shown to be associated with the Src/ERK1/2 pathway. 


\subsection{Summary and Conclusion}

In conclusion, this study investigated the alterations of the cytoskeleton and the modification of related proteins during neural invasion of pancreatic cancer cells. Here, we demonstrated that the cytoskeletal rearrangements are important phenomena in pancreatic cancer and can accelerate neural invasion and migration of pancreatic cancer cells. Moreover, we also found that the expression of phospho-paxillin was specifically up-regulated in lamellipodia during neural invasion. Furthermore, this study illuminated one of the key cytokines, i.e. MCP-1/CCL2, to be crucial for neural invasion. In fact, MCP-1/CCL2 can mediate the upregulation of phospho-paxillin and contribute to neural invasion via the Src/ERK1/2 MAPK pathway. Understanding the mechanisms of neural invasion and the interaction between cancer cells and neurons are important for facilitating the development of innovative treatments for cancer as well as for neural invasion. Overall, our findings elucidate a novel and potential strategy for targeted therapeutics against neural invasion, which merits further study. 


\subsection{Literature}

Abdiche, Y. N., D. S. Malashock and J. Pons (2008). "Probing the binding mechanism and affinity of tanezumab, a recombinant humanized anti-NGF monoclonal antibody, using a repertoire of biosensors." Protein Sci 17(8): 1326-1335.

Abedi, H. and I. Zachary (1997). "Vascular endothelial growth factor stimulates tyrosine phosphorylation and recruitment to new focal adhesions of focal adhesion kinase and paxillin in endothelial cells." J Biol Chem 272(24): 15442-15451.

Alblazi, K. M. and C. H. Siar (2015). "Cellular protrusions--lamellipodia, filopodia, invadopodia and podosomes--and their roles in progression of orofacial tumours: current understanding." Asian Pac J Cancer Prev 16(6): 2187-2191.

Applewhite, D. A., M. Barzik, S. Kojima, T. M. Svitkina, F. B. Gertler and G. G. Borisy (2007). "Ena/VASP proteins have an anti-capping independent function in filopodia formation." Mol Biol Cell 18(7): 2579-2591.

Azuma, K., M. Tanaka, T. Uekita, S. Inoue, J. Yokota, Y. Ouchi and R. Sakai (2005).

"Tyrosine phosphorylation of paxillin affects the metastatic potential of human osteosarcoma." Oncogene 24(30): 4754-4764.

Bao, J., S. Wang, L. K. Gunther, S. Kitajiri, C. Li and T. Sakamoto (2015). "The actinbundling protein TRIOBP-4 and -5 promotes the motility of pancreatic cancer cells." Cancer Lett 356(2 Pt B): 367-373.

Bapat, A. A., G. Hostetter, D. D. Von Hoff and H. Han (2011). "Perineural invasion and associated pain in pancreatic cancer." Nat Rev Cancer 11(10): 695-707.

Bapat, A. A., G. Hostetter, D. D. Von Hoff and H. Y. Han (2011). "Perineural invasion and associated pain in pancreatic cancer." Nature Reviews Cancer 11(10): 695-707. 
Bockman, D. E., M. Buchler and H. G. Beger (1994). "Interaction of pancreatic ductal carcinoma with nerves leads to nerve damage." Gastroenterology 107(1): 219-230.

Bose, S. and J. Cho (2013). "Role of chemokine CCL2 and its receptor CCR2 in neurodegenerative diseases." Arch Pharm Res 36(9): 1039-1050.

Bray, F., J. Ferlay, I. Soerjomataram, R. L. Siegel, L. A. Torre and A. Jemal (2018). "Global cancer statistics 2018: GLOBOCAN estimates of incidence and mortality worldwide for 36 cancers in 185 countries." CA Cancer J Clin 68(6): 394-424.

Brown, M. C. and C. E. Turner (2004). "Paxillin: adapting to change." Physiol Rev 84(4): $1315-1339$

Burdyga, A., A. Conant, L. Haynes, J. Zhang, K. Jalink, R. Sutton, J. Neoptolemos, E. Costello and A. Tepikin (2013). "cAMP inhibits migration, ruffling and paxillin accumulation in focal adhesions of pancreatic ductal adenocarcinoma cells: effects of PKA and EPAC." Biochim Biophys Acta 1833(12): 2664-2672.

Butler, A. A., V. A. Blakesley, A. Koval, R. deJong, J. Groffen and D. LeRoith (1997). "In vivo regulation of Crkll and CrkL proto-oncogenes in the uterus by insulin-like growth factor-I. Differential effects on tyrosine phosphorylation and association with paxillin." J Biol Chem 272(44): 27660-27664.

Ceyhan, G. O., F. Bergmann, M. Kadihasanoglu, B. Altintas, I. E. Demir, U. Hinz, M. W. Muller, T. Giese, M. W. Buchler, N. A. Giese and H. Friess (2009). "Pancreatic neuropathy and neuropathic pain--a comprehensive pathomorphological study of 546 cases." Gastroenterology 136(1): 177-186 e171. 
Ceyhan, G. O., I. E. Demir, B. Altintas, U. Rauch, G. Thiel, M. W. Muller, N. A. Giese, H. Friess and K. H. Schafer (2008). "Neural invasion in pancreatic cancer: a mutual tropism between neurons and cancer cells." Biochem Biophys Res Commun 374(3): 442-447.

Ceyhan, G. O., N. A. Giese, M. Erkan, A. G. Kerscher, M. N. Wente, T. Giese, M. W. Buchler and H. Friess (2006). "The neurotrophic factor artemin promotes pancreatic cancer invasion." Ann Surg 244(2): 274-281.

Ceyhan, G. O., C. W. Michalski, I. E. Demir, M. W. Muller and H. Friess (2008). "Pancreatic pain." Best Pract Res Clin Gastroenterol 22(1): 31-44.

Ceyhan, G. O., K. H. Schafer, A. G. Kerscher, U. Rauch, I. E. Demir, M. Kadihasanoglu, C. Bohm, M. W. Muller, M. W. Buchler, N. A. Giese, M. Erkan and H. Friess (2010). "Nerve Growth Factor and Artemin Are Paracrine Mediators of Pancreatic Neuropathy in Pancreatic Adenocarcinoma." Annals of Surgery 251(5): 923-931.

Ceyhan, G. O., K. H. Schafer, A. G. Kerscher, U. Rauch, I. E. Demir, M. Kadihasanoglu, C. Bohm, M. W. Muller, M. W. Buchler, N. A. Giese, M. Erkan and H. Friess (2010). "Nerve growth factor and artemin are paracrine mediators of pancreatic neuropathy in pancreatic adenocarcinoma." Ann Surg 251(5): 923-931.

Chang, L. and R. D. Goldman (2004). "Intermediate filaments mediate cytoskeletal crosstalk." Nat Rev Mol Cell Biol 5(8): 601-613.

Chen, J. and K. A. Gallo (2012). "MLK3 regulates paxillin phosphorylation in chemokinemediated breast cancer cell migration and invasion to drive metastasis." Cancer Res 72(16): $4130-4140$

Chiu, H. Y., K. H. Sun, S. Y. Chen, H. H. Wang, M. Y. Lee, Y. C. Tsou, S. C. Jwo, G. H. Sun and S. J. Tang (2012). "Autocrine CCL2 promotes cell migration and invasion via PKC 
activation and tyrosine phosphorylation of paxillin in bladder cancer cells." Cytokine 59(2): 423-432.

Collins, M. A., F. Bednar, Y. Q. Zhang, J. C. Brisset, S. Galban, C. J. Galban, S. Rakshit, K. S. Flannagan, N. V. Adsay and M. P. di Magliano (2012). "Oncogenic Kras is required for both the initiation and maintenance of pancreatic cancer in mice." Journal of Clinical Investigation 122(2): 639-653.

Cui, W., X. Wang, Y. C. Liu, Y. L. Wan, H. J. Guo and J. Zhu (2006). "[Expression of HIC5/ARA55 in colonrectal cancer and its mechanisms of action]." Beijing Da Xue Xue Bao Yi Xue Ban 38(3): 280-283.

D'Alessandro, R., M. G. Refolo, C. Lippolis, N. Carella, C. Messa, A. Cavallini and B. I. Carr (2018). "Strong enhancement by IGF1-R antagonists of hepatocellular carcinoma cell migration inhibition by Sorafenib and/or vitamin K1." Cell Oncol (Dordr) 41(3): 283-296.

Dagouassat, M., N. Suffee, H. Hlawaty, O. Haddad, F. Charni, C. Laguillier, R. Vassy, L. Martin, P. O. Schischmanoff, L. Gattegno, O. Oudar, A. Sutton and N. Charnaux (2010). "Monocyte chemoattractant protein-1 (MCP-1)/CCL2 secreted by hepatic myofibroblasts promotes migration and invasion of human hepatoma cells." Int J Cancer 126(5): 1095-1108.

de Vicente, J. C., P. Rosado, P. Lequerica-Fernandez, E. Allonca, L. Villallain and G. Hernandez-Vallejo (2013). "Focal adhesion kinase overexpression: correlation with lymph node metastasis and shorter survival in oral squamous cell carcinoma." Head Neck 35(6): 826-830

Demir, I. E., A. Boldis, P. L. Pfitzinger, S. Teller, E. Brunner, N. Klose, T. Kehl, M. Maak, M. Lesina, M. Laschinger, K. P. Janssen, H. Algul, H. Friess and G. O. Ceyhan (2014). 
"Investigation of Schwann cells at neoplastic cell sites before the onset of cancer invasion." $\underline{J}$ Natl Cancer Inst 106(8).

Demir, I. E., G. O. Ceyhan, F. Liebl, J. G. D'Haese, M. Maak and H. Friess (2010). "Neural invasion in pancreatic cancer: the past, present and future." Cancers (Basel) 2(3): 15131527.

Demir, I. E., G. O. Ceyhan, U. Rauch, B. Altintas, M. Klotz, M. W. Muller, M. W. Buchler, H. Friess and K. H. Schafer (2010). "The microenvironment in chronic pancreatitis and pancreatic cancer induces neuronal plasticity." Neurogastroenterology and Motility 22(4): $480-+$.

Demir, I. E., H. Friess and G. O. Ceyhan (2012). "Nerve-cancer interactions in the stromal biology of pancreatic cancer." Front Physiol 3: 97.

Demir, I. E., H. Friess and G. O. Ceyhan (2015). "Neural plasticity in pancreatitis and pancreatic cancer." Nature Reviews Gastroenterology \& Hepatology 12(11): 649-659.

Demir, I. E., C. Jager, A. M. Schlitter, B. Konukiewitz, L. Stecher, S. Schorn, E. Tieftrunk, F. Scheufele, L. Calavrezos, R. Schirren, I. Esposito, W. Weichert, H. Friess and G. O. Ceyhan (2018). "R0 Versus R1 Resection Matters after Pancreaticoduodenectomy, and Less after Distal or Total Pancreatectomy for Pancreatic Cancer." Ann Surg 268(6): 1058-1068.

Demir, I. E., K. Kujundzic, P. L. Pfitzinger, O. C. Saricaoglu, S. Teller, T. Kehl, C. M. Reyes, L. S. Ertl, Z. Miao, T. J. Schall, E. Tieftrunk, B. Haller, K. N. Diakopoulos, M. U. Kurkowski, M. Lesina, A. Kruger, H. Algul, H. Friess and G. O. Ceyhan (2017). "Early pancreatic cancer lesions suppress pain through CXCL12-mediated chemoattraction of Schwann cells." Proceedings of the National Academy of Sciences of the United States of America 114(1): E85-E94. 
Demir, I. E., E. Tieftrunk, M. Maak, H. Friess and G. O. Ceyhan (2011). "Pain mechanisms in chronic pancreatitis: of a master and his fire." Langenbecks Arch Surg 396(2): 151-160.

Devreotes, P. and A. R. Horwitz (2015). "Signaling networks that regulate cell migration." Cold Spring Harb Perspect Biol 7(8): a005959.

di Mola, F. F. and P. di Sebastiano (2008). "Pain and pain generation in pancreatic cancer." Langenbecks Arch Surg 393(6): 919-922.

Dobosz, L., M. Kaczor and T. J. Stefaniak (2016). "Pain in pancreatic cancer: review of medical and surgical remedies." ANZ J Surg 86(10): 756-761.

Dogterom, M. and G. H. Koenderink (2019). "Actin-microtubule crosstalk in cell biology." Nat Rev Mol Cell Biol 20(1): 38-54.

el-Deiry, W. S., J. W. Harper, P. M. O'Connor, V. E. Velculescu, C. E. Canman, J. Jackman, J. A. Pietenpol, M. Burrell, D. E. Hill, Y. Wang and et al. (1994). "WAF1/CIP1 is induced in p53-mediated G1 arrest and apoptosis." Cancer Res 54(5): 1169-1174.

el-Deiry, W. S., T. Tokino, V. E. Velculescu, D. B. Levy, R. Parsons, J. M. Trent, D. Lin, W. E. Mercer, K. W. Kinzler and B. Vogelstein (1993). "WAF1, a potential mediator of p53 tumor suppression." Cell 75(4): 817-825.

Esposito, D., P. Patel, R. M. Stephens, P. Perez, M. V. Chao, D. R. Kaplan and B. L. Hempstead (2001). "The cytoplasmic and transmembrane domains of the p75 and Trk a receptors regulate high affinity binding to nerve growth factor." Journal of Biological Chemistry 276(35): 32687-32695.

Faix, J. and R. Grosse (2006). "Staying in shape with formins." Dev Cell 10(6): 693-706.

Fang, W. B., I. Jokar, A. Zou, D. Lambert, P. Dendukuri and N. Cheng (2012). "CCL2/CCR2 chemokine signaling coordinates survival and motility of breast cancer cells through Smad3 
protein- and p42/44 mitogen-activated protein kinase (MAPK)-dependent mechanisms." $\mathbb{J}$ Biol Chem 287(43): 36593-36608.

Farmer, P., H. Bonnefoi, V. Becette, M. Tubiana-Hulin, P. Fumoleau, D. Larsimont, G. Macgrogan, J. Bergh, D. Cameron, D. Goldstein, S. Duss, A. L. Nicoulaz, C. Brisken, M. Fiche, M. Delorenzi and R. Iggo (2005). "Identification of molecular apocrine breast tumours by microarray analysis." Oncogene 24(29): 4660-4671.

Feng, F. Y., Y. Qian, M. H. Stenmark, S. Halverson, K. Blas, S. Vance, H. M. Sandler and D. A. Hamstra (2011). "Perineural invasion predicts increased recurrence, metastasis, and death from prostate cancer following treatment with dose-escalated radiation therapy." Int $J$ Radiat Oncol Biol Phys 81(4): e361-367.

Feng, H., L. Chen, Q. Wang, B. Shen, L. Liu, P. Zheng, S. Xu, X. Liu, J. Chen and J. Teng (2013). "Calumenin-15 facilitates filopodia formation by promoting TGF-beta superfamily cytokine GDF-15 transcription." Cell Death Dis 4: e870.

Fife, C. M., J. A. McCarroll and M. Kavallaris (2014). "Movers and shakers: cell cytoskeleton in cancer metastasis." British Journal of Pharmacology 171(24): 5507-5523.

Finak, G., N. Bertos, F. Pepin, S. Sadekova, M. Souleimanova, H. Zhao, H. Chen, G. Omeroglu, S. Meterissian, A. Omeroglu, M. Hallett and M. Park (2008). "Stromal gene expression predicts clinical outcome in breast cancer." Nat Med 14(5): 518-527.

Fong, A. M., L. A. Robinson, D. A. Steeber, T. F. Tedder, O. Yoshie, T. Imai and D. D. Patel (1998). "Fractalkine and CX3CR1 mediate a novel mechanism of leukocyte capture, firm adhesion, and activation under physiologic flow." J Exp Med 188(8): 1413-1419. 
Friess, H., S. Shrikhande, M. Shrikhande, M. Martignoni, C. Kulli, A. Zimmermann, A. Kappeler, H. Ramesh and M. Buchler (2002). "Neural alterations in surgical stage chronic pancreatitis are independent of the underlying aetiology." Gut 50(5): 682-686.

Furukawa, T., W. P. Duguid, L. Rosenberg, J. Viallet, D. A. Galloway and M. S. Tsao (1996). "Long-term culture and immortalization of epithelial cells from normal adult human pancreatic ducts transfected by the E6E7 gene of human papilloma virus 16." Am J Pathol 148(6): 1763-1770.

Gunning, P., G. O'Neill and E. Hardeman (2008). "Tropomyosin-based regulation of the actin cytoskeleton in time and space." Physiol Rev 88(1): 1-35.

Hall, A. (1998). "Rho GTPases and the actin cytoskeleton." Science 279(5350): 509-514.

Hall, A. (2012). "Rho family GTPases." Biochem Soc Trans 40(6): 1378-1382.

Hanahan, D. and R. A. Weinberg (2011). "Hallmarks of cancer: the next generation." Cell 144(5): 646-674.

He, S., S. He, C. H. Chen, S. Deborde, R. L. Bakst, N. Chernichenko, W. F. McNamara, S. Y. Lee, F. Barajas, Z. Yu, H. A. Al-Ahmadie and R. J. Wong (2015). "The chemokine (CCL2CCR2) signaling axis mediates perineural invasion." Mol Cancer Res 13(2): 380-390.

Hefti, F. F., A. Rosenthal, P. A. Walicke, S. Wyatt, G. Vergara, D. L. Shelton and A. M. Davies (2006). "Novel class of pain drugs based on antagonism of NGF." Trends Pharmacol Sci 27(2): 85-91.

Herrera, R. (1998). "Modulation of hepatocyte growth factor-induced scattering of HT29 colon carcinoma cells. Involvement of the MAPK pathway." J Cell Sci 111 ( Pt 8): 1039-1049. Hou, X., Y. Zhang and H. Qiao (2016). "CCL18 promotes the invasion and migration of gastric cancer cells via ERK1/2/NF-kappaB signaling pathway." Tumour Biol 37(1): 641-651. 
Hruban, R. H., G. J. Offerhaus, S. E. Kern, M. Goggins, R. E. Wilentz and C. J. Yeo (1998). "Tumor-suppressor genes in pancreatic cancer." J Hepatobiliary Pancreat Surg 5(4): 383391.

Huang, C., K. Jacobson and M. D. Schaller (2004). "A role for JNK-paxillin signaling in cell migration." Cell Cycle 3(1): 4-6.

Huang, S. and D. E. Ingber (1999). "The structural and mechanical complexity of cell-growth control." Nat Cell Biol 1(5): E131-138.

Huda, S., S. Soh, D. Pilans, M. Byrska-Bishop, J. Kim, G. Wilk, G. G. Borisy, K. KandereGrzybowska and B. A. Grzybowski (2012). "Microtubule guidance tested through controlled cell geometry." Journal of Cell Science 125(23): 5790-5799.

Imai, T., K. Hieshima, C. Haskell, M. Baba, M. Nagira, M. Nishimura, M. Kakizaki, S. Takagi, H. Nomiyama, T. J. Schall and O. Yoshie (1997). "Identification and molecular characterization of fractalkine receptor CX3CR1, which mediates both leukocyte migration and adhesion." Cell 91(4): 521-530.

Imoto, A., S. Mitsunaga, K. Higuchi and A. Ochiai (2013). "Neural Invasion Induces Cachexia via Astrocytic Activation of Neural Route in Pancreatic Cancer." Gastroenterology 144(5): S673-S673.

Jacquemet, G., I. Paatero, A. F. Carisey, A. Padzik, J. S. Orange, H. Hamidi and J. Ivaska (2017). "FiloQuant reveals increased filopodia density during breast cancer progression." J Cell Biol 216(10): 3387-3403.

Jaffe, A. B. and A. Hall (2005). "Rho GTPases: biochemistry and biology." Annu Rev Cell Dev Biol 21: 247-269. 
Jagadeeswaran, R., H. Surawska, S. Krishnaswamy, V. Janamanchi, A. C. Mackinnon, T. Y. Seiwert, S. Loganathan, R. Kanteti, T. Reichman, V. Nallasura, S. Schwartz, L. Faoro, Y. C. Wang, L. Girard, M. S. Tretiakova, S. Ahmed, O. Zumba, L. Soulii, V. P. Bindokas, L. L. Szeto, G. J. Gordon, R. Bueno, D. Sugarbaker, M. W. Lingen, M. Sattler, T. Krausz, W. Vigneswaran, V. Natarajan, J. Minna, E. E. Vokes, M. K. Ferguson, A. N. Husain and R. Salgia (2008). "Paxillin is a target for somatic mutations in lung cancer: implications for cell growth and invasion." Cancer Res 68(1): 132-142.

Johnson, H. E., S. J. King, S. B. Asokan, J. D. Rotty, J. E. Bear and J. M. Haugh (2015). "Factin bundles direct the initiation and orientation of lamellipodia through adhesion-based signaling." J Cell Biol 208(4): 443-455.

Johnston, M., E. Yu and J. Kim (2012). "Perineural invasion and spread in head and neck cancer." Expert Rev Anticancer Ther 12(3): 359-371.

Jordan, M. A. and L. Wilson (2004). "Microtubules as a target for anticancer drugs." Nat Rev Cancer 4(4): 253-265.

Jun, Q., W. Zhiwei, M. Lilin, K. Jing and N. Qichao (2011). "Effects of paxillin on HCT-8 human colorectal cancer cells." Hepatogastroenterology 58(112): 1951-1955.

Kamisawa, T., L. D. Wood, T. Itoi and K. Takaori (2016). "Pancreatic cancer." Lancet 388(10039): 73-85.

Kanteti, R., S. K. Batra, F. E. Lennon and R. Salgia (2016). "FAK and paxillin, two potential targets in pancreatic cancer." Oncotarget 7(21): 31586-31601.

Kaplan, D. R., B. L. Hempstead, D. Martin-Zanca, M. V. Chao and L. F. Parada (1991). "The trk proto-oncogene product: a signal transducing receptor for nerve growth factor." Science 252(5005): 554-558. 
Karlsson, R., E. D. Pedersen, Z. Wang and C. Brakebusch (2009). "Rho GTPase function in tumorigenesis." Biochim Biophys Acta 1796(2): 91-98.

Ketterer, K., S. Rao, H. Friess, J. Weiss, M. W. Buchler and M. Korc (2003). "Reverse transcription-PCR analysis of laser-captured cells points to potential paracrine and autocrine actions of neurotrophins in pancreatic cancer." Clinical Cancer Research 9(14): 5127-5136.

Kim, D., B. You, H. Lim and S. J. Lee (2011). "Toll-like receptor 2 contributes to chemokine gene expression and macrophage infiltration in the dorsal root ganglia after peripheral nerve injury." Mol Pain 7: 74.

Kim, W. Y. and N. E. Sharpless (2006). "The regulation of INK4/ARF in cancer and aging." Cell 127(2): 265-275.

Klein, R., V. Nanduri, S. Q. Jing, F. Lamballe, P. Tapley, S. Bryant, C. Cordoncardo, K. R. Jones, L. F. Reichardt and M. Barbacid (1991). "The Trkb Tyrosine Protein-Kinase Is a Receptor for Brain-Derived Neurotrophic Factor and Neurotrophin-3." Cell 66(2): 395-403.

Koshiba, T., R. Hosotani, Y. Miyamoto, J. Ida, S. Tsuji, S. Nakajima, M. Kawaguchi, H. Kobayashi, R. Doi, T. Hori, N. Fujii and M. Imamura (2000). "Expression of stromal cellderived factor 1 and CXCR4 ligand receptor system in pancreatic cancer: a possible role for tumor progression." Clin Cancer Res 6(9): 3530-3535.

Kowalski, P. J. and A. F. G. Paulino (2002). "Perineural invasion in adenoid cystic carcinoma: Its causation/promotion by brain-derived neurotrophic factor." Human Pathology 33(9): 933-936.

Lamballe, F., R. Klein and M. Barbacid (1991). "Trkc, a New Member of the Trk Family of Tyrosine Protein-Kinases, Is a Receptor for Neurotrophin-3." Cell 66(5): 967-979. 
Lee, R., P. Kermani, K. K. Teng and B. L. Hempstead (2001). "Regulation of cell survival by secreted proneurotrophins." Science 294(5548): 1945-1948.

Lee, S. H., R. Hollingsworth, H. Y. Kwon, N. Lee and C. Y. Chung (2012). "beta-arrestin 2dependent activation of ERK1/2 is required for ADP-induced paxillin phosphorylation at Ser(83) and microglia chemotaxis." Glia 60(9): 1366-1377.

Leventhal, P. S. and E. L. Feldman (1997). "Insulin-like Growth Factors as Regulators of Cell Motility Signaling Mechanisms." Trends Endocrinol Metab 8(1): 1-6.

Li, H. G., D. R. Xie, X. M. Shen, H. H. Li, H. Zeng and Y. J. Zeng (2005). "Clinicopathological significance of expression of paxillin, syndecan-1 and EMMPRIN in hepatocellular carcinoma." World J Gastroenterol 11(10): 1445-1451.

Li, M. Q., H. P. Li, Y. H. Meng, X. Q. Wang, X. Y. Zhu, J. Mei and D. J. Li (2012).

"Chemokine CCL2 enhances survival and invasiveness of endometrial stromal cells in an autocrine manner by activating Akt and MAPK/Erk1/2 signal pathway." Fertil Steril 97(4): 919-929.

Li, S., J. Lu, Y. Chen, N. Xiong, L. Li, J. Zhang, H. Yang, C. Wu, H. Zeng and Y. Liu (2017). "MCP-1-induced ERK/GSK-3beta/Snail signaling facilitates the epithelial-mesenchymal transition and promotes the migration of MCF-7 human breast carcinoma cells." Cell Mol Immunol 14(7): 621-630.

Liebig, C., G. Ayala, J. A. Wilks, D. H. Berger and D. Albo (2009). "Perineural Invasion in Cancer A Review of the Literature." Cancer 115(15): 3379-3391.

Lim, Y., S. T. Lim, A. Tomar, M. Gardel, J. A. Bernard-Trifilo, X. L. Chen, S. A. Uryu, R. Canete-Soler, J. Zhai, H. Lin, W. W. Schlaepfer, P. Nalbant, G. Bokoch, D. Ilic, C. Waterman-Storer and D. D. Schlaepfer (2008). "PyK2 and FAK connections to p190Rho 
guanine nucleotide exchange factor regulate RhoA activity, focal adhesion formation, and cell motility." J Cell Biol 180(1): 187-203.

Lindsay, T. H., B. M. Jonas, M. A. Sevcik, K. Kubota, K. G. Halvorson, J. R. Ghilardi, M. A. Kuskowski, E. B. Stelow, P. Mukherjee, S. J. Gendler, G. Y. Wong and P. W. Mantyh (2005). "Pancreatic cancer pain and its correlation with changes in tumor vasculature, macrophage infiltration, neuronal innervation, body weight and disease progression." Pain 119(1-3): 233246.

Lopez-Colome, A. M., I. Lee-Rivera, R. Benavides-Hidalgo and E. Lopez (2017). "Paxillin: a crossroad in pathological cell migration." J Hematol Oncol 10(1): 50.

Machesky, L. M. (2008). "Lamellipodia and filopodia in metastasis and invasion." FEBS Lett 582(14): 2102-2111.

Mackinnon, A. C., M. Tretiakova, L. Henderson, R. G. Mehta, B. C. Yan, L. Joseph, T. Krausz, A. N. Husain, M. E. Reid and R. Salgia (2011). "Paxillin expression and amplification in early lung lesions of high-risk patients, lung adenocarcinoma and metastatic disease." $\mathrm{J}$ Clin Pathol 64(1): 16-24.

Madan, R., M. B. Smolkin, R. Cocker, R. Fayyad and M. H. Oktay (2006). "Focal adhesion proteins as markers of malignant transformation and prognostic indicators in breast carcinoma." Hum Pathol 37(1): 9-15.

Makohon-Moore, A. and C. A. lacobuzio-Donahue (2016). "Pancreatic cancer biology and genetics from an evolutionary perspective." Nat Rev Cancer 16(9): 553-565.

Malvezzi, M., P. Bertuccio, F. Levi, C. La Vecchia and E. Negri (2013). "European cancer mortality predictions for the year 2013." Ann Oncol 24(3): 792-800. 
Marchesi, F., M. Locatelli, G. Solinas, M. Erreni, P. Allavena and A. Mantovani (2010). "Role of CX3CR1/CX3CL1 axis in primary and secondary involvement of the nervous system by cancer." Journal of Neuroimmunology 224(1-2): 39-44.

Marchesi, F., L. Piemonti, G. Fedele, A. Destro, M. Roncalli, L. Albarello, C. Doglioni, A. Anselmo, A. Doni, P. Bianchi, L. Laghi, A. Malesci, L. Cervo, M. Malosio, M. Reni, A. Zerbi, V. Di Carlo, A. Mantovani and P. Allavena (2008). "The Chemokine Receptor CX3CR1 Is Involved in the Neural Tropism and Malignant Behavior of Pancreatic Ductal Adenocarcinoma." Cancer Research 68(21): 9060-9069.

Marechal, R., P. Demetter, N. Nagy, A. Berton, C. Decaestecker, M. Polus, J. Closset, J. Deviere, I. Salmon and J. L. Van Laethem (2010). "High expression of CXCR4 may predict poor survival in resected pancreatic adenocarcinoma (vol 100, pg 1444, 2009)." British Journal of Cancer 103(6): 930-930.

Marivin, A., J. Berthelet, J. Cartier, C. Paul, S. Gemble, A. Morizot, W. Boireau, M. Saleh, J. Bertoglio, E. Solary and L. Dubrez (2014). "clAP1 regulates TNF-mediated cdc42 activation and filopodia formation." Oncogene 33(48): 5534-5545.

Melamed, I., C. E. Turner, K. Aktories, D. R. Kaplan and E. W. Gelfand (1995). "Nerve growth factor triggers microfilament assembly and paxillin phosphorylation in human B lymphocytes." J Exp Med 181(3): 1071-1079.

Memmel, S., D. Sisario, C. Zoller, V. Fiedler, A. Katzer, R. Heiden, N. Becker, L. Eing, F. L. R. Ferreira, H. Zimmermann, M. Sauer, M. Flentje, V. L. Sukhorukov and C. S. Djuzenova (2017). "Migration pattern, actin cytoskeleton organization and response to PI3K-, mTOR-, and Hsp90-inhibition of glioblastoma cells with different invasive capacities." Oncotarget 8(28): 45298-45310. 
Meng, X. G. and S. W. Yue (2014). "Dexamethasone disrupts cytoskeleton organization and migration of T47D Human breast cancer cells by modulating the AKT/mTOR/RhoA pathway." Asian Pac J Cancer Prev 15(23): 10245-10250.

Mestayer, C., M. Blanchere, F. Jaubert, B. Dufour and I. Mowszowicz (2003). "Expression of androgen receptor coactivators in normal and cancer prostate tissues and cultured cell lines." Prostate 56(3): 192-200.

Miknyoczki, S. J., D. Lang, L. Huang, A. J. Klein-Szanto, C. A. Dionne and B. A. Ruggeri (1999). "Neurotrophins and Trk receptors in human pancreatic ductal adenocarcinoma: expression patterns and effects on in vitro invasive behavior." Int J Cancer 81(3): 417-427. Miyoshi, Y., H. Ishiguro, H. Uemura, K. Fujinami, H. Miyamoto, Y. Miyoshi, H. Kitamura and Y. Kubota (2003). "Expression of AR associated protein 55 (ARA55) and androgen receptor in prostate cancer." Prostate 56(4): 280-286.

Monami, G., E. M. Gonzalez, M. Hellman, L. G. Gomella, R. Baffa, R. V. lozzo and A. Morrione (2006). "Proepithelin promotes migration and invasion of 5637 bladder cancer cells through the activation of ERK1/2 and the formation of a paxillin/FAK/ERK complex." Cancer Res 66(14): 7103-7110.

Montone, R., M. G. Romanelli, A. Baruzzi, F. Ferrarini, E. Liboi and P. M. Lievens (2018). "Mutant FGFR3 associated with SADDAN disease causes cytoskeleton disorganization through PLCgamma1/Src-mediated paxillin hyperphosphorylation." Int J Biochem Cell Biol 95: 17-26.

Mu, G., Q. Ding, H. Li, L. Zhang, L. Zhang, K. He, L. Wu, Y. Deng, D. Yang, L. Wu, M. Xu, J. Zhou and H. Yu (2018). "Gastrin stimulates pancreatic cancer cell directional migration by activating the Galpha12/13-RhoA-ROCK signaling pathway." Exp Mol Med 50(5): 59. 
Na'ara, S., M. Amit and Z. Gil (2018). "L1CAM induces perineural invasion of pancreas cancer cells by upregulation of metalloproteinase expression." Oncogene.

Nykjaer, A., R. Lee, K. K. Teng, P. Jansen, P. Madsen, M. S. Nielsen, C. Jacobsen, M.

Kliemannel, E. Schwarz, T. E. Willnow, B. L. Hempstead and C. M. Petersen (2004). "Sortilin is essential for proNGF-induced neuronal cell death." Nature 427(6977): 843-848.

Okada, Y., G. Eibl, J. P. Duffy, H. A. Reber and O. J. Hines (2003). "Glial cell-derived neurotrophic factor upregulates the expression and activation of matrix metalloproteinase -9 in human pancreatic cancer." Surgery 134(2): 293-299.

Okada, Y., G. Eibl, S. Guha, J. P. Duffy, H. A. Reber and O. J. Hines (2004). "Nerve growth factor stimulates MMP-2 expression and activity and increases invasion by human pancreatic cancer cells." Clinical \& Experimental Metastasis 21(4): 285-292.

Ono, H., M. D. Basson and H. Ito (2014). "PTK6 promotes cancer migration and invasion in pancreatic cancer cells dependent on ERK signaling." PLoS One 9(5): e96060.

Ouyang, H., L. Mou, C. Luk, N. Liu, J. Karaskova, J. Squire and M. S. Tsao (2000). "Immortal human pancreatic duct epithelial cell lines with near normal genotype and phenotype." Am J Pathol 157(5): 1623-1631.

Pandey, P., S. Rachagani, S. Das, P. Seshacharyulu, Y. Sheinin, N. Naslavsky, Z. Pan, B. L. Smith, H. L. Peters, P. Radhakrishnan, N. R. McKenna, S. S. Giridharan, D. Haridas, S. Kaur, M. A. Hollingsworth, R. G. MacDonald, J. L. Meza, S. Caplan, S. K. Batra and J. C. Solheim (2015). "Amyloid precursor-like protein 2 (APLP2) affects the actin cytoskeleton and increases pancreatic cancer growth and metastasis." Oncotarget 6(4): 2064-2075. 
Park, H. S., J. M. Lee, H. K. Choi, S. H. Hong, J. K. Han and B. I. Choi (2009). "Preoperative evaluation of pancreatic cancer: comparison of gadolinium-enhanced dynamic MRI with MR cholangiopancreatography versus MDCT." J Magn Reson Imaging 30(3): 586-595.

Pribic, J. and D. Brazill (2012). "Paxillin phosphorylation and complexing with Erk and FAK are regulated by PLD activity in MDA-MB-231 cells." Cell Signal 24(8): 1531-1540.

Qin, J., F. Wang, H. Jiang, J. Xu, Y. Jiang and Z. Wang (2015). "MicroRNA-145 suppresses cell migration and invasion by targeting paxillin in human colorectal cancer cells." Int J Clin Exp Pathol 8(2): 1328-1340.

Rabow, M. W., M. Q. B. Petzel and S. H. Adkins (2017). "Symptom Management and Palliative Care in Pancreatic Cancer." Cancer J 23(6): 362-373.

Rahib, L., B. D. Smith, R. Aizenberg, A. B. Rosenzweig, J. M. Fleshman and L. M. Matrisian (2014). "Projecting cancer incidence and deaths to 2030: the unexpected burden of thyroid, liver, and pancreas cancers in the United States." Cancer Res 74(11): 2913-2921.

Rankin, S., R. Hooshmand-Rad, L. Claesson-Welsh and E. Rozengurt (1996). "Requirement for phosphatidylinositol 3'-kinase activity in platelet-derived growth factor-stimulated tyrosine phosphorylation of p125 focal adhesion kinase and paxillin." J Biol Chem 271(13): 78297834.

Rasheed, K., I. Abdulsalam, S. Fismen, O. Grimstad, B. Sveinbjornsson and U. Moens (2018). "CCL17/TARC and CCR4 expression in Merkel cell carcinoma." Oncotarget 9(59): 31432-31447.

Redston, M. S., C. Caldas, A. B. Seymour, R. H. Hruban, L. da Costa, C. J. Yeo and S. E. Kern (1994). "p53 mutations in pancreatic carcinoma and evidence of common involvement of homocopolymer tracts in DNA microdeletions." Cancer Res 54(11): 3025-3033. 
Ren, L., Y. Xu, C. Liu, S. Wang and G. Qin (2017). "IL-17RB enhances thyroid cancer cell invasion and metastasis via ERK1/2 pathway-mediated MMP-9 expression." Mol Immunol 90: 126-135.

Ridley, A. J. (2006). "Rho GTPases and actin dynamics in membrane protrusions and vesicle trafficking." Trends Cell Biol 16(10): 522-529.

Roe, J. S., C. I. Hwang, T. D. D. Somerville, J. P. Milazzo, E. J. Lee, B. Da Silva, L. Maiorino, H. Tiriac, C. M. Young, K. Miyabayashi, D. Filippini, B. Creighton, R. A. Burkhart, J. M. Buscaglia, E. J. Kim, J. L. Grem, A. J. Lazenby, J. A. Grunkemeyer, M. A. Hollingsworth, P. M. Grandgenett, M. Egeblad, Y. Park, D. A. Tuveson and C. R. Vakoc (2017). "Enhancer Reprogramming Promotes Pancreatic Cancer Metastasis." Cell 170(5): 875-+.

Roy, I., N. P. Zimmerman, A. C. Mackinnon, S. Tsai, D. B. Evans and M. B. Dwinell (2014). "CXCL12 chemokine expression suppresses human pancreatic cancer growth and metastasis." PLoS One 9(3): e90400.

Ryan, D. P., T. S. Hong and N. Bardeesy (2014). "Pancreatic adenocarcinoma." N Engl J Med 371(22): 2140-2141.

Salvi, A. and T. Thanabalu (2017). "Expression of N-WASP is regulated by HiF1alpha through the hypoxia response element in the N-WASP promoter." Biochem Biophys Rep 9: 13-21.

Scanlon, C. S., R. Banerjee, R. C. Inglehart, M. Liu, N. Russo, A. Hariharan, E. A. van Tubergen, S. L. Corson, I. A. Asangani, C. M. Mistretta, A. M. Chinnaiyan and N. J. D'Silva (2015). "Galanin modulates the neural niche to favour perineural invasion in head and neck cancer." Nat Commun 6: 6885. 
Schneider, M. B., J. Standop, A. Ulrich, U. Wittel, H. Friess, A. Andren-Sandberg and P. M. Pour (2001). "Expression of nerve growth factors in pancreatic neural tissue and pancreatic cancer." J Histochem Cytochem 49(10): 1205-1210.

Schorn, S., I. E. Demir, B. Haller, F. Scheufele, C. M. Reyes, E. Tieftrunk, M. Sargut, R. Goess, H. Friess and G. O. Ceyhan (2017). "The influence of neural invasion on survival and tumor recurrence in pancreatic ductal adenocarcinoma - A systematic review and metaanalysis." Surg Oncol 26(1): 105-115.

Schorn, S., I. E. Demir, C. M. Reyes, C. Saricaoglu, N. Samm, R. Schirren, E. Tieftrunk, D. Hartmann, H. Friess and G. O. Ceyhan (2017). "The impact of neoadjuvant therapy on the histopathological features of pancreatic ductal adenocarcinoma - A systematic review and meta-analysis." Cancer Treat Rev 55: 96-106.

Schrader, A. J., O. Lechner, M. Templin, K. E. Dittmar, S. Machtens, M. Mengel, M. ProbstKepper, A. Franzke, T. Wollensak, P. Gatzlaff, J. Atzpodien, J. Buer and J. Lauber (2002). "CXCR4/CXCL12 expression and signalling in kidney cancer." Br J Cancer 86(8): 12501256.

Scott, G., H. Liang and D. Luthra (1996). "Stem cell factor regulates the melanocyte cytoskeleton." Pigment Cell Res 9(3): 134-141.

Sen, A., I. De Castro, D. B. Defranco, F. M. Deng, J. Melamed, P. Kapur, G. V. Raj, R. Rossi and S. R. Hammes (2012). "Paxillin mediates extranuclear and intranuclear signaling in prostate cancer proliferation." J Clin Invest 122(7): 2469-2481.

Sherr, C. J. (1996). "Cancer cell cycles." Science 274(5293): 1672-1677.

Siegel, R. L., K. D. Miller and A. Jemal (2017). "Cancer Statistics, 2017." CA Cancer J Clin 67(1): 7-30. 
Siegel, R. L., K. D. Miller and A. Jemal (2018). "Cancer statistics, 2018." CA Cancer J Clin 68(1): 7-30.

Singh, J., K. Sharma and P. P. Pillai (2018). "PDGFR inhibition mediated intracellular signalling in C6 glioma growth and migration: role of ERK and ROCK pathway." Cytotechnology 70(1): 465-477.

Soppet, D., E. Escandon, J. Maragos, D. S. Middlemas, S. W. Reid, J. Blair, L. E. Burton, B. R. Stanton, D. R. Kaplan, T. Hunter, K. Nikolics and L. F. Parada (1991). "The Neurotrophic Factors Brain-Derived Neurotrophic Factor and Neurotrophin-3 Are Ligands for the Trkb Tyrosine Kinase Receptor." Cell 65(5): 895-903.

Squinto, S. P., T. N. Stitt, T. H. Aldrich, S. Davis, S. M. Bianco, C. Radziejewski, D. J. Glass, P. Masiakowski, M. E. Furth, D. M. Valenzuela, P. S. Distefano and G. D. Yancopoulos (1991). "Trkb Encodes a Functional Receptor for Brain-Derived Neurotrophic Factor and Neurotrophin-3 but Not Nerve Growth-Factor." Cell 65(5): 885-893.

Steeg, P. S. (2006). "Tumor metastasis: mechanistic insights and clinical challenges." Nat Med 12(8): 895-904.

Stevenson, R. P., D. Veltman and L. M. Machesky (2012). "Actin-bundling proteins in cancer progression at a glance." Journal of Cell Science 125(5): 1073-1079.

Subauste, M. C., O. Pertz, E. D. Adamson, C. E. Turner, S. Junger and K. M. Hahn (2004). "Vinculin modulation of paxillin-FAK interactions regulates ERK to control survival and motility." J Cell Biol 165(3): 371-381.

Sun, L. H., F. Q. Yang, C. B. Zhang, Y. P. Wu, J. S. Liang, S. Jin, Z. Wang, H. J. Wang, Z. S. Bao, Z. X. Yang and T. Jiang (2017). "Overexpression of Paxillin Correlates with Tumor Progression and Predicts Poor Survival in Glioblastoma." CNS Neurosci Ther 23(1): 69-75. 
Sun, X., G. Cheng, M. Hao, J. Zheng, X. Zhou, J. Zhang, R. S. Taichman, K. J. Pienta and J. Wang (2010). "CXCL12 / CXCR4 / CXCR7 chemokine axis and cancer progression." Cancer Metastasis Rev 29(4): 709-722.

Svitkina, T. M., E. A. Bulanova, O. Y. Chaga, D. M. Vignjevic, S. Kojima, J. M. Vasiliev and G. G. Borisy (2003). "Mechanism of filopodia initiation by reorganization of a dendritic network." J Cell Biol 160(3): 409-421.

Tang, Z., N. Zhang, W. Di and W. Li (2015). "Inhibition of microtubule-associated protein 1 light chain 3B via small-interfering RNA or 3-methyladenine impairs hypoxia-induced HO8910PM and HO8910 epithelial ovarian cancer cell migration and invasion and is associated with RhoA and alterations of the actin cytoskeleton." Oncol Rep 33(3): 14111417.

Taniuchi, K., M. Furihata, S. Naganuma, K. Dabanaka, K. Hanazaki and T. Saibara (2018). "BCL7B, a predictor of poor prognosis of pancreatic cancers, promotes cell motility and invasion by influencing CREB signaling." Am J Cancer Res 8(3): 387-404.

Taniuchi, K., M. Furihata, S. Naganuma and T. Saibara (2018). "WAVE2 is associated with poor prognosis in pancreatic cancers and promotes cell motility and invasiveness via binding to ACTN4." Cancer Med 7(11): 5733-5751.

Tapia, J. A., C. Camello, R. T. Jensen and L. J. Garcia (1999). "EGF stimulates tyrosine phosphorylation of focal adhesion kinase ( $\mathrm{p} 125 \mathrm{FAK}$ ) and paxillin in rat pancreatic acini by a phospholipase $\mathrm{C}$-independent process that depends on phosphatidylinositol 3-kinase, the small GTP-binding protein, p21rho, and the integrity of the actin cytoskeleton." Biochim Biophys Acta 1448(3): 486-499. 
Tempero, M. A., M. P. Malafa, M. Al-Hawary, H. Asbun, A. Bain, S. W. Behrman, A. B. Benson, 3rd, E. Binder, D. B. Cardin, C. Cha, E. G. Chiorean, V. Chung, B. Czito, M. Dillhoff, E. Dotan, C. R. Ferrone, J. Hardacre, W. G. Hawkins, J. Herman, A. H. Ko, S. Komanduri, A. Koong, N. LoConte, A. M. Lowy, C. Moravek, E. K. Nakakura, E. M. O'Reilly, J. Obando, S. Reddy, C. Scaife, S. Thayer, C. D. Weekes, R. A. Wolff, B. M. Wolpin, J. Burns and S. Darlow (2017). "Pancreatic Adenocarcinoma, Version 2.2017, NCCN Clinical Practice Guidelines in Oncology." J Natl Compr Canc Netw 15(8): 1028-1061.

Thiery, J. P., H. Acloque, R. Y. Huang and M. A. Nieto (2009). "Epithelial-mesenchymal transitions in development and disease." Cell 139(5): 871-890.

Ueno, T., M. Toi, H. Saji, M. Muta, H. Bando, K. Kuroi, M. Koike, H. Inadera and K. Matsushima (2000). "Significance of macrophage chemoattractant protein-1 in macrophage recruitment, angiogenesis, and survival in human breast cancer." Clin Cancer Res 6(8): 3282-3289.

Vasioukhin, V., C. Bauer, M. Yin and E. Fuchs (2000). "Directed actin polymerization is the driving force for epithelial cell-cell adhesion." Cell 100(2): 209-219.

Velasco-Velazquez, M. A., N. Salinas-Jazmin, N. Mendoza-Patino and J. J. Mandoki (2008). "Reduced paxillin expression contributes to the antimetastatic effect of 4-hydroxycoumarin on B16-F10 melanoma cells." Cancer Cell Int 8: 8.

Von Hoff, D. D., T. Ervin, F. P. Arena, E. G. Chiorean, J. Infante, M. Moore, T. Seay, S. A. Tjulandin, W. W. Ma, M. N. Saleh, M. Harris, M. Reni, S. Dowden, D. Laheru, N. Bahary, R. K. Ramanathan, J. Tabernero, M. Hidalgo, D. Goldstein, E. Van Cutsem, X. Wei, J. Iglesias and M. F. Renschler (2013). "Increased survival in pancreatic cancer with nab-paclitaxel plus gemcitabine." N Engl J Med 369(18): 1691-1703. 
Wang, G., W. Huang, W. Li, S. Chen, W. Chen, Y. Zhou, P. Peng and W. Gu (2018). "TFPI-2 suppresses breast cancer cell proliferation and invasion through regulation of ERK signaling and interaction with actinin-4 and myosin-9." Sci Rep 8(1): 14402.

Wang, H., J. Cai, S. Du, Z. Guo, B. Xin, J. Wang, W. Wei and X. Shen (2017).

"Fractalkine/CX3CR1 induces apoptosis resistance and proliferation through the activation of the AKT/NF-kappaB cascade in pancreatic cancer cells." Cell Biochem Funct 35(6): 315-326.

Wang, J., Z. G. Zhuang, S. F. Xu, Q. He, Y. G. Shao, M. Ji, L. Yang and W. Bao (2015). "Expression of CCL2 is significantly different in five breast cancer genotypes and predicts patient outcome." Int J Clin Exp Med 8(9): 15684-15691.

Wang, K., I. E. Demir, J. G. D'Haese, E. Tieftrunk, K. Kujundzic, S. Schorn, B. Xing, T. Kehl, H. Friess and G. O. Ceyhan (2014). "The neurotrophic factor neurturin contributes toward an aggressive cancer cell phenotype, neuropathic pain and neuronal plasticity in pancreatic cancer." Carcinogenesis 35(1): 103-113.

Wang, L. P., J. Cao, J. Zhang, B. Y. Wang, X. C. Hu, Z. M. Shao, Z. H. Wang and Z. L. Ou (2015). "The human chemokine receptor CCRL2 suppresses chemotaxis and invasion by blocking CCL2-induced phosphorylation of p38 MAPK in human breast cancer cells." Med Oncol 32(11): 254.

Wang, W., H. Zhao, S. Zhang, E. Kang, Y. Chen, C. Ni, S. Zhang and M. Zhu (2009). "Patterns of expression and function of the p75(NGFR) protein in pancreatic cancer cells and tumours." Ejso 35(8): 826-832.

Watson, J. J., S. J. Allen and D. Dawbarn (2008). "Targeting nerve growth factor in pain: what is the therapeutic potential?" BioDrugs 22(6): 349-359. 
Webb, D. J., M. J. Schroeder, C. J. Brame, L. Whitmore, J. Shabanowitz, D. F. Hunt and A. R. Horwitz (2005). "Paxillin phosphorylation sites mapped by mass spectrometry." J Cell Sci 118(Pt 21): 4925-4929.

Wei, W., H. Li, N. Li, H. Sun, Q. Li and X. Shen (2013). "WNT5A/JNK signaling regulates pancreatic cancer cells migration by Phosphorylating Paxillin." Pancreatology 13(4): 384392.

Wicki, A., F. Lehembre, N. Wick, B. Hantusch, D. Kerjaschki and G. Christofori (2006). "Tumor invasion in the absence of epithelial-mesenchymal transition: podoplanin-mediated remodeling of the actin cytoskeleton." Cancer Cell 9(4): 261-272.

Wood, J. N. (2010). "Nerve growth factor and pain." N Engl J Med 363(16): 1572-1573.

Wu, G. S., Y. L. Song, Z. Q. Yin, J. J. Guo, S. P. Wang, W. W. Zhao, X. P. Chen, Q. W. Zhang, J. J. Lu and Y. T. Wang (2013). "Ganoderiol A-enriched extract suppresses migration and adhesion of MDA-MB-231 cells by inhibiting FAK-SRC-paxillin cascade pathway." PLoS One 8(10): e76620.

Yamasaki, M., H. Arai, N. Ashida, K. Ishii and T. Kita (2001). "Monocyte chemoattractant protein 1 causes differential signalling mediated by proline-rich tyrosine kinase 2 in THP-1 cells." Biochem J 355(Pt 3): 751-756.

Yasui, H., Y. Ohnishi, M. Nakajima and M. Nozaki (2017). "Migration of oral squamous cell carcinoma cells are induced by HGF/c-Met signalling via lamellipodia and filopodia formation." Oncol Rep 37(6): 3674-3680.

Yeh, P. S., W. Wang, Y. A. Chang, C. J. Lin, J. J. Wang and R. M. Chen (2016). "Honokiol induces autophagy of neuroblastoma cells through activating the PI3K/Akt/mTOR and 
endoplasmic reticular stress/ERK1/2 signaling pathways and suppressing cell migration." Cancer Lett 370(1): 66-77.

Yilmaz, M. and G. Christofori (2009). "EMT, the cytoskeleton, and cancer cell invasion." Cancer Metastasis Rev 28(1-2): 15-33.

Zhao, H., Y. Jiao and Z. Zhang (2015). "Deguelin inhibits the migration and invasion of lung cancer A549 and H460 cells via regulating actin cytoskeleton rearrangement." Int J Clin Exp Pathol 8(12): 15582-15590.

Zhou, J. and P. Giannakakou (2005). "Targeting microtubules for cancer chemotherapy." Curr Med Chem Anticancer Agents 5(1): 65-71.

Zhu, M. J., W. B. Ou, C. D. Fletcher, P. S. Cohen, G. D. Demetri and J. A. Fletcher (2007). "KIT oncoprotein interactions in gastrointestinal stromal tumors: therapeutic relevance." Oncogene 26(44): 6386-6395.

Zhu, Z., H. Friess, F. F. diMola, A. Zimmermann, H. U. Graber, M. Korc and M. W. Buchler (1999). "Nerve growth factor expression correlates with perineural invasion and pain in human pancreatic cancer." J Clin Oncol 17(8): 2419-2428.

Zhu, Z. W., J. Kleeff, H. Kayed, L. Wang, M. Korc, M. W. Buchler and H. Friess (2002). "Nerve growth factor and enhancement of proliferation, invasion, and tumorigenicity of pancreatic cancer cells." Molecular Carcinogenesis 35(3): 138-147. 


\subsection{Acknowledgments}

By writing these acknowledgment part, I have mixed emotions. Looking back on the past 30 years in my life, I have spent the most memorable and happiest 3 years here. Upon the end of this thesis, I would like to express my endless gratitude and appreciation to all people who have offered me great assistance and support during my 3 years in Technische Universität München.

First and foremost, I would like to thank my supervisor, Prof. Dr. med Güralp Onur Ceyhan, for his scientific supervision, instruction, and support. Prof. Dr. med Güralp Onur Ceyhan has a noble personality, profound knowledge, and rigorous academic attitude which benefit us tremendously. I always remembered the first time I met Prof. Dr. med Güralp Onur Ceyhan in his office, and he told me that "we open the door for you, but you have to walk inside yourself". This sentence always inspires and encourages me to work with perspiration, persistence and positive attitude.

Then, I would like to express my sincere gratitude to my mentor, PD. Dr. med Ihsan Ekin Demir, who not only offered me valuable suggestions in the academic studies, but also changed my attitude to research. PD. Dr. med Ihsan Ekin Demir is more than just a mentor to me. He also served as a perfect model to be a researcher and surgeon. His insightful comments on our projects, which deliver many helpful ideas to us, have enlightened us a lot. Without the brilliant ideas and valuable suggestions and the patient guidance, this thesis could not be finished. Words can hardly express my appreciation to PD. Dr. med Ihsan Ekin Demir, but I appreciate my mentor from the depth of my heart.

I would like to thank our postdoc, Dr. rer. nat Steffen Teller, who discussed the project, provided excellent ideas, as well as taught me research techniques, including western blotting, qPCR, immunohistochemistry et al. In the first day I came to our lab, I stood in the main 
entrance of hospital uneasily and nervously. Dr. rer. nat Steffen Teller came to me with a reassuring smile and led me to our lab. Without the kind supports and patient instructions from our postdoc, this thesis would not have reached its current form.

I would like to thank our technician, Mrs. Ulrike Bourquain, the mother in our lab, who keeps the lab in perfect order, for her tireless technical assistance. I would like to thank Nadja Maeritz for taking care of our mouse work and making it much easier. I would like to thank Dr. Shenghan Wang, who picked me up at the airport in the first day I came to München. I would like to appreciate Dr. Pavel Stupakov for teaching me research techniques. I would like to thank my other colleagues including Dr.med Okan Safak, Dr. Laura Fangmann, Dr. Hossam Taher, Teresa Zwick, Dr. Hendrik Steenfadt, Dr. Paulo Pfitzinger, Gülsüm Yurteri for their generous supports during these years.

I would like to thank the China Scholarship Council for supporting and funding me during I stay in Germany.

Finally, I would like to thank my beloved parents Dr. Guichen Wang and Mrs. Shuhong Hou, who have been making a nice, sweet and loving family, for their continuous and endless support both materially and spiritually. I am deeply indebted to them for the encouragement, which inspires me all the time and the lovely family, which let me finish my study without scruple. 